\title{
Feasibility of screening and referring women experiencing marital violence by engaging frontline workers: Evidence from rural Bihar
}

Shireen J. Jejeebhoy

K.G. Santhya

Population Council

Santosh Kumar Singh

Population Council

A.J. Francis Zavier

Population Council

Neelanjana Pandey

Population Council

See next page for additional authors

Follow this and additional works at: https://knowledgecommons.popcouncil.org/departments_sbsr-pgy

Part of the Demography, Population, and Ecology Commons, Domestic and Intimate Partner Violence Commons, Family, Life Course, and Society Commons, and the International Public Health Commons How does access to this work benefit you? Let us know!

\section{Recommended Citation}

Jejeebhoy, Shireen J., K.G. Santhya, Santosh Kumar Singh, A.J. Francis Zavier, Neelanjana Pandey, Rajib Acharya, Komal Saxena, Aparajita Gogoi, Madhu Joshi, and Sandeep Ojha. 2017. "Feasibility of screening and referring women experiencing marital violence by engaging frontline workers: Evidence from rural Bihar." New Delhi: Population Council. 


\section{Authors}

Shireen J. Jejeebhoy, K.G. Santhya, Santosh Kumar Singh, A.J. Francis Zavier, Neelanjana Pandey, Rajib Acharya, Komal Saxena, Aparajita Gogoi, Madhu Joshi, and Sandeep Ojha 
능
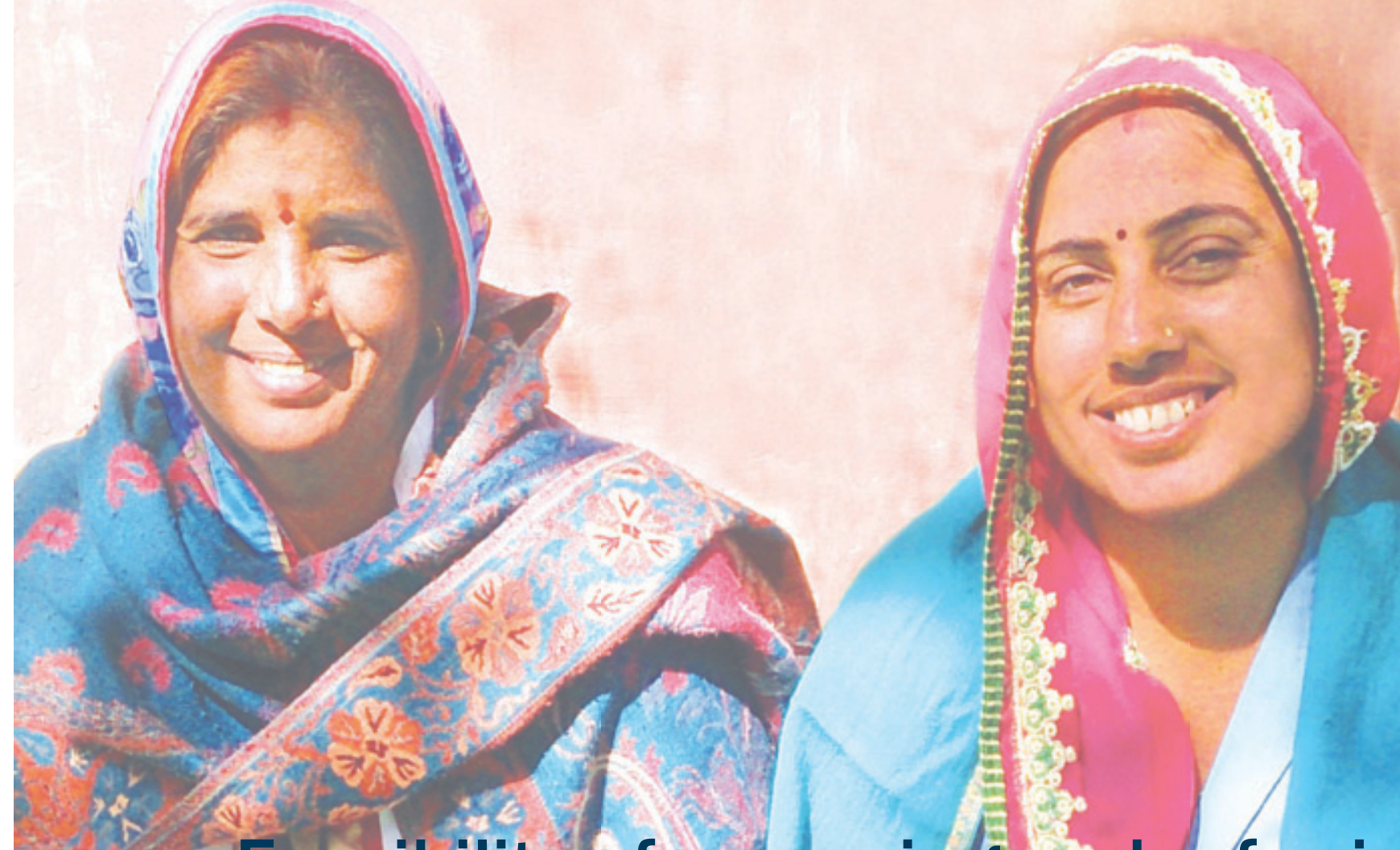

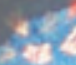

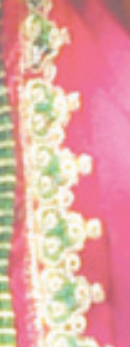

Feasibility of screening and referring women experiencing maritalviolence by engaging frontline workers: Evidence from rural Bihar

Shireen J Jejeebhoy K G Santhya

Santosh Kumar Singh

A J Francis Zavier

Neelanjana Pandey

Rajib Acharya

Komal Saxena

\section{y}

Aparajita Gogoi

Madhu Joshi

Sandeep Ojha

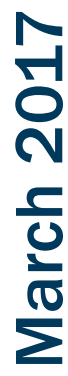

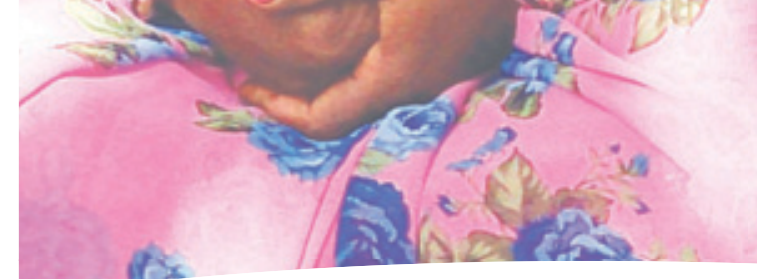


The Population Council confronts critical health and development issues-from stopping the spread of HIV to improving reproductive health and ensuring that young people lead full and productive lives. Through biomedical, social science, and public health research in 50 countries, we work with our partners to deliver solutions that lead to more effective policies, programs, and technologies that improve lives around the world. Established in 1952 and headquartered in New York, the Council is a nongovernmental, nonprofit organization governed by an international board of trustees.

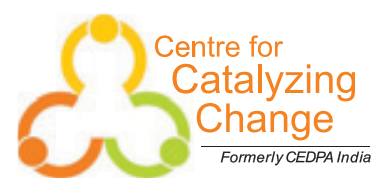

The Centre for Development and Population Activities, India is now the Centre for Catalyzing Change (C3). Over two decades of sustained work to empower and mobilize young people, men and women commemorates the journey of the organisation, that began as one of the first organizations working with life skills education for adolescents through it comprehensive programs. We are a non-governmental organization with the mission to empower women in all sectors of development and to that end we work with young people, including in and out of school adolescent boys and girls in rural and urban India. Our technical expertise extends to incubating, implementing and scaling up programs focused on its thematic areas of youth education, gender and maternal health/reproductive rights, specialising in at- scale programme implementation, monitoring and evaluation. Till date, we have reached more than one million girls and boys in India and equipped them with practical life skills, improved confidence in personal decision-making and increased self-esteem. In the past couple of years we have been using digital technology to build young people's capacities on health, life skills and gender equity issues.

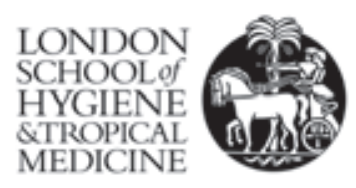

Our mission is to improve health and health equity in the UK and worldwide; working in partnership to achieve excellence in public and global health research, education and translation of knowledge into policy and practice.

Suggested Citation: Jejeebhoy, S. J., K. G. Santhya, S. Singh et al. 2017. Feasibility of screening and referring women experiencing marital violence by engaging frontline workers: Evidence from rural Bihar. New Delhi: Population Council.

For additional copies of the report please contact:

\section{Population Council}

Zone 5A, Ground Floor

India Habitat Centre, Lodi Road

New Delhi, India 110003

Phone: +91-11-2464 2901

Email: info.india@popcouncil.org

Website: www.popcouncil.org

The study has been funded by UK aid from the UK Government; however the views expressed do not necessarily reflect the UK Government's official policies. 


\section{Feasibility of screening and referring women experiencing marital violence by engaging frontline workers: Evidence from rural Bihar}

Shireen J Jejeebhoy

K G Santhya

Santosh Kumar Singh

A J Francis Zavier

Neelanjana Pandey

Rajib Acharya

Komal Saxena
Aparajita Gogoi

Madhu Joshi

Sandeep Ojha 


\section{Table of Content}

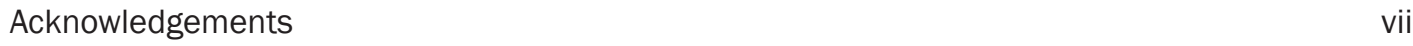

Executive summary $\quad$ ix

Chapter $1 \quad$ Introduction 1

Chapter $2 \quad$ Socio-demographic profile of study participants 10

Chapter $3 \quad$ Do Kadam Barabari Ki Ore: The intervention 14

Chapter $4 \quad$ Feasibility and acceptability of the Do Kadam project activities: Women's perspectives 19

Chapter $5 \quad$ Perspectives of ASHAs, AWWs and ANMs 35

Chapter $6 \quad$ Summary and recommendations 49

Appendix Table 1: Construction of the wealth index 53

$\begin{array}{lr}\text { References } & 54\end{array}$

$\begin{array}{lr}\text { Authors } & 56\end{array}$

$\begin{array}{lr}\text { List of Investigators } & 57\end{array}$ 


\section{List of Tables}

Table 1.1: $\quad$ Profile of the study district and state

Table 1.2: $\quad$ Response rate at baseline, follow-up rate at endline, and reasons for non-response and loss to follow up

Table 1.3:

In-depth interview respondents at baseline and endline

Table 2.1: $\quad$ Household characteristics of surveyed women

Selected household characteristics of pregnant women and women with a

0-5-year-old child, baseline survey, 2015

Table 2.2: $\quad$ Socio-demographic characteristics of surveyed women

Selected socio-demographic characteristics of pregnant women and women with a

0-5-year-old child, baseline survey, 2015

Table 2.3: $\quad$ Childbearing experiences of surveyed women

Selected childbearing characteristics of pregnant women and women with a

0-5-year-old child, baseline survey, 2015

Table 2.4: $\quad$ Gender role attitudes held by surveyed women

Selected indicators of agency of pregnant women and women with a

0-5-year-old child, baseline survey, 2015

Table 2.5: $\quad$ Women's experience of violence perpetrated by their husband and other family members Selected indicators of violence perpetrated by the husband and other family members on pregnant women and women with a 0-5-year-old child in the 12 months preceding the interview, baseline survey, 2015

Table 4.1: $\quad$ Acquaintance and interaction with ASHAs, AWWs, and ANMs

Percentage of women reporting acquaintance and interaction in preceding six months

with ASHA, AWW or ANM, baseline and endline surveys, 2015 and 2016

Table 4.2: $\quad$ Interaction on violence-related matters with ASHAs and AWWs

Percentage of women reporting violence-related discussion and screening, and receipt of a violence-related brochure in the six months preceding the interview, endline survey, 2016

Table 4.3: $\quad$ Characteristics of women reporting violence-related interaction with ASHAs or AWWs at endline Percentage of women according to baseline socio-demographic characteristics and violence experienced in the 12 months preceding the baseline survey, by screening status and reported interaction with ASHAs and AWWs about violence, endline, 2016

Table 4.4: $\quad$ Attendance at street plays/nukkad nataks

Percentage of women reporting attendance at nukkad nataks and conveying its messages to others in the family in the six months preceding the interview, endline survey, 2016

Table 4.5:

Disclosure of violence experience at screening to ASHA or AWW by selected characteristics Percentage of screened women who disclosed their marital violence experience to the ASHA or AWW, by selected characteristics, endline survey, 2016 
Table 4.6: $\quad$ Reporting of violence experience to survey interviewer and to the ASHA or AWW Percentage of all women screened by their reports (at baseline) of experience of violence perpetrated by their husband or other family members in the 12 months preceding the baseline interview to the survey interviewer and to the ASHA or AWW, endline, 2016

Table 4.7: $\quad$ Perceptions about quality of interaction with ASHA or AWW on marital violence Percentage of women who disclosed their experience of marital violence and who reported that the ASHA or AWW had counselled them and paid them repeated visits, and the content of counselling provided, endline survey, 2016

Table 4.8: $\quad$ Help-seeking practices of women who experienced physical and/or sexual violence, by interaction on violence-related topics with ASHAs/AWWs and disclosure status Percentage of women reporting experiences of physical and/or sexual violence in the six months prior to the baseline and endline interviews and had sought help from family, friends, or from service providers, 2015 and 2016, baseline and endline survey

\section{List of Figures}

Figure 1: $\quad$ Percentage of women reporting discussion on violence-related matters, screening for violence, and receipt of a violence-related brochure in the six months preceding the interview, endline survey, 2016

Figure 2: $\quad$ Percentage of screened women who disclosed their marital violence experience to the ASHA or AWW by selected characteristics, 2016, endline survey

Figure 3: $\quad$ Percentage of women who had experienced physical and/or sexual violence in the six months prior to the baseline and endline interviews reporting having sought help from formal or informal sources, baseline and endline surveys, 2015 and 2016

Figure 4: $\quad$ Percentage of women who had experienced physical and/or sexual violence in the six months prior to the endline interview and sought help from formal or informal sources, according to interactions with FLWs on violence-related matters, 2016, endline survey

Figure 3.1: $\quad$ Abuse Assessment Screen (AAS) 


\section{Acknowledgements}

We are grateful to the UK Department for International Development (DFID) for supporting our programme of research, Do Kadam Barabari Ki Ore (Two Steps Towards Equality), to assess what works to address violence against women in Bihar state, India. Under this programme of research and evaluation, a total of five projects were implemented in partnership with the Centre for Catalyzing Change and the London School of Hygiene and Tropical Medicine. One of the five projects, findings of which are presented in this report, tested the feasibility of engaging frontline workers to screen women for their experience of domestic violence, inform them about their options in case of such an experience and provide basic counselling and referral to women who report such experiences.

This study has benefitted immeasurably from the inputs of many. In particular, we are grateful to Mamta Kohli, Nupur Barua, Nel Druce, Arundhati Choudhury, and Peter Evans from DFID India Office, for their support and especially to Mamta Kohli, Nupur Barua and Nel Druce for their guidance and insights throughout the course of this project. We are extremely grateful, moreover, to several officials of the Government of Bihar whose encouragement and support made it possible for us to conduct the study in the state of Bihar. We would like to acknowledge support from Shri Sanjay Kumar, former Executive Director, Department of Health, Shri Rahul Kumar, former Additional Executive Director, Department of Health, and Shri Imamuddin Ahmad, Director of Social Welfare and Shri Baidyanath Yadav, former Director, Integrated Child Development Scheme.

Lori Heise from the London School of Hygiene and Tropical Medicine and Kelly Hallman from the Population Council, New York provided valuable inputs into the intervention design and the study protocol. Madhuri Das, formerly Gender and Social Inclusion Expert, BTAST of the SWASTH project and Ngo Thoai from the Population Council, New York reviewed and commented on an earlier version of this report. We are most grateful to them for their critical comments and suggestions, which we have incorporated into this report.

At the Population Council, several colleagues have supported us in both the technical and administrative aspects of this study. We are grateful to MA Jose for overseeing the administration of the fieldwork and to Komal Saxena, an author of this report, who also took on the responsibility of overseeing the editing of the report, and preparing the manuscript for publication. We would also like to acknowledge support from Annu Kurien for her inputs in editing the manuscript; we are grateful to her for her contribution and careful attention to detail, which have made the report more readable and accurate.

At the Centre for Catalyzing Change, we acknowledge the contributions of the Do Kadam team members and especially Alok Kumar in the Patna office, and Ruby Rajni and Rakesh Kumar, the project's field animators at the block level. Without their dedicated work, this project would not have been successful.

We would also like to acknowledge the dedication of our research assistants who conducted the survey and the indepth interviews with women from the study community and frontline workers.

Finally, we would like to record our deep appreciation of the frontline workers who took part in the intervention and the women from the community who gave us their valuable insights about the feasibility and acceptability of project activities. We hope that our recommendations based on the insights and experiences that they shared with us will help shape programmes intended to address the issue of violence against women and girls in Bihar.

$\begin{array}{ll}\text { Shireen J Jejeebhoy } & \text { Aparajita Gogoi } \\ \text { K G Santhya } & \text { Madhu Joshi } \\ \text { Santosh Kumar Singh } & \text { Sandeep Ojha } \\ \text { A J Francis Zavier } & \\ \text { Neelanjana Pandey } & \\ \text { Rajib Acharya } & \\ \text { Komal Saxena } & \end{array}$




\section{Executive summary}

In recognition of the magnitude of marital violence and its serious consequences for women and their children, India has instituted several laws, policies, and programmes that are intended to prevent violence against women and support women who experience it. The National Health Mission has identified violence prevention and services for women in distress as a key priority for frontline workers; Accredited Social Health Activists (ASHAs) are sensitised on how to recognise a woman facing violence, take appropriate actions for prevention of violence, and facilitate access to services available for women experiencing violence (National Health Mission, n.d.). However, evidence on what works and what does not work to reduce women's experience of intimate partner violence and ensure that those who face violence seek appropriate help remains limited, and this absence of evidence remains a key challenge underlying the gap between policy and programme commitments and the reality of women's lives in the country. In order to fill this gap, the Population Council, together with partners, the Centre for Catalyzing Change (C3) and the London School of Hygiene and Tropical Medicine, with support from UKaid, implemented the Do Kadam Barabari ki Ore (Two Steps Towards Equality) project. Implemented in rural areas of Patna district in Bihar, the project engaged frontline workers (FLWs), namely, ASHAs, anganwadi workers (AWWs), and, to a lesser extent, auxiliary nurse-midwives (ANMs) of the state's Department of Health and Family Welfare and Women Development Corporation (WDC) to screen women for their experience of marital violence, inform them about their options in case of such an experience, and provide basic counselling and referral, as needed, to women reporting the experience.

Specifically, objectives of the programme were to (a) test the extent to which FLWs succeeded in administering a short screening tool to identify women facing violence; (b) assess the extent to which women facing violence did indeed disclose their experience to FLWs; (c) describe women's experiences of the project and the quality of counselling, information, referrals, and support provided to them; and (d) understand the experiences of FLWs who delivered the intervention. In short, it aimed to assess the extent to which the engagement of existing FLWs is an acceptable health sector response for rural women who are at risk of marital violence. In view of the fact that marital violence is often initiated early in married life and takes place even during pregnancy and in view of the focus of FLWs on pregnant women, lactating women, and children in ages $0-5$, we sought to test our intervention specifically among women in ages up to 39 years who were pregnant or had children in ages $0-5$. We used an available screening tool that has been widely used (McFarlane et al., 1992).

To our knowledge, interventions that have employed FLWs, as opposed to facility-based workers, to screen and counsel women about violence have not been conducted, and this is a first effort to implement and evaluate the feasibility of such a model.

\section{The intervention}

The Do Kadam intervention was focused on all ASHAs and AWWs serving nine villages located within a distance of 5-6 kilometres from one primary health centre (PHC) of one block in Patna district.

The intervention programme was delivered from August 2015 to January 2016. It comprised a number of components: (a) development of a curriculum and other materials and organisation of a three-day capacity-building programme for ASHAs, AWWs, and, to a lesser extent, ANMs during which this curriculum was imparted to them; (b) screening of eligible women by trained ASHAs and AWWs, followed by awareness-building among all women, provision of basic counselling, and referral to health facilities and other services for women in distress, as needed, over a period of six months; (c) follow-up interactions between Do Kadam project staff and FLWs on a regular basis, including monthly meetings during which FLWs shared their progress and discussed feasible ways of addressing the needs of individual women they had encountered and enabling women in distress to overcome obstacles to seeking help; and (d) community-level events to sensitise communities on violence against women.

Each ASHA and AWW was assigned some 30-50 women who were pregnant or had a child in ages 0-5 and were in ages up to 39 years to screen, inform, counsel, follow-up, and refer as required. ANMs were included in the project as mentors to ASHAs and AWWs and as referral points for women in need.

\section{Evaluation design}

A mixed-method design was used to evaluate the Do Kadam programme, using both quantitative and qualitative methods. These comprised panel surveys before (baseline survey) and after (endline survey) the implementation of the programme among pregnant women and women with young children, that is, those 
considered at elevated risk of marital violence, and in-depth interviews with FLWs and selected baseline survey participants. A total of 1,153 married women in ages 18-39 years who were pregnant or had children in the age group 0-5 were interviewed at baseline, and 1,081 of these women were followed up some two months following the completion of the intervention. The baseline survey was conducted in June 2015 and the endline in March-April 2016. Aside from the surveys, we conducted in-depth interviews with a selected panel of 10 women from the intervention village who had reported the experience of violence in the baseline survey; we interviewed these women at two points in time-three months after the baseline survey (midline interview) and shortly after the endline survey (endline interview) were completed. There were 39 ASHAs, AWWs, and ANMs serving project villages who were interviewed about the time of the baseline survey, and 38 of these women were re-interviewed at endline.

\section{Pre-intervention context}

Baseline survey findings confirm a patriarchal socio-cultural setting in which women's agency-their decision-making authority, their freedom of movement, their self-efficacy, for example-was compromised in many ways, and many women continued to uphold beliefs that accepted the perceived right of a husband to exercise violence on his wife. Most women acknowledged that a man has the right to beat his wife, and most women (90\%) reported the experience of emotional, physical, or sexual violence perpetrated on them by their husband or other family members in the year prior to the interview. Two-thirds of all women reported the experience of physical and/or sexual violence perpetrated by a husband or other family members. For the most part, violence was perpetrated by their husband as opposed to a family member, and the majority-four in five women-who experienced violence perpetrated by their husband had experienced it frequently, that is, more than once in a month, and one-quarter had been injured as a consequence of the violence they experienced.

We note that while the percentage of women who reported the experience of recent physical or sexual violence in the National Family health Survey-4 (NFHS-4) is considerably lower (43\%) than the proportion in our baseline survey (67\%), our sample consisted of young women with children in ages 0-5 or in the process of childbearing-a group observed to be far more at risk of spousal violence than older women married for longer periods of time-whereas the NFHS survey included ever-married women in ages 15-49 in Bihar in general (IIPS, 2016).

\section{Feasibility and acceptability of interventions by engaging FLWs: Perspectives of women}

\section{Significantly increased interactions between FLWs and women on violence- related issues}

Findings show that interactions between FLWs and women on violence-related issues increased significantly following the implementation of the Do Kadam project (Figure 1). While at baseline, just three percent of women reported any interaction on violencerelated matters with an ASHA or AWW, by endline, half of all women (48\%) reported that the ASHA or AWW had screened them, provided them the Do Kadam brochure on services for women experiencing violence, informed them about women's rights, available services, and safety issues relating to violence, and/or counselled their husband or family members. With regard to screening, fewer-just 39 percent of all women-reported that the ASHA or AWW had screened them for their experience of violence (compared with the baseline survey
Figure 1: Percentage of women reporting discussion on violencerelated matters, screening for violence, and receipt of a violencerelated brochure in the six months preceding the interview, endline survey, 2016

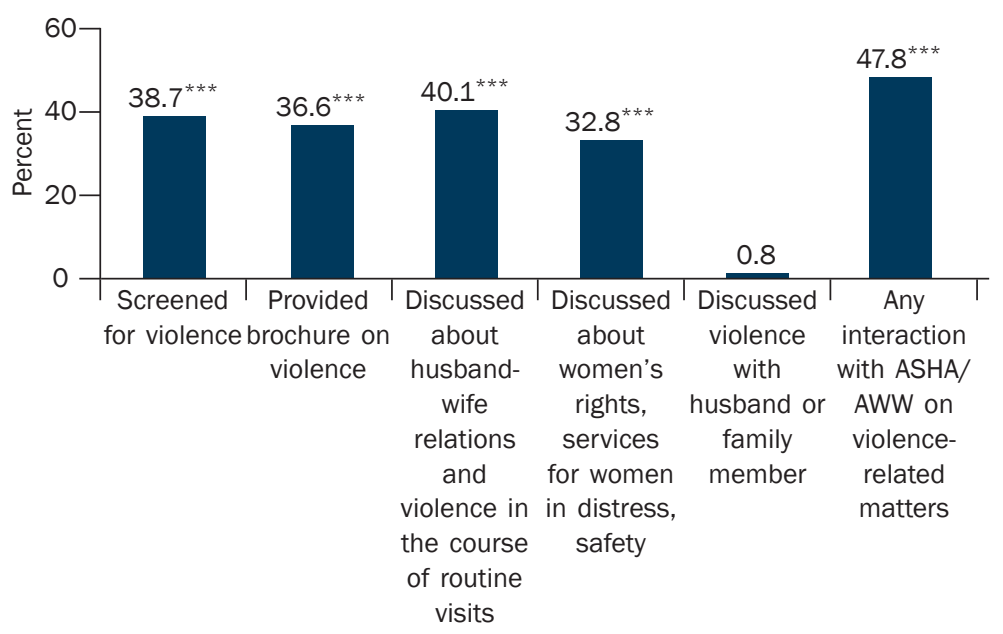

Note: ${ }^{* *}$ indicates that difference between baseline and endline values was significant at $p<=0.001$. 
where not a single woman reported screening), with screening more likely to have been conducted among women belonging to scheduled castes, poorly educated women, and working women than others. At the same time, we noted that in in-depth interviews at both midline and endline, several women suggested that violence-related topics were not discussed or were fleetingly discussed, and the few who were given the brochure could not explain its contents, which raised questions about the skill and comfort levels of ASHAs and AWWs in addressing issues relating to violence.

\section{Reluctance of many women to disclose their experiences to ASHAs and AWWs}

Despite the opportunity to report violence that was offered through the screening procedure, relatively few women who were screened by ASHAs and AWWs disclosed their experience of violence to them. Indeed, of all women screened at endline, 15 percent reported at baseline the experience of emotional, physical, or sexual violence to the survey interviewer as well as to the ASHA or AWW; however, as many as 76 percent had reported their experience of violence to the survey interviewer at the time of the baseline survey but not to the ASHA or AWW; just two women (less than 1\%) had disclosed their experience to the ASHA or AWW but not to the survey interviewer.

On the whole, among screened women who had acknowledged in the baseline survey that they had experienced emotional, physical, or sexual violence perpetrated by their husband or a family member in the year preceding the interview, just 16 percent had admitted their experience of violence to the ASHA or AWW at screening. Of those who had reported physical or sexual violence at baseline, 20 percent had acknowledged their experience of violence to the ASHA or AWW. As seen in Figure 2, disclosure of violence was significantly more likely among older than younger women $(p \leq .10)$, among poorly educated than well-educated women ( $p \leq .05)$, among those who experienced frequent violence or severe violence than women with a less intense experience of violence $(p \leq .001)$, and among those who had been screened in private than those who had been screened in the presence of other family members or in a group ( $p \leq .05)$. Insights from in-depth interviews suggest that women who reported that they had disclosed their experience of violence to the ASHA or AWW had acknowledged that the ASHA or AWW had made multiple visits to them to discuss violence-related matters; narratives also suggest that disclosure varied with the skill of ASHAs and AWWs in drawing out women who might otherwise have resisted revealing their experiences.

\section{Mixed findings on quality of interaction between the ASHA or AWW and respondent}

One-third of all women who had disclosed their experience of violence reported that the ASHA or AWW had simply empathised with them or provided general information, and one out of eight health workers had recommended that they tolerate the violence or make efforts to adjust to their husband's demands. Just one-quarter reported that the health worker had recommended that she access a service (for example, police, helpline), one out of six was encouraged to seek support from family and friends, and one out of ten was helped to draw up a safety plan. In indepth interviews, women reiterated that counselling was of a general nature, although some women did report that they had been counselled to seek out the ASHA or AWW when violence was experienced and had actually sought refuge with the health worker when they had subsequently experienced violence, while others reported that the health worker had counselled their husband or family member.

\section{Informal and formal sources of support}

Findings from the surveys and in-depth interviews emphasise that even at endline, many women continued to suffer the violence perpetrated against them without disclosing their experience to family and friends or to formal 
service providers. However, among women who had reported physical and/or sexual violence, we found that a larger proportion of women had shared their experiences with friends and family or had sought services from formal sources at endline than at baseline ( $\mathrm{p} \leq .001$; figure 3). Moreover, those who had interacted with ASHAs/ AWWs about violence-related topics and those who had disclosed their experiences to ASHAs/AWWs were more likely than others to have shared their experiences informally or sought services from formal sources of support ( $p \leq .001$; figure 4).

Figure 3: Percentage of women who had experienced physical and/or sexual violence in the six months prior to the baseline and endline interviews reporting having sought help from formal or informal sources, baseline and endline surveys, 2015 and 2016

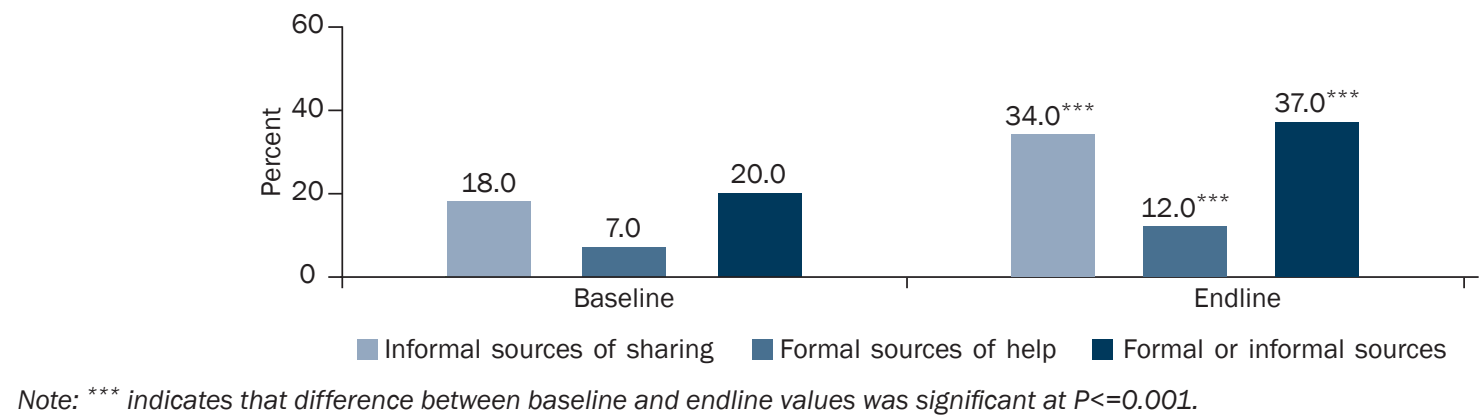

Figure 4: Percentage of women who had experienced physical and/or sexual violence in the six months prior to the endline interview and sought help from formal or informal sources, according to interactions with FLWs on violencerelated matters, 2016, endline survey

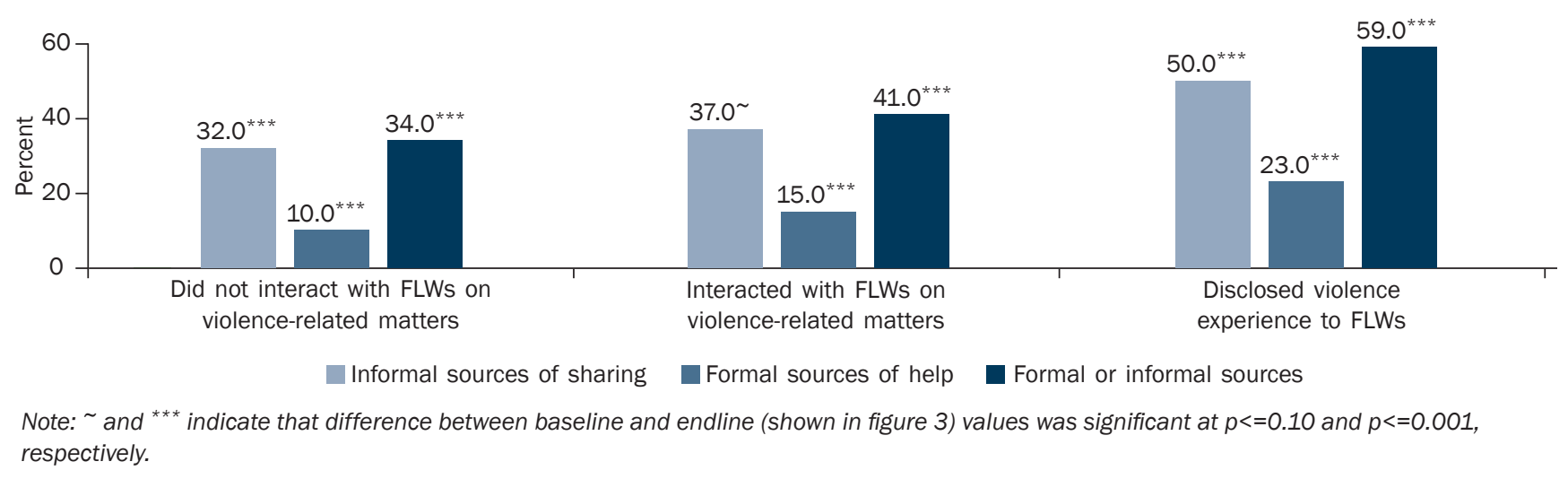

\section{Disclosure and subsequent experience of violence}

While numbers are limited and findings are just illustrative, we note that among women who had reported the experience of violence at baseline and had disclosed their experience to the ASHA or AWW in the course of the project, few reported that violence had abated over the course of the intervention. Indeed, of those reporting the experience of emotional, physical, or sexual violence at baseline, 95 percent (of 62 women) continued to report experience of violence at endline. Evidence of a reduction in violence was more apparent when we considered only those who reported physical and/or sexual violence (irrespective of whether they had also experienced emotional violence): Thus, 63 percent (of 57 women) reporting the experience at baseline continued to do so at endline. In in-depth interviews, considerably more women reported that they had not experienced emotional, physical, and/ or sexual violence at endline than they had at baseline interviews. Of those who reported continued experience of violence, most attributed their experience to their husband's misuse of alcohol, suspicions entertained by husbands of the wife's infidelity, delay in preparing the husband's meal, and, for one woman, dowry demands that the woman's family could not fulfil. Of those who reported a reduction in marital violence, just a few attributed this decline to the intervention of the ASHA or AWW; at least one woman attributed the decline in violence that she faced to her ability to threaten her husband with the options provided to her by the ASHA or AWW, and a second to the counselling that the ASHA or AWW had provided her husband. 


\section{Feasibility and acceptability of interventions by engaging FLWs: Perspectives of FLWs}

The FLWs were interviewed in-depth prior to the initiation of the intervention and at its conclusion. Their narratives confirm that the capacity-building associated with the Do Kadam project not only reached all FLWs, but also covered it far more comprehensively than the orientation imparted earlier and encompassed awareness about violence against women and women's rights, an introduction to the screening tool and its use, ways of approaching women about violence, and the services FLWs should offer women. By endline, moreover, narratives suggest that ASHAs and AWWs were far more proactive about approaching, screening, and counselling women about violence than they were at baseline and more confident about screening women for violence, helping women to overcome their reluctance and fears about revealing their experiences to them, while recognising the need for privacy, giving assurances of confidentiality, and posing questions in a non-threatening manner. Some ASHAs and AWWs had enlisted the support of their own husband in counselling the husband of women reporting experiences of violence. They reported that the project-developed card that they distributed to women had a positive effect on both informing and empowering women about their rights and options and raising fears among men about the consequences of violating these rights. For the most part, ASHAs and AWWs reported that they had resolved women's problems on their own (11 out of 16 ASHAs and six out of 12 AWWs who discussed referrals). Very few reported referring women in distress to the ANM or to other support services (two out of 16 ASHAs and five out of 12 AWWs). FLWs were well aware of and familiar with the themes of the last component of the programme, that is, street plays to sensitise communities at large on violence against women. Many of them suggested that these events had an effect on changing attitudes to violence in their village, although we acknowledge that data from women suggest that relatively few had been exposed to these street plays. On the whole, FLWs were fairly unanimous in their view that the project had resulted in positive change at community level, that project activities could easily be incorporated into the regular responsibilities of FLWs, and that the programme should be scaled up throughout the state (14 out of 16 ASHAs, 15 out of 16 AWWs, and all four ANMs who discussed this topic).

\section{Lessons for scaling up}

Overall, our findings from the experience of implementing the Do Kadam programme have been encouraging. They suggest that interactions between FLWs and women on violence-related issues increased significantly and that project activities could be incorporated into the regular responsibilities of FLWs. Yet, we note that many women did not disclose their experiences of marital violence to FLWs and that the quality of counselling and support was not uniform. Several recommendations emerge, including the need to recognise that domestic violence is both a public health concern and a violation of women's rights, on the one hand, and to understand, on the other, the importance of incorporating screening, counselling, and referrals of women experiencing violence into the responsibilities of FLWs, as listed below.

\section{Build an appreciation of the public health consequences and rights violations of domestic violence}

Programmes are needed that sensitise communities and key community influentials about the adverse public health consequences of domestic and intimate partner violence as well as on the rights violations that such violence implies. Strong advocacy measures must be undertaken not only at community level, but also through the Department of Health and Family Welfare, the Department of Social Welfare, and other related bodies that address women's concerns to enable a deep engagement into understanding the health and rights implications of violence.

\section{Strengthen capacity-building efforts}

Efforts are needed to strengthen the capacity-building of ASHAs and AWWs in particular to enable them to communicate empathetically with women in need and develop the confidence to draw out women who suffer violence. ASHA, AWW, and ANM training programmes need to incorporate a strong focus on skill-building and include demonstrations on how to approach women, build trust, and provide effective counselling and support to those in need.

We speculate that efforts to incorporate responsibilities to address violence into the duties of FLWs requires a more intensive capacity-building component than we were able to provide. We suggest that a more intensive focus on the subject of violence against women is incorporated into the FLW training package, with efforts to enable FLWs to integrate issues relating to the identification and support of women facing violence into their regular responsibilities. 


\section{Prioritise violence reduction as a key component of FLW responsibilities}

Efforts are needed to place counselling and services on violence-related matters at par with other sexual and reproductive health services offered by ASHAs and AWWs and be supervised by ANMs; compensation for accompanying women who experience violence to referral points may be considered.

\section{Build stronger links between ASHAs/AWWs and ANMs}

Challenges were also experienced in facilitating a strong and supportive relationship between ASHAs and AWWs, on the one hand, and ANMs, on the other, Indeed, few ASHAs and AWWs sought the help of ANMs, and few ANMs appeared interested in supporting or encouraging ASHAs and AWWs. ANMs need to be better engaged in violencereduction activities and be held responsible for monitoring the work of ASHAs and AWWs. They need to demonstrate to those who are uncomfortable about approaching women how to conduct screening and counselling and also mentor ASHAs and AWWs on how to address difficult cases.

\section{Address links to support services and referrals for women in distress}

We acknowledge that while the programme was intended to raise awareness among FLWs and women themselves about services available for women in distress, attention must be paid to improving the quality of services provided by others, notably, the police and courts, orienting service providers about bringing services closer to women, and making efforts to empower FLWs to accompany women in need to reach these services.

\section{Incorporating the Do Kadam experience into the regular responsibilities of ASHAs and AWWs}

Finally, we note that FLWs are ideally placed to screen, counsel, refer, and support women in their communities who experience violence. Many FLWs acknowledged that the inclusion of counselling and screening on violence-related matters was acceptable and could well be incorporated into their regular activities. Findings lend support for the integration of elements of the Do Kadam programme-screening mechanisms, basic counselling, referral linkagesinto the FLW capacity-building programmes as well as into their job descriptions and performance-monitoring activities. Findings also call for a convergence in FLW service delivery responsibilities between the Department of Health and Family Welfare and the Integrated Child Development Services (ICDS), Department of Social Welfare.

Our model has shown that community-based workers can be engaged to screen women on their experience of marital violence, provide them information about the options available to women experiencing violence, and counsel those in need. At the same time, our experience has highlighted the need for extensive investments in capacitybuilding and supportive supervision, so that reducing the incidence of violence becomes as much of a priority in the health system as enhancing pregnancy-related outcomes, improving nutrition levels, and promoting family planning. 


\section{Chapter 1 Introduction}

Marital violence is widespread in India: nationally, as many as one in three (35\%) women in ages 15-49 had experienced physical or sexual violence within marriage in 2005-06, and 50 percent of men and 56 percent of currently married women justified marital violence in at least one situation (IIPS and Macro International, 2007). The problem is most acute in the state of Bihar, where 56 percent of women reported the experience of marital violence and 57 percent of women and men alike justified wife-beating (IIPS and Macro International, 2007), although the recent National Family Health Survey-4 (NFHS-4) noted that the proportion of ever-married women who had experienced marital violence has declined to 43 percent (IIPS, 2016). Young and newly married women are disproportionately at risk (IIPS and Population Council, 2010; Santhya and Jejeebhoy, 2005). Indeed, as many as 23 percent of all ever-married women, which translates into 62 percent of ever-married women who had ever experienced marital violence, had experienced such violence for the first time within two years of marriage (IIPS and Macro International, 2007).

Violence against women is a serious public health concern. There is considerable global evidence of the implications of marital violence for the health and well-being of women and their children. In the reproductive health arena, marital violence has been associated with non-use of and an unmet need for contraception as well as the occurrence of unintended pregnancy, induced abortion, symptoms of gynaecological morbidity, and even foetal and infant mortality (Garcia-Moreno et al., 2005; Krug, et al., 2002). The evidence also suggests that young women and recently married women are at heightened risk of experiencing marital violence (Bates et al., 2004; Boyle et al., 2009; Dalal, Rahman, and Jansson, 2009). These adverse outcomes have been also observed among married women in India, and, notably, even among married young women (Jejeebhoy, Santhya, and Acharya, 2013). Studies have observed, for example, that women in the reproductive ages who experienced marital violence were significantly more likely than those who had not to experience unwanted pregnancy, pregnancy loss, induced abortions, pregnancy-related complications, and perinatal and infant mortality (Ackerson and Subramanian, 2009; Ahmed, Koenig, and Stephenson, 2006; Jejeebhoy, 1998; Johnson and Sengupta, 2008; Muthal-Rathore, Tripathi, and Arora, 2002; Singh, Mahapatra, and Dutta, 2008; Stephenson et al., 2008). Associations with gynaecological morbidity and HIV infection have also been observed (Silverman et al., 2008; Stephenson, Koenig, and Ahmed, 2006; Sudha, Morrison, and Zhu, 2007; Weiss et al., 2008). Adverse mental health outcomes have also been observed (Patel et al., 2006; Chowdhury and Patel, 2008; Jejeebhoy et al., 2010).

In recognition of the magnitude of marital violence and its serious consequences for women and their children, India has instituted several laws, policies, and programmes that are intended to prevent violence against women and support women who experience it. These include, notably, the National Policy for the Empowerment of Women, 2001, and the Protection of Women from Domestic Violence (DV) Act, 2005, (Government of India, Ministry of Law and Justice, 2005). The National Health Mission has identified violence prevention and services for women in distress as a key priority for FLWs. Accredited Social health Activists (ASHAs) are sensitised on how to recognise a woman facing violence, take appropriate actions for prevention of violence, and facilitate access to services for women experiencing violence (National Health Mission, n.d.). Notwithstanding these commitments, evidence on what works and what does not work to reduce women's experience of intimate partner violence and ensure that those who face violence seek appropriate help remains limited, and this absence of evidence remains a key challenge underlying the gap between policy and programme commitments and the reality of women's lives in the country.

In order to fill this gap, the Population Council, together with partners, the Centre for Catalyzing Change (C3) and the London School of Hygiene and Tropical Medicine, with support from UKaid, implemented the Do Kadam Barabari ki Ore (Two Steps Towards Equality) project in rural areas of Patna district in Bihar. The objective was to engage frontline workers (FLWs), namely, ASHAs, anganwadi workers (AWWs), and, to a lesser extent, auxiliary nurse midwives (ANMs) of the state's Department of Health and Family Welfare and Women Development Corporation (WDC) to screen women for their experience of marital violence, inform them about their options in case of such an experience, and provide basic counselling and referral, as needed, to women reporting such experience. ${ }^{1}$ In particular, it sought

\footnotetext{
${ }^{1}$ The Do Kadam Barabari ki Ore programme comprised, aside from this project, the development and evaluation of a number of other interventions for the prevention of violence against women and girls in Bihar that incorporated evidence-based best practices from India and globally. These included projects focused on changing attitudes and practices among boys in ages 13-21 who were members of youth clubs falling under the Nehru Yuvak Kendra Sangathan (NYKS), changing attitudes in the community through locally elected representatives (Panchayati Raj Institution [PRI] members), changing attitudes among women members of self-help Groups (SHGs) falling under the Women Development Corporation, and the husbands of these SHG members.
} 
to support and build upon the National Health Mission's commitment to engage ASHAs for reducing violence against women and girls. Specifically, we drew upon promising practices observed in the literature and adapted, implemented, and evaluated an intervention that was feasible, using an existing structure and service setting and that was responsive to socio-economic and institutional environments in Bihar. The Population Council evaluated the feasibility of the intervention. This report describes the project and its implementation and explores its feasibility. It examines the extent to which the project succeeded in enabling FLWs to identify, inform, counsel, and refer women, it highlights the challenges faced, and it makes recommendations for strengthening the role of FLWs in preventing intimate partner violence and supporting women who experience such violence. To our knowledge, interventions that have employed FLWs, as opposed to facility-based workers, to screen and counsel women about violence have not been conducted, and this is a first effort to implement and evaluate the feasibility of such a model.

\section{Objective}

The goal of the evaluation was to assess the feasibility of the Do Kadam Barabari Ki Ore project on marital violence. It addresses the extent to which the engagement of FLWs is an acceptable and feasible health sector response for rural women who are at risk of marital violence. Specifically, objectives of the evaluation were to (a) test the extent to which FLWs succeeded in administering a short screening tool to identify women facing violence; (b) assess the extent to which women facing violence did indeed disclose their experience to FLWs; (c) describe women's experiences of the project and the quality of counselling, information, referrals, and support provided to them; and (d) understand the experiences of FLWs who delivered the intervention.

In view of the fact that marital violence is often initiated early in married life and takes place even during pregnancy and in view of the focus of FLWs on pregnant women, lactating women, and children in ages $0-5$, we sought to test our intervention specifically among women in ages up to 39 years who were pregnant or had children in the age group 0-5. We used an available screening tool that has been widely used (McFarlane et al., 1992).

\section{Background and rationale}

Given the inegalitarian norms persisting in India, it follows that women's typical reaction to violence committed by their husband is silence and toleration (Jejeebhoy, Santhya, and Acharya, 2014). Indeed, just 24 percent of women who had experienced marital violence reported that they had sought help from anyone; help was, moreover, sought overwhelmingly from a family member or friend rather than those in authority or, more specifically, a healthcare provider. Indeed, help from someone in authority was sought by just three percent of women, with fewer than one percent approaching the health system (IIPS and Macro International, 2007). In a qualitative study in rural Bihar, India, even though women recognised that they could seek help from the authorities, including local self-government representatives (panchayats), the police, and the courts, women admitted that they had not heard of a single woman who had taken these measures (Jejeebhoy, Santhya, and Sabarwal, 2013). A number of serious obstacles that prevent women from seeking help, even from healthcare providers were reported. Women in Bihar feared that revealing the experience of violence to others would exacerbate the violence they experienced ('Women believe that if they ask someone for help, their husband will harm them'); and that disclosing the incident would compromise the family's 'honour' ('It will amount to insulting her marital family.... No woman would want her house to be regarded with disrespect'). They also harboured fears of abandonment and separation from children ('They are scared that if they go out to ask for help, they will be thrown out of the house') and they upheld the belief that men were entitled to perpetrate violence on their wife ('He has the right to beat her ... because he is her guardian; if she makes any mistake... if she does not cook food for him in time'). As a result, aside from toleration, suicide was recognised as one of the few options available to women experiencing spousal violence. Women expressed this option as follows: 'She can burn herself, hang herself' and 'If their husbands beat them too much, they can strangle themselves or consume poison', and 'She will commit suicide [by throwing herself] under the train' (Jejeebhoy et al., 2013).

The hands-off approach of providers also plays an important role in limiting women's care-seeking from the health sector. Norms regarding the acceptability of marital violence are pervasive not only among rural women, but also among providers themselves (Agrawal and Banerjee, 2012; Majumdar, 2004). At the same time, providers hold the attitude that what happens within the home is private; therefore, dealing with the issue of domestic violence is the responsibility of others and not that of healthcare providers, and that beyond the physical injuries that result from domestic violence, such violence is not a health issue (Baker-White, 2010). Many providers are likely to be unaware of the law and their responsibilities under the law, the magnitude of marital violence and its adverse long term consequences for women's health, or the support services to which women at risk can be referred (Baker-White, 2010). Moreover, the present medical and nursing syllabi do not teach healthcare providers about counselling and treating women who experience violence nor include practical skill development to prepare the 
healthcare providers to deal with domestic violence issues, and thus most providers are not trained to address domestic violence issues (Agrawal and Banerjee, 2012; Baker-White, 2010; Majumdar, 2004).

At the same time, the pre-service training curricula of ANMs, ASHAs, and AWWs do not emphasise the role of FLWs in recognising and preventing violence against women, although the ASHA programme contains a special module on the topic (Ministry of Health and Family Welfare, n.d.). Even so, we note that ASHAs are sensitised on likely symptoms of women's experience of violence (vague complaints, anxiety, fear, depression, bruises on the body, sleeping problems, for example) but are not trained to probe or screen women directly for their experience of violence. This indirect approach may also hamper ASHAs' ability to systematically identify women at risk.

As such, even when treating a woman who shows obvious signs of violence, providers do not seize the opportunity to probe the woman' s situation or offer her counselling, treatment, or a referral.

Several screening tools are available that assess women's risk of marital violence and have been implemented in different healthcare settings (for example, Basile, Hertz, and Back, 2007; McFarlane et al., 1992). Whether probing and screening women who come into contact with the health system is an appropriate health sector response has been debated in the global literature. Recent WHO clinical and policy guidelines for responding to intimate partner violence do not recommend universal screening of women, arguing that while such screening does enable a greater reporting of violence, it does not necessarily result in a reduction in violence or an improvement in women' s health. The guidelines also indicate that in high-prevalence settings with limited resources and referral networks, benefits to women are unclear. It recommends, instead, that women who disclose any form of violence should be offered firstline support, comprising non-judgemental support, practical care, linkages with other support services, assistance in defining a safety plan for herself and her children, and provision or mobilisation of social support (WHO, 2013). In India, where few women would seek a provider and disclose the experience of violence and where few women have the freedom of movement or the required resources to visit a health facility, there is a compelling need for the health system to play a more proactive role.

Such a proactive role may be played by the strong network of FLWs, namely, ASHAs, AWWs, and ANMs that serve rural populations in India. These health workers are village based, they are familiar with women in their communities, and they act as a link between women and the formal health system. Typically, these workers are from the village, and while better educated than the average woman, they come from a similar background, are likely to know which women are most at risk, are able to gain their trust and become their confidante, and are, in short, less threatening figures of authority. As such, these healthcare workers may play an important role in identifying women who have experienced violence, providing them with the first-line support recommended by the WHO, and supporting them in disclosing their experiences to and seeking help from a healthcare provider in the formal health system during their routine visits to a health facility for pregnancy, contraception, or child health services.

\section{Study setting}

Bihar was the locale for our study. It is the third largest state in the country and has a population of 104.1 million, constituting nine percent of India's population (in 2011); 17 percent of the population belong to socially disadvantaged castes and tribes (Office of the Registrar General and Census Commissioner, India, 2013). It is one of the most poorly developed states in the country: 34 percent of the state's population was estimated to be living below the poverty line (Planning Commission, 2013), and a significant proportion of the population remains illiterate (for example, 52\% of women were illiterate) (Office of Registrar General and Census Commissioner, 2013). Child marriage is more widespread in Bihar than in any other state in the country: 69 percent of 20-24-year-old women were married before the age of 18 years, 33 percent below age 15, and 10 percent below age 13 in $2005-06$ (IIPS and Macro International, 2007). Moreover, Bihar ranks highest among all states in India with regard to women's experience of violence within marriage (IIPS and Macro International, 2007). Norms justifying partner violence are strongly held by both men and women in Bihar-57\% of women and men alike justified wife-beating (IIPS and Macro International, 2007). ${ }^{2}$ Violence against women and girls is widely perceived by women and men as acceptable under some circumstances, notably, women's perceived disobedience.

Our intervention was based in Patna district, the district housing the state capital. Table 1.1 presents a comparative profile of socio-demographic indicators in Patna district as compared with Bihar state as a whole. Patna district comprises six percent of the state's population; and given that it houses the state capital, it is far less rural than the state as a whole. Hindus constitute a somewhat larger proportion of the population of Patna compared with Bihar as

\footnotetext{
2 Findings from the NFHS-4 suggest that the percentage of women reporting the experience of spousal violence had declined to 45 percent by 2015 (IIPS, 2016), a steep decline that requires further investigation.
} 
a whole (92\% versus $83 \%$ ), although percentages belonging to socially disadvantaged castes and tribes are similar for both $(16 \%-17 \%)$. With regard to socio-demographic indicators, Patna district is clearly better off than the state as a whole. Literacy rates are higher among both men and women in Patna district than in the state as a whole and the population and child sex ratios somewhat more adverse. Fertility and infant mortality rates are far lower in Patna than in Bihar. Of note, however, is that marriage continues to take place in childhood for considerable percentages in both Patna district and Bihar state: 11-12 percent of girls in both were married and as many as 36 percent of married girls in ages 15-19 in Patna were already mothers, a somewhat larger proportion than in Bihar as a whole (30\%) in 2011.

Table 1.1: Profile of the study district and state

\begin{tabular}{|c|c|c|}
\hline Socio-demographic indicators & Bihar State & Patna district \\
\hline Population $^{a}$ & $104,099,452$ & $5,838,465$ \\
\hline Rural $(\%)^{a}$ & 88.7 & 56.9 \\
\hline Scheduled castes and tribes (SCs/STs) $(\%)^{a}$ & 17.2 & 15.9 \\
\hline Hindu $(\%)^{b}$ & 82.7 & 91.7 \\
\hline Muslim $(\%)^{\mathrm{b}}$ & 16.9 & 7.5 \\
\hline Male literacy $(\%)^{\mathrm{a}}$ & 71.2 & 78.5 \\
\hline Female literacy $(\%)^{a}$ & 51.5 & 62.0 \\
\hline Overall sex ratio $(\mathrm{F} / \mathrm{M})^{\mathrm{a}}$ & 918 & 897 \\
\hline Child sex ratio $\left(0-6\right.$ years) $(\mathrm{F} / \mathrm{M})^{\mathrm{a}}$ & 935 & 909 \\
\hline Total fertility rate, AHS $2012-13^{c}$ & 3.5 & 2.6 \\
\hline Infant mortality rate, AHS $2012-13^{c}$ & 48 & 31 \\
\hline $15-21$-year-old boys who were ever married $(\%)^{d}$ & 11.8 & 11.6 \\
\hline $15-17$-year-old girls who were ever married $(\%)^{d}$ & 11.6 & 11.2 \\
\hline 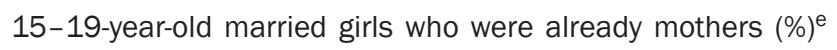 & 29.7 & 35.8 \\
\hline $\begin{array}{l}\text { Women (15-49 years) whose body mass index (BMI) is } \\
\text { below normal }(\mathrm{BMI}<18.5 \mathrm{~kg} / \mathrm{m} 2)^{f}\end{array}$ & 30.4 & 24.0 \\
\hline Non-pregnant women age $15-49$ years who are anaemic & & \\
\hline$(<12.0 \mathrm{~g} / \mathrm{dl})(\%)^{\mathrm{f}}$ & 60.4 & 58.0 \\
\hline Institutional births $(\%)^{f}$ & 63.8 & 86.4 \\
\hline Use of any contraception $(\%)^{f}$ & 24.1 & 39.4 \\
\hline Unmet need for family planning & 21.2 & 17.8 \\
\hline
\end{tabular}

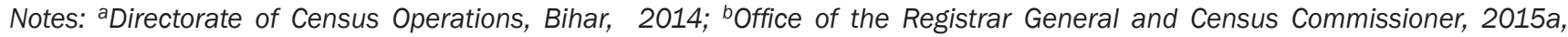

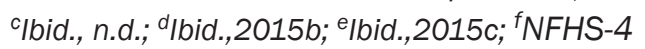

As far as contraception and maternal health conditions are concerned, indicators for Patna district and Bihar state differed considerably. A somewhat smaller proportion of women in Patna were found to have a body mass index below normal than in Bihar as a whole (24\% versus 30\%), although levels of anaemia among non-pregnant women were similar (58\%-60\%). Institutional delivery was more common in Patna than in the state as a whole (64\% in Bihar state versus $86 \%$ in Patna district). Contraceptive prevalence was also higher in Patna (24\% in Bihar state versus $39 \%$ in Patna district), although the levels of unmet need for family planning were similar (18\%-21\%).

There are a total of 84 primary health centres (PHCs) in Patna district; each serves a population of about 30,000. Each $\mathrm{PHC}$ is managed by one or two doctors, one or two staff nurses, and 14 paramedical staff. Auxiliary nurse midwives are responsible for outreach activities in the villages served by the PHC. In particular, ANMs hold monthly Village Health and Nutrition Days at which they provide antenatal and postpartum check-ups to women, immunisation to pregnant women and infants, contraceptive information and supplies, and regular check-ups and referrals to women and children as appropriate, in each village served; in many instances, these VHNDs take place within the anganwadi. ASHAs are village-based functionaries who serve as a link between communities and the health system. They are typically from the village in which they serve, have at least eight years of education, and are expected to make home visits to women to inform them about pregnancy-related care, newborn, infant and child care, contraception, and so on, provide contraceptive supplies and medicines as appropriate, escort pregnant women to the PHC for delivery, and conduct other activities intended to promote community health in their village. Each village is served by one or two ASHAs. 
The Integrated Child Development Services (ICDS) provides nutritional supplementation to pregnant women, lactating women, and to children in pre-school ages in each village. At least one anganwadi centre is located in each village and is managed by an AWW who is expected to both supervise the provision of supplementary nutrition and provide pre-school education for those in ages 2-6; she also participates in health events and may distribute contraceptives.

AWWs and ASHAs both work at village level and often work jointly, for example, on issues relating to pregnancy care, newborn and child health, and so on. ANMs are expected to mentor and supervise the work of ASHAs and are linked with AWWs through the VHNDs that are often run with support from both AWWs and ASHAs.

\section{The intervention}

The Do Kadam programme was conducted among FLWs operating under the auspices of the Department of Health and Family Welfare and ICDS of the Government of Bihar.

The project was implemented with inputs from the two departments. They provided the much-needed authorisation for implementing the intervention and permitted C3 India and the Population Council to coordinate with block-level health and ICDS functionaries. They also expressed interest in lessons of the project for upscaling.

The project was implemented among ASHAs and AWWs serving nine villages located within a radius of 5-6 kilometres from the PHC in one block in Patna district. The intervention focused on all ASHAs and AWWs serving these nine villages. Each of these villages was served by at least one ASHA and one AWW; a total of five ANMs served these nine villages. The intervention aimed to build the capacity of FLWs for them to screen, inform, counsel, and refer women who had experienced violence, and thereby reduce the experience of marital violence among these young women. We adapted an available screening tool, namely the Abuse Assessment Screen (McFarlane, Parker, Soeken, and Bullock, 1992; Basile, Hertz, Back, 2007). Each ASHA and AWW was assigned some 30-50 women who were not older than 39 years at the time of the baseline survey and who were pregnant or had a child in the age group 0-5 years; they were expected to screen, inform, counsel, follow-up, and refer these women as needed. ANMs were also included in the project as mentors to ASHAs and AWWs and as referral points for women in need.

Participatory methodologies were used to build FLW capacity, with role plays and discussions of case studies. A training programme was held in which C3 India sensitised FLWs on women's rights, the unacceptability of marital violence, and services available for women in distress. Population Council staff members familiarised them with the project, the screening tool, and how to administer it in a non-threatening way and record responses. Finally, we sought to develop communication and basic counselling skills of FLWs and support them in making referrals for women in need. Over the course of the project, a team of core trainers from C3 India oversaw the programme implemented by these FLWs and held monthly refresher meetings with them in which progress and problems were discussed and solutions sought.

Over the seven-month intervention, each ASHA and AWW visited the homes of women, whom they had been assigned to serve, in the course of their regular home visits to women in the community. They administered the screening tool in a conversational way, and if privacy was available and rapport developed, probed more deeply into experiences of violence. In subsequent visits to women who had experienced domestic violence, they provided basic counselling and support, and if the violence was severe, referred women to the ANM or to available services for women in distress. Each woman was provided a brochure in which details of services available were provided. Finally, community events, in the form of street plays, were also organised to sensitise communities more generally on women's rights and services for women who have experienced violence. The intervention is discussed in greater length in Chapter 3.

\section{Study design}

The intervention was implemented in one block of Patna district, namely, Phulwarisharif. We selected the block purposively, because it was in relatively close proximity to Patna and thus to facilities for women in distress, namely, the Patna helpline, the local female police station, short stay homes located in neighbouring districts, alcohol deaddiction centres, and so on. Phulwarisharif block resembled the Patna district average in terms of female literacy and percentage of the scheduled caste/tribe population. In the next step, we selected villages located within a radius of 5-6 kilometres from the single PHC located in the block; there were nine such villages, containing a population of 18,308 according to the 2011 census.

A mixed-method design was used to evaluate the Do Kadam programme, using both quantitative and qualitative methods-panel surveys before (baseline survey) and after (endline survey) the implementation of the programme 
and in-depth interviews with FLWs and selected baseline survey participants. In order to evaluate the feasibility and acceptability of the intervention, we required a sample of 1,100 women in ages up to 39 years and who were pregnant or had children in the age group 0-5. Following the selection of intervention villages, we enumerated all households in the study villages to identify households containing eligible respondents and listed some 10,000 households. This was followed by a survey of all eligible respondents, as specified earlier, who had been identified in the house-listing exercise in the study villages. At baseline, the team identified a total of 1,312 eligible women and successfully interviewed 1,153 women. We completed the baseline data collection in June 2015.

Aside from the surveys, we conducted in-depth interviews with a selected panel of 10 women from intervention village who had reported the experience of violence in the baseline survey; we interviewed these women at two points in time-three months after the baseline survey (midline interview) and shortly after the endline survey (endline interview) were completed. There were 39 ASHAs, AWWs, and ANMs serving project villages who were interviewed about the time of the baseline survey, and 38 of these women were re-interviewed at endline.

The endline assessment was carried out from March-April 2016, that is, two months following the completion of the intervention. In the endline survey, we re-interviewed consenting baseline respondents; of the 1,153 women successfully interviewed at baseline, a total of 1,081 women were successfully re-interviewed at endline. In-depth interviews were repeated, in addition, with ten women, and 38 out of the 39 FLWs with whom in-depth interviews had been held at midline.

In short, while our design did not include a comparison group, it allowed us to assess the feasibility of our intervention among a group of women targeted for services by FLWs (pregnant women, and women with children in ages 0-5) and also to assess changes in their interaction on violence-related matters with FLWs over the course of our intervention.

\section{Study instruments}

Four study instruments were developed-a household listing form (only at baseline) to identify eligible respondents; a survey questionnaire to gather information from eligible women; and two in-depth interview guides-one for baseline respondents who had reported the experience of marital violence and one for FLWs in order to gather their insights.

Responses to the household listing form were gathered from a responsible adult member of the household. The household listing form identified all households in the study villages at the time of the baseline that contained a pregnant woman or a woman with at least one child in the ages 0-5 and who was not older than 39 years.

The questionnaire for eligible women was more or less identical at baseline and endline. It focused on respondents' background characteristics, their agency, and gender role attitudes, particularly with regard to violence against women and girls. It also focused on women's experiences of non-consensual sex and physical violence of various forms (from slapping to burning), alcohol consumption among women, their reports of alcohol consumption by their husband, knowledge about the Domestic Violence (DV) Act, injuries suffered, and the nature of help available and sought among women who had reported the experience of violence. In addition, we probed experiences of their contact with FLWs over the duration of the intervention on the issue of marital violence, and whether behaviours and experiences had changed since the project was initiated. We also elicited their perceptions about the acceptability and feasibility of the programme and whether they attributed any change in gender role attitudes or experiences of violence against women to the intervention.

The In-Depth Interview (IDI) guide included broad thematic areas to be covered and key questions that served as prompts under each broad theme. The in-depth interview focused on the life experiences of the respondent; her relations and interaction with her husband; gender role attitudes relating to violence against women and girls; and finally, experience of emotional, physical, and sexual violence in marriage. We also probed study participants' perspectives about the extent to which they interacted with FLWs on issues of violence and violence-related helpseeking, the nature of this interaction, and the perceived effectiveness, quality, and acceptability of their interaction with ASHAs, AWWs, and ANMs (as appropriate).

Guides for FLWs similarly contained questions that explored her life and work, her own attitudes to and experience of violence in marriage, the extent and circumstances of her contact with women in the community, and her perceptions of her role as a key community worker, particularly with regard to stopping violence against women. At endline, the guide focused, in addition, on perceptions about the entire intervention and activities conducted at community level over the course of the intervention to stop violence against women. We focused on the nature of the FLW's interactions with pregnant women and those with children in ages 0-5 on issues related to marital violence and help-seeking in the course of the intervention, the effectiveness and acceptability of the interventions 
made by them, whether those with whom they had interacted had sought support and its outcome, and whether they perceived that they had been successful in reducing the incidence of violence in their village and enabling women in need to seek help.

All study instruments were prepared in English, translated into Hindi, and pre-tested. In-depth interviews were taped, transcribed, and translated into English.

\section{Recruitment, training, and fieldwork}

A total of six young men underwent training for conducting the house-listing exercise prior to the baseline survey. They conducted the household listing, and the information they obtained was used to identify eligible women for the survey. In addition, at baseline, 20 young women for conducting the survey and one male supervisor were trained. Following training, 17 young women were appointed to administer the survey instruments; three young women were trained, additionally, to conduct the in-depth interviews. These research assistants were graduates in science or social science streams, proficient in Hindi and had 3-4 years of experience in conducting field-based studies. Training was conducted by Population Council staff members. Training for the household listing was completed in two days. For the baseline survey, however, interviewers underwent a seven-day training programme that included a combination of classroom sessions, mock interviews, and field practice. Training focused on interviewing methods, details of the questionnaire, and research ethics, including issues of confidentiality and privacy. The interviewers were divided into three teams. Each team had one field editor who was responsible for field editing, back-checks, and quality control of interviews; the supervisor was responsible for the overall management of fieldwork and teamrelated logistics as well as assisting in field editing and back-checking.

The endline survey and in-depth interviews were conducted by eight of the young women who had conducted the baseline survey and in-depth interviews; they attended a short three-day refresher training programme.

Principal investigators made frequent visits to monitor and supervise data collection operations. Each team regularly completed quality-control sheets, which gave the team, the coordinator, and principal investigators an opportunity to review the quality of ongoing fieldwork. These quality control sheets were designed to provide information on response rates in each village covered and track reporting of interaction with FLWs as well as on violence and interviewer performance.

\section{Ethical considerations}

We recognised that serious ethical concerns could arise in both the survey and the in-depth interviews and we adopted suitable precautionary measures. First and foremost, we recognised that women may fear adverse repercussions if they disclosed experiences of marital violence. To allay these fears, we assured all respondents that the data gathered were entirely anonymous; that the interviewers would not share their responses with anyone, including their family members, the authorities, or FLWs; and that names would never be recorded on the questionnaire. The following strategies were adopted, moreover, to maintain privacy and confidentiality.

The interviewers underwent extensive training in ethical issues. Emphasis was laid on explaining the content of the questionnaire, the respondent's right to refuse to participate or answer any question, and the requirement of informed consent. At the same time, we trained interviewers on how to ask sensitive questions regarding violence and alcohol abuse in empathetic and non-judgemental ways, and emphasised the importance of offering to refer those in need to available services for women in distress. Third, before entering a primary sampling unit (PSU), the interviewer teams were instructed to apprise community leaders of the study and seek their support for its implementation in the community. This step ensured that community support was forthcoming and enabled team members to easily build rapport within the community. We note that despite the sensitive nature of the questions, not a single PSU refused permission to our teams on the grounds of study content.

Every effort was made to maintain privacy in the course of the interview. To ensure that the interviews were not overheard by family members or others, the interviewers conducted the interview in a separate room in the respondent's home, asked questions in whispers, called on a co-interviewer to hold parallel discussions with adults or others interested in listening to the interview, or re-scheduled the interview so as to enable full confidentiality. Interviewers were permitted to skip to relatively non-sensitive sections in case the interview was observed by others. Finally, the interviewers were instructed that if privacy could not be ensured, the interview must be terminated without asking sensitive questions. Notwithstanding these efforts, we acknowledge that during the interview some women may not have accurately reported the experience of violence.

All of the questionnaires were anonymous and names were never recorded on the questionnaire. In order to preserve the confidentiality of the respondent, signing the consent form was optional; however, the interviewer was required 
to sign a statement that she or he had explained the content of the consent form to the respondent. Consent forms were detached and stored separately from the questionnaires. Finally, we also recognised the need for responding appropriately to requests from respondents for help or information related to violence and help-seeking options. Our field staff members were trained and equipped to refer such requests to local NGOs or relevant government authorities as appropriate.

The protocol for this study was approved by the Population Council's Institutional Review Board.

\section{Data processing}

All completed questionnaires were sent to the Population Council's office in New Delhi for editing and data processing. Completed questionnaires were re-checked and further edited in the office for omissions and consistency. Responses to open-ended questions were scrutinised and common responses were provided codes. For entering the edited data, a special software package was developed using CSPro 5.1. Data were entered twice by different entry operators to minimise entry problems. The raw data were validated and cleaned to remove possible inconsistencies. The analysis of data was carried out using SPSS 18.0 and STATA 13.0. For textual data, a coding scheme was developed. Coded blocks of text related to specific themes, for example, gender role attitudes, or experiences of violence, help-seeking practices, and so on, with a focus on assessing changes that took place among individuals over the course of the intervention.

The feasibility of the intervention was measured by comparing women's experiences of interaction with ASHAs and AWWs on topics related to violence-specifically, the extent to which interaction had increased, and more specifically, whether women recalled being screened for violence by the ASHA or AWW; we also explored the extent to which women admitted their experience of violence to these workers, and elicited their perceptions about action taken, its quality, and whether it had resulted in any change in their experience of violence. Interviews with ASHAs, AWWs, and ANMs revealed their experiences and the feasibility of the intervention as perceived by them in the time span from the baseline to the endline interviews. Specifically, the evaluation among women relied on data from the panel surveys conducted before the intervention was initiated (baseline survey) and after its conclusion (endline survey), supplemented by in-depth interviews held with a small number of survey respondents a few months after the intervention was initiated (midline interview) and after its conclusion (endline interview). The evaluation among FLWs relied on in-depth interviews held with them prior to the initiation of the intervention (baseline interview) and some months following its conclusion (endline interview).

\section{Response rates}

Table 1.2 summarises the number of respondents identified and successfully interviewed at baseline and endline. At baseline, out of the 1,312 eligible women of age group 15-39 years identified, we interviewed a total of 1,153 (88\%). At endline, we were able to follow-up and re-interview 1,081 women (94\%).

Table 1.2: Response rate at baseline, follow-up rate at endline, and reasons for non-response and loss to follow up

\begin{tabular}{|c|c|c|}
\hline $\begin{array}{l}\text { Response rate at baseline, follow-up rate at endline, and reasons } \\
\text { for non-response and loss to follow-up }\end{array}$ & Baseline & Endline \\
\hline \multicolumn{3}{|l|}{ Response rate and follow-up rate } \\
\hline Women identified at baseline & 1312 & \\
\hline Women interviewed at baseline/endline & 1153 & 1081 \\
\hline Response rate at baseline (\%) & 87.9 & \\
\hline Follow-up rate at endline (\%) & & 93.8 \\
\hline \multicolumn{3}{|l|}{ Reasons for non-response/loss to follow-up } \\
\hline Not at home/hostel & 153 & 46 \\
\hline Respondent refused & 5 & 12 \\
\hline Partly completed & 1 & \\
\hline Respondent had migrated out ${ }^{a}$ & & 12 \\
\hline Respondent died in the previous year & & 2 \\
\hline Total non-response/ lost to follow up & 159 & 72 \\
\hline
\end{tabular}

Note: ${ }^{a}$ Women who had migrated out at the time of the baseline house-listing exercise were not included. 
Reasons for non-response at baseline and loss to follow-up at endline are presented in Table 1.2. They show that at baseline, the leading reasons for non-response was that the respondent was not at home even after three visits made by the field team (12\%). At endline, loss to follow-up was largely because the respondent was unavailable for interview even after 3-4 visits by the field teams (4\%). Other reasons included out-migration of the respondent (1\%) and refusal (1\%). We note that two women had died in the period between the baseline and endline surveys.

Table 1.3 summarises the number of FLWs and baseline survey respondents who were interviewed in-depth at baseline/midline and followed-up at endline. All 16 ASHAs and 18 AWWs were successfully interviewed at baseline and at endline. In addition, of the five ANMs serving project villages at baseline, four were re-interviewed at endline; unfortunately, one ANM died of natural causes shortly after the baseline interview. In addition, in-depth interviews were held with ten women from the community who had participated in the baseline survey interview. Five each had experienced moderate and severe violence, and all were successfully re-interviewed at endline.

Table 1.3: In-depth interview respondents at baseline and endline

\begin{tabular}{lcc}
\hline Respondents & Baseline $^{\mathbf{a}}$ /Midline $^{\mathbf{b}}$ & Endline $^{\text {(n) }}$ \\
\hline ASHA & 16 & 16 \\
AWW & 18 & 18 \\
ANM & 5 & 4 \\
Total number of FLWs & 39 & 38 \\
Selected baseline survey respondents (married women) & 10 & 10 \\
\hline
\end{tabular}

Notes: ${ }^{a} A S H A s, A W W s$ and ANMs; ${ }^{b}$ Selected baseline survey respondents.

\section{Structure of the report}

The report is divided into five chapters, including this introductory chapter. In Chapter 2, we present a sociodemographic profile of women who were eligible for the Do Kadam project to provide the context in which the intervention was conducted. In Chapter 3, we describe the objectives, the design, and the key components of the intervention. Drawing on survey data, Chapter 4 describes the women's interactions with ASHAs and AWWs on violence-related matters in an attempt to assess the feasibility of the Do Kadam programme from women's perspectives. Chapter 5 presents FLWs' own perceptions about the intervention, their role in implementing it, and the challenges they faced. In Chapter 6 , we summarise the main findings of the evaluation. 


\section{Chapter 2 \\ Socio-demographic profile of study participants}

Drawing on baseline survey data, this chapter provides a brief socio-demographic profile of pregnant women and women with children in ages 0-5 from study communities prior to the start of the Do Kadam Barabari Ki Ore project.

\section{Household characteristics}

Table 2.1 describes the household characteristics of women residing in study settings. Findings suggest that communities were almost entirely Hindu and that half of them belonged to scheduled castes. Economic status data suggest that the majority of women came from resource-poor households; only 34 percent lived in a pucca house (with a roof, walls, and floor made of permanent materials) and only 32 percent had access to a flush toilet. However, almost all (97\%) lived in households with electricity. Household economic status was measured using a wealth index composed of household asset data on ownership of selected durable goods, including means of transportation and access to a number of amenities. The wealth index was constructed by allocating scores to a household's reported assets or amenities (for details of the scores, see Appendix Table 1). Index scores, so constructed, ranged from 0 to 54 . The household wealth index reconfirms a situation of considerable poverty: the average household scored only 20.2 on the wealth index (of a maximum possible score of 54). On average, women lived in households containing six persons.

Table 2.1: Household characteristics of surveyed women Selected household characteristics of pregnant women and women with a 0-5-year-old child, baseline survey, 2015

\begin{tabular}{lc}
\hline Household characteristics & Baseline (N=1153) \\
\hline Religion (\%) & 99.8 \\
Hindu & \\
Caste (\%) & 49.5 \\
SC & 47.6 \\
OBC & 2.9 \\
General & \\
Household economic status & 22.9 \\
Standard of living index (ranges 0 to 57 (Mean) & 96.9 \\
Has electricity (\%) & 32.0 \\
Has access to a flush or pit toilet (\%) & 65.1 \\
Has no access to any toilet facility (\%) & 33.7 \\
Lives in a pucca house (\%) & \\
Household size & 5.6 \\
Number of household members (mean) & \\
\hline
\end{tabular}

\section{Socio-demographic profile of women}

Table 2.2 presents a profile of respondents who participated in the survey at baseline. Respondents were young, aged 25 on average, with more than half in ages 18-24. Most were poorly educated, reporting an average of just 4.5 years of schooling; indeed, 47 percent had never been to school, just 34 percent had completed eight or more years of education, and even fewer, 21 percent, had completed a secondary school education. Husbands were, on average five years older than respondents (mean age 29), and just slightly better educated (completed six years of education on average). With regard to participation in economic activity, about two in five respondents had been engaged in paid work in the preceding 12 months (38\%). 
Exposure to mass media was assessed through three indicators: whether or not women watched television or attended film shows sometimes or often; and whether those with five or more years of education read newspapers, magazines, or books, or accessed the internet sometimes or often. Findings confirm considerable exposure to the media: 73 percent reported regular exposure to television, and one-quarter $(26 \%)$ of those with five or more years of schooling were exposed regularly to the print media. In contrast, just one percent of women reported regular exposure to the theatre.

Table 2.2: Socio-demographic characteristics of surveyed women Selected socio-demographic characteristics of pregnant women and women with a 0-5-year-old child, baseline survey, 2015

\begin{tabular}{|c|c|}
\hline Socio-demographic characteristics & Baseline ( $\mathrm{N}=1153)$ \\
\hline \multicolumn{2}{|l|}{ Age (\%) } \\
\hline $18-24$ & 51.4 \\
\hline $25-30$ & 36.8 \\
\hline 31 and above & 11.8 \\
\hline Mean age of women & 24.9 \\
\hline Mean age of husband ${ }^{a}$ & 28.9 \\
\hline \multicolumn{2}{|l|}{ Education (\%) } \\
\hline No formal education & 47.0 \\
\hline Completed Class 8 and above & 33.8 \\
\hline Completed Class 10 and above & 20.8 \\
\hline Number of years of education completed (mean) & 4.5 \\
\hline Number of years of education completed by husband ${ }^{b}$ (mean) & 6.0 \\
\hline \multicolumn{2}{|l|}{ Work (\%) } \\
\hline Engaged in paid work in the last year & 38.4 \\
\hline \multicolumn{2}{|l|}{ Mass media exposure (\%) } \\
\hline Regular (at least weekly) exposure to television & 73.4 \\
\hline Regular (at least weekly) exposure to newspapers, magazines, books ${ }^{c}$ & 25.9 \\
\hline Regular (at least monthly) exposure to films (at a theatre) & 1.0 \\
\hline $\begin{array}{l}\text { Regular exposure to television, newspaper/magazine/, books (at least weekly) or films (at least } \\
\text { monthly) }\end{array}$ & 74.1 \\
\hline \multicolumn{2}{|l|}{ Mobile phone access (\%) } \\
\hline Has own mobile phone & 30.8 \\
\hline Does not own a mobile phone but has access to one & 55.2 \\
\hline
\end{tabular}

aExcludes 38 women who did not know their husband's age; 'Excludes 50 women who did not know their husband's educational status; ${ }^{c} N=631$, i.e., applicable to women who had completed at least five years of education.

Most women owned or had access to a mobile phone (86\%). However, far fewer reported that they owned a mobile phone (31\%).

Childbearing experiences of respondents are reported in Table 2.3. On average, women had 2.7 live births and 2.4 surviving children at the time of the interview, with almost three in four women reporting at least one son and one daughter.

Attitudes were by and large, traditional. Almost nine in ten women (89\%) agreed that husbands had a right to beat their wife in at least one out of six situations probed (Table 2.4). Indeed, 88 percent of women agreed that a man has the right to beat his wife if she has an affair with another man. More than two out of five women agreed that a man should beat his wife if she goes out without permission (41\%), disobeys him (52\%), or makes a mistake (45\%), and one-third (34\%) agreed that he should beat her if she does not care for their children to his satisfaction. On the whole, of the six situations probed, women acknowledged a man's right to exercise violence over his wife in 2.5 situations. 
Table 2.3: Childbearing experiences of surveyed women

Selected childbearing characteristics of pregnant women and women with a 0-5-year-old child, baseline survey, 2015

Selected childbearing characteristics

Baseline $(\mathrm{N}=1153)$

\section{Children ever born and surviving}

Number of children ever born (mean)

2.7

Number of children surviving (mean)

2.4

Has one or more sons (\%)

73.7

Has one or more daughters (\%)

73.0

Pregnancy status

Currently pregnant (\%)

Table 2.4: Gender role attitudes held by surveyed women

Selected indicators of agency of pregnant women and women with a 0-5-year-old child, baseline survey, 2015

\begin{tabular}{lc}
\hline Attitudes about the acceptability of marital violence & Baseline (N=1153) \\
\hline It is all right for a husband to beat his wife: & 87.8 \\
If she has a relationship with another man (\%) & 40.9 \\
If she goes out without telling him (\%) & 41.9 \\
If she disobeys him (\%) & 45.3 \\
If she makes a mistake (\%) & 33.6 \\
If she does not take care of her children to his satisfaction (\%) & 88.7 \\
In at least one of the above situations (\%) & 2.5 \\
Mean number of the above situations in which wife-beating is acceptable & \\
\hline
\end{tabular}

\section{Experience of violence}

We measured violence by way of a series of questions probing emotional, physical, and sexual violence perpetrated by the husband and/or other family members. In assessing emotional violence, we probed whether they had insulted or humiliated the respondent or her natal family members or done anything to intimidate the respondent (yelling at her, throwing things, etc). To assess physical violence, we explored women's responses about whether their husband or other family members had slapped them, twisted their arm or pulled their hair, pushed, shook, or threw something at them, punched them, beat, kicked or dragged them, tried to choke or burn them, or attacked them with a weapon. Sexual violence was assessed through a single question about whether their husband or other family members had forced them to engage in sexual relations.

The experience of violence perpetrated by the husband and, to a lesser extent, by other family members over the 12 months preceding the baseline interview was widespread (Table 2.5). More than nine out of ten women (91\%) reported the experience of emotional, physical, or sexual violence, and two out of three (67\%) reported the experience of physical or sexual violence perpetrated by their husband and/or other family members in the year preceding the interview.

Violence perpetrated by the husband was about as widespread, with 89 percent reporting the experience of emotional, physical or sexual violence perpetrated by their husband in the 12 months preceding the interview. Two-thirds reported the experience of physical or sexual violence (67\%), with 48 percent and 51 percent reporting the experience of physical and sexual violence, respectively. We note that the percentage of women who reported the experience of recent physical or sexual violence in NFHS-4 is considerably lower (43\%) than in our baseline survey, and we reiterate that while our sample comprised young women with children in ages $0-5$ or who were in the process of childbearing-a group observed to be far more at risk of spousal violence than older women married for longer periods of time-the NFHS survey included ever-married women in ages 15-49 in Bihar in general (IIPS, 2016)

Findings confirm moreover that violence was frequent for large proportions of women, and for some, that it had resulted in injury. Four in five women, for example, who had experienced any incident of physical or sexual violence 
Table 2.5: Women's experience of violence perpetrated by their husband and other family members Selected indicators of violence perpetrated by the husband and other family members on pregnant women and women with a 0-5-year-old child in the 12 months preceding the interview, baseline survey, 2015

Violence perpetrated by husband and/or other family members (\%)

Physical violence

Sexual violence

Physical or sexual violence

Emotional, physical, or sexual violence

Violence perpetrated by husband (\%)

Emotional violence

Physical violence

47.7

Sexual violence

50.7

Physical or sexual violence

66.7

Emotional, physical, or sexual violence

Frequency of violence (perpetrated by husband) among women who experienced violence in preceding 12 months ( $\mathrm{N}=769)(\%)$

Violence experience more than once a month

Injury experienced from violence perpetrated by husband or other family members (N=769) (\%)

Injury experienced from violence in preceding 12 months

perpetrated by their husband reported that they experienced such violence frequently, that is, more than once in a month. One-quarter of women (26\%) who had experienced physical or sexual violence perpetrated by their husband or other family members had been injured as a result.

\section{Summary}

In summary, findings suggest that pregnant women and women with children in the age group 0-5 years in our sample were Hindu and came from socially disadvantaged castes. Economic and social disadvantages characterised their life: for example, they came from poor households that contained a large numbers of members and had, on average, just 4.5 years of education. Despite the fact that they were young (average age 25), they had already experienced almost three live births, and many reported pregnancy loss. Husbands were, on average, five years older than respondents (29 years on average), and just modestly better educated (six years on average). Mass media exposure was not universal, however almost three-quarters of women had regular access to television, and about four out of five women owned a mobile phone or had access to someone else's mobile phone.

Findings also confirm a patriarchal socio-cultural setting in which many women continued to uphold beliefs that accepted the perceived right of a husband to exercise violence on his wife. In addition, most women (89\%) acknowledged a man's right to beat his wife in at least one of six situations that ranged from going out without his permission to disobedience and from making a mistake/not caring for her children to having an affair with another man.

Violence against women was widespread. Nine in ten women reported the experience of emotional, physical, or sexual violence perpetrated on them by their husband or other family members in the year prior to the interview, while twothirds reported the experience of physical and/or sexual violence perpetrated by them. Violence perpetrated by the husband was reported by about as many women as those reporting violence perpetrated by their husband or any other family member. Given that our sample consisted of young women with children in ages 0-5 or in the process of childbearing-a group observed to be far more at risk of spousal violence than older women married for longer periods of time-we note that these percentages were considerably higher than those reported in the recent NFHS survey, which provides findings from ever-married women in ages 15-49 in Bihar in general. Finally, we note that the majority-four in five women-who experienced violence perpetrated by their husband had experienced it frequently, that is, more than once in a month, and one-quarter had been injured as a consequence of the violence they experienced.

It is in this context of overall poverty, inegalitarian gender norms, and widespread violence against women that our intervention was implemented. 


\section{Chapter 3 \\ Do Kadam Barabari Ki Ore: The intervention}

In this chapter, we briefly describe the objectives, the design, and key components of the intervention. We also discuss the challenges faced in implementing the intervention.

\section{Objectives of the Do Kadam Barabari Ki Ore intervention}

The programme sought to sensitise and build the capacity of ASHAs and AWWs to screen women for violence, raise awareness of women's rights and services available to women experiencing violence, and counsel, refer, and support women reporting the experience of violence within the home. In the longer term, the programme aimed, through such action, to reduce women's experience of further violence in marriage, and enhance their awareness and use of services. In short, it aimed to empower ASHAs and AWWs to act as intermediaries between women who were at risk of further violence and the ANM, the formal health system, and other sources of support for women in distress. The intervention targeted pregnant women and women with at least one child in the age group 0-5, from nine villages of Phulwarisharif block of Patna district.

The intervention was conducted with the support and permission of the Government of Bihar's Department of Health and Family Welfare and ICDS. Implementing the intervention within existing government structures with a wide reach meant that replication and upscaling of the model if proven successful was possible.

\section{Main components of the intervention programme}

The Do Kadam programme was implemented over a six-month period, from August 2015 to January 2016. It focused on building the capacity of ASHAs and AWWs to identify women at risk of marital violence, build their awareness of the Protection of Women from Domestic Violence (DV) Act, 2005, and services available for women who experience violence, and support those in distress to seek help from ANMs, healthcare facilities, and other available support services. The programme also sought to build the capacity of ANMs to serve as mentors to ASHAs and AWWs. The project thus aimed to support these FLWs to incorporate the prevention of marital violence and provision of support to those at risk of violence into their routine responsibilities.

The intervention comprised multiple activities: (a) development of a curriculum and other materials for ASHAs and AWWs (and as their mentors, ANMs) and organisation of a three-day training programme to impart this curriculum; (b) screening of eligible women by trained ASHAs and AWWs, followed by awareness-building among all women, provision of basic counselling, and referral to health facilities and other services for women in distress as needed over a six-month period; (c) interaction with ANMs to discuss cases of women in distress and referral of women in need to ANMs; and (d) monthly meetings between Do Kadam project staff and FLWs during which FLWs shared their progress and discussed feasible ways of addressing the needs of individual women they had encountered and enabling women in distress to overcome obstacles to seeking help.

\section{Materials development}

C3 India developed the curriculum for the three-day training programme as well as take-away materials and a register format in which FLWs recorded the results of their screening and described the follow-up action taken at each visit with women. We note that we were required to complete the training within three days, as the authorities were reluctant to permit FLWs to attend a training programme of longer duration.

In order to structure the three-day training programme, a manual was prepared that addressed two key domains of relevance to the project. First, it sought to raise awareness among FLWs about women's rights, including those relating to their right to freedom from violence and right to services available for women in distress, and change attitudes among FLWs about the acceptability of marital violence and traditional notions of male superiority; it also raised awareness about the underlying causes of marital violence and its impact on women's health and well-being. Second, it sought to build the communication and counselling skills of FLWs. It emphasised ways of building rapport with women who may have experienced violence but were reluctant to disclose the experience; of screening and identifying women who had experienced marital violence; of providing basic counselling and appropriate referrals to women in distress; and of supporting those who wished to seek help from accessing such help. They were also exposed to the screening tool and trained in its administration and recording of responses.

A brochure was also developed, and a set provided to FLWs to share with women in the community as well as to those in positions of authority, such as PRI and SHG members. The brochure was developed for a low-literacy 
audience and contained pictorial depictions of forms of violence against women and listed the protection and support services available under the law. It also contained the telephone number of the helpline.

A card (the $Z$ card) was also developed that contained information similar to the brochure as well as simple messages to FLWs on why and how they could support women in need.

\section{Screening Form}

We used an adapted version of the Abuse Assessment Screen developed by the American Medical Association for administration in clinical settings (Figure 3.1). In view of the fact that it was to be administered by FLWs in a traditional society in which marital violence is perceived as acceptable, we trained workers to build rapport with women before administering the tool and to intersperse screening questions within a larger conversation about the woman's and her children's health. Responses were recorded in a register maintained by the FLW on each woman assigned to her and formed the basis upon which the FLW made subsequent visits and guided the content of those visits.

Figure 3.1: Abuse Assessment Screen (AAS)

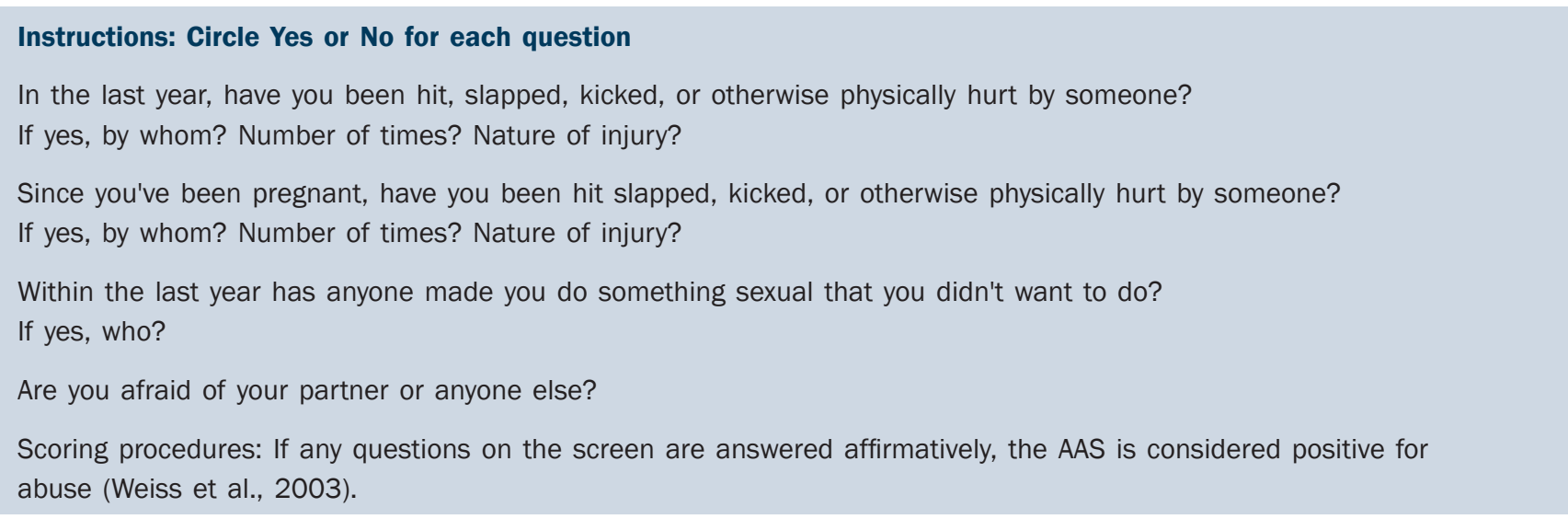

Source: American Medical Association, 1992

\section{Capacity-building of FLWs}

The three-day initial training programme for FLWs was conducted in July 2015 at the PHC in Phulwarisharif. Resource persons included the $\mathrm{C} 3$ and Population Council team members and the Coordinator of the Patna Helpline, who described available support services provided by the Government of Bihar. A total of 38 out of 39 FLWs registered under the PHC attended the training programme (one could not attend because of severe illness). These included 16 ASHAs, 18 AWWs, and four ANMs.

The training programme contained structured sessions on understanding the root causes of gender inequality, forms of violence, and the role that healthcare providers can play in addressing the issue by identifying and supporting women facing or at risk of violence. Specifically, FLWs were oriented on (a) gender, discrimination and patriarchy within the family and community; (b) the extent and nature of domestic violence; (c) causes and consequences of violence against women (including how it may affect health-seeking behaviours that FLWs aim to promote); (d) links between alcohol consumption among men and violence against women and girls (VAWG); (e) sensitisation on attitudes, values, and societal prejudices and norms; and (f) The policy and legislative framework, notably the contents of the DV Act, 2005, and the Criminal Law (Amendment) Act, 2013.

Skills were also built. We familiarised FLWs on the procedures for using the screening checklist and on documentation and record keeping. There were additional sessions on communications skills and basic counselling skills. In these sessions, training focused on their role in supporting women at risk of violence, and, more specifically, on enhancing their skills in making decisions on the appropriate course of action for women at risk/in distress; providing basic support; referring women to higher-level authorities for counselling and services (to ANMs by ASHAs and AWWs, and also to PHCs or higher-level facilities, police, legal aid, helpline, short stay homes, and so on); and ensuring nonjudgmental and supportive attitudes. The capacity of ANMs to mentor and supervise this aspect of the work of ASHAs and AWWs (as in other health-related matters) were also addressed.

Finally, efforts were made to link FLWs with support organisations. This included the criminal justice sector, domestic violence advocates, local NGOs, and a helpline through exposure visits and talks by authorities to apprise them of the spread of available support services-exposure visits were made to the district helpline, police, and any women's organisation in the area that provides support to women who report the fear or experience of violence as well as to 
local gram pancahayats and panchayat samiti members to enlist the support of locally elected representatives.

Sessions were interactive and participants were encouraged to share their own experiences, take part in role play and other interactive activities, and hone their skills in screening and counselling. The participants practised the screening process, and at these sessions, instructions on filling the forms were also reiterated. During the training, they were given basic instructions on the dos and don'ts of screening and counselling for violence experience, such as, refraining from asking questions in the presence of other family members and interspersing screening questions with discussions on health issues more generally. They were also taught how to build rapport with women, gain their trust, assure them of confidentiality, and how to interact with family members in ways that would not arouse suspicions.

Trainers noted that the skills of ASHAs and AWWs to listen, communicate, and take action (informing women about support services, advising them on safety planning, speaking to family members and husbands, etc.) were limited, and hence trainers focused on strengthening the ability of FLWs to build rapport with women and probe their violence experiences in non-judgemental ways.

At the conclusion of the training programme, FLWs were assigned some 30-50 women, who were either pregnant or had a child in the age group 0-5, and they were tasked with visiting, screening, and following-up these women over the next six months. ASHAs were given lists of pregnant women and those with children in the ages 0-2 years; AWWs were asked to follow-up those women with children in ages 2-5 years through home visits, that is, the group with whom ASHAs and AWWs were most likely to interact.

During the course of the six months (August 2015 to January 2016) during which FLWs carried out the project, two one-day refresher training programmes were held at the health subcentres. The training programmes reinforced the skills gained in the initial training programme, especially in the areas of understanding the DV Act and communication and counselling skills. It provided additional opportunities for FLWs to role play the counselling process and possible actions they could take to prevent violence and support women in need.

\section{Monthly meetings with ASHAs and AWWs}

Monthly meetings were held at each of the three health subcentres serving the nine villages in our sample. During these meetings, FLWs discussed their progress over the previous month, highlighted difficulties in filling the screening form or counselling women, and sought guidance for handling the obstacles they experienced in identifying and supporting women in need. ASHAs and AWWs shared their difficult cases with C3 India programme staff members as well as with ANMs and the helpline counsellor who advised them on strategies and processes to be followed in advising women and speaking to their husbands/in-laws. Most cases of marital violence reported by ASHAs and AWWs were attributed to the husband's alcohol abuse and extramarital affairs; several noted that violence was attributed to the inability of the woman to produce sons, and they sought advice on how to counsel women reporting these reasons for violence.

These monthly meetings also offered an opportunity for C3 India programme staff members to review registers and scrutinise the notes of screened cases, assess the progress made by FLWs, and offer guidance as appropriate. Monthly meetings were also used to discuss strategies for addressing husbands and other perpetrators.

The rest of the review meetings focused on activities for follow-up of screened women and for identifying support for weaker ASHAs and AWWs. An interactive game was used in one of the review meetings to generate interest and enable the ASHAs and AWWs to reflect on their own attitudes and beliefs.

\section{Screening of and follow-up support to women in distress}

Following the initial training, ASHAs and AWWs visited women in the list provided to them and screened them using the questions in the Abuse Assessment Screen. Women were provided the project-developed brochure, and those women identified as having experienced marital violence in the year preceding the interview were targeted for followup visits. At follow-up, the ASHA/AWW provided counselling and information about the law, helped women develop safety plans, and referred those in need to both local institutions (PRI, SHGs, local NGOs) and available services, such as the women's helpline, women's police station, and short stay homes. In some instances, ASHAs and AWWs also discussed violence issues with husbands and family members. The ANM supported the work of the ASHA/AWW largely in the course of her attendance at monthly review meetings.

There was some concern that the experience of marital violence, and sexual violence in particular, may have been under-reported by women in the course of screening by ASHAs and AWWs, and hence programme staff encouraged ASHAs and AWWs to conduct screening over more than one visit. 
We note that while we did not intend for ASHAs and AWWs to interact with or counsel perpetrators- husbands or other family members-many women who reported the experience of violence requested FLWs to do so, and, as a result, during refresher training programmes, discussions were held on how to address or counsel husbands or family members who may have perpetrated violence on the woman. A few ASHAs and AWWs reported in monthly meetings that they had enlisted the support of their own husbands to speak to husbands who were reportedly abusing their wives.

\section{Community/social mobilisation activities at the village level}

In addition, in each of the nine project villages, street plays (nukkad nataks) were held to raise community awareness. The FLWs played an important role in mobilising community attendance at these street plays as well as in ensuring the presence of community leaders (PRI/SHG members and other influential persons). The nukkad nataks were aimed to create community-level awareness about violence against women. They focused on imparting new ideas relating to norms and attitudes, marital violence and its health consequences for women, women's rights and available support mechanisms for redress, alcohol abuse as well as the role of health workers and community leaders in helping women take action to stop incidents of violence. The FLWs invited PRI, SHG, and other local opinion makers to express their views about the need for a violence-free community following the several performances of street plays. Community members attended these plays, and the performance was followed by discussions about alcohol abuse and gender discrimination.

\section{Challenges faced in implementing intervention activities}

Overall, the implementation of the Do Kadam programme proceeded as we had envisaged, and our experience points to the feasibility of employing FLWs to screen women for violence and support those in need. Many ASHAs and AWWs succeeded in posing screening questions to women in the course of their regular duties, and counselling those in need. Monthly meetings were indeed held, and offered an opportunity to FLWs to share their concerns with their colleagues and the project implementers. The importance of addressing violence against women was increasingly recognised among FLWs, and many expressed commitment to working toward its elimination, and believed that violence-related screening and counselling could be folded into their regular responsibilities.

We did, however, face a number of operational challenges when implementing the intervention. A key challengeone that was difficult to overcome in a short intervention-was the difficulty in building the range of skills required of FLWs to implement this intervention effectively. Many ASHAs and AWWs, the main FLWs administering the intervention, were not able to read and write fluently, which made it difficult to administer the screening tool and document their progress. At the same time, many FLWs held the same traditional norms about masculinity and the acceptability of marital violence as did women in the community, and it was difficult to deter them from holding attitudes that maintained that women must tolerate marital violence or that marital violence was acceptable if women had erred in some way. Finally, communication skills were limited among many FLWs; they were shy about discussing intimate matters such as violence, and their skills in building rapport with women, engage them in telling their stories, and counselling and referring those in need were limited. Despite monthly meetings, regular refresher training programmes and support in making home visits, many ASHAs and AWWs exhibited discomfort in playing a proactive role in identifying and supporting women in need. Because of their difficulty in connecting and building rapport with women on issues related to violence, the experience of violence was not reported by considerable proportions of women in the initial visit, and this required FLWs to make additional visits, often accompanied by a more confident FLWs or project staff member. We speculate that conducting such a programme requires a more intensive capacity-building component than we were able to provide, and we suggest that a more intensive focus on violence against women should be incorporated into the FLW training package, with efforts to enable them to integrate issues relating to the identification and support of women facing violence into their regular responsibilities.

Challenges were also experienced in facilitating a strong and supportive relationship between ASHAs and AWWs, on the one hand, and ANMs, on the other. We had envisaged that ANMs would play a supportive and supervisory role, that they would mentor and guide ASHAs and AWWs facing difficulties, and that they would make home visits themselves in cases that the ASHA or AWW was unable to adequately address. Unfortunately, because of competing demands on ANMs' time, it proved difficult for ANMs to allot time to this additional responsibility. Not all ANMs were able to attend the entire training programme organised for them, or organise monthly meetings, or review ASHA and AWW records, or participate in discussions about difficult cases. Again, we believe that incorporating 
the prevention of violence against women into the regular responsibilities of ANMs and incorporating a focus on prevention strategies in the ANM training and refresher training packages are critical for ensuring ANM support for the prevention of marital violence and activities intended to support and refer women who experience it.

A third challenge was in convincing women to seek help from healthcare facilities, the police, the helpline, or shelters for women in distress. The FLWs reported that although they had recommended external help-seeking to women who reported severe or prolonged violence, women were unwilling to seek help. They were reluctant to lodge complaints against their husband with the helpline or police for fear of adverse repercussions from their husband or marital family members. Many women reported to ASHAs and AWWs that they had no faith in the effectiveness of public sector services and hence preferred not to use these facilities. Finally, several women reported that they did not have the freedom of movement to visit a police station or other services on their own or that the facilities to which they were referred were located too far away from their home to make a visit feasible. Our experience highlights the need for support services to become more accessible to women at community level and to provide outreach mechanisms that may both allay women's concerns about travelling far to access services and enable service providers to confront and counsel perpetrators without requiring the woman to file formal charges against a family member.

Finally, we note that while FLWs are ideally placed to incorporate among their responsibilities the provision of information, basic counselling and referrals for the prevention of marital violence, and support for women who experience such violence, several challenges persisted. For one, gender-based violence is not covered in the pre-service training of AWWs or ANMs; while there is a special module on the topic in the training of ASHAs, it is not clear how many ASHAs have been exposed to this module (Ministry of Health and Family Welfare, n.d). Nor is the identification and support of women who have experienced violence included explicitly in the responsibilities of FLWs, and, as such, FLWs did not prioritise the activities proposed under the Do Kadam project. Competing demands on FLWs' time posed yet another challenge. These are not insurmountable challenges. Indeed, the ASHA training module contains a general discussion on identifying and targeting women who are at risk of violence, and the screening tool employed in this project provides a more objective means of such identification. What is required now is a commitment to incorporate violence-screening and services into the regular responsibilities of FLWs as well as inclusion of the key elements of the Do Kadam curriculum into the regular pre- and in-service training of FLWs along with regular monitoring of information, counselling, and referrals provided by FLWs to women in their communities.

\section{Summary}

The intervention programme was delivered from August 2015 to January 2016 to women who were in ages up to 39 years and who were pregnant and/or had children in the age group 0-5 years in nine villages of one block of Patna district. It comprised a number of components: (a) development of a curriculum and other materials for FLWs and organisation of a three-day training programme to impart this curriculum to FLWs; (b) screening of eligible women by trained FLWs, followed by awareness-building among all women, provision of basic counselling, and referral to health facilities and other services for women in distress, as needed, over a six-month period; (c) follow-up interactions between Do Kadam project staff and FLWs on a regular basis, including monthly meetings during which FLWs shared their progress and discussed feasible ways of addressing the needs of individual women they had encountered and of enabling women in distress to overcome obstacles to seeking help; and (d) community-level events to sensitise communities on violence against women.

Overall, the implementation of the Do Kadam programme proceeded as we had envisaged, and our experience points to the feasibility of employing FLWs to screen women for violence and support those in need. We did however face a number of operational challenges when implementing the Do Kadam programme through FLWs. A key challenge-one that was difficult to overcome in a short intervention-was the difficulty in building the range of skills required by FLWs to implement this intervention effectively. The FLWs, for example, displayed uneven levels of fluency in reading and writing, several were uncomfortable discussing these personal matters with women, and still others believed that marital violence was justifiable and thus needed no intervention. Challenges were also experienced in facilitating a strong and supportive relationship between ASHAs and AWWs, on the one hand, and ANMs, on the other, and in convincing women to seek help from healthcare facilities, the police, the helpline, or shelters for women in distress. Indeed, women preferred to have FLWs convey messages to their husband about desisting from violence against women. Finally, we note that FLWs are ideally placed to screen, counsel, refer, and support women in their communities who experience violence. An unscaled programme will need to integrate elements of the Do Kadam programme-screening mechanisms, basic counselling, referral linkages-into the FLW capacity-building programmes as well as into their job descriptions and performance monitoring activities. 


\section{Chapter 4 \\ Feasibility and acceptability of the Do Kadam project activities: Women's perspectives}

This chapter focuses on the interactions of pregnant women and women with a child in the ages 0-5 years with ASHAs and AWWs and their experiences of the Do Kadam project. It draws on data from the survey of these women as well as on data from in-depth interviews with selected survey respondents conducted about three months following the initiation of the project and at its conclusion. Findings focus on the responses of 1,081 women, who were interviewed during both the baseline and the endline survey, and of the 10 survey respondents who were also interviewed in-depth at two points in time.

All survey participants were asked about their exposure to FLWs, namely, ASHAs, AWWs, and ANMs, in the preceding six months, whether FLWs had sought information from them about their experience of marital violence and had counselled or referred them elsewhere for help; we also inquired whether the FLW had provided them with a brochure from the Do Kadam project that informed them on actions a woman can take and facilities she may approach if experiencing marital violence. They were asked whether they had disclosed their experience of violence to the FLW and about the action taken or counselling provided by the FLW. Finally, we probed whether they had attended the nukkad nataks held by the project and their awareness of messages delivered in these events.

\section{Contact with ASHAs and/or AWWs}

This section describes women's contact with FLWs and their experience of violence, as recalled by them at the time of both the baseline and the endline survey. Findings presented in Table 4.1 show that almost all women were acquainted with the ASHA or AWW of their village (98\% at baseline; $99 \%$ at endline), with about as many women reporting acquaintance with each of these FLWs. Fewer reported acquaintance with the ANM who served their village-84 percent at baseline and 77 percent at endline.

Contact with an ASHA or AWW increased somewhat over the course of the intervention. On the whole, 87 percent of women reported that they had some contact with an ASHA (74\%) or AWW (72\%) in the six months preceding

Table 4.1: Acquaintance and interaction with ASHAs, AWWs, and ANMs

Percentage of women reporting acquaintance and interaction in preceding six months with ASHA, AWW or ANM, baseline and endline surveys, 2015 and 2016

\begin{tabular}{lcc}
\hline $\begin{array}{l}\text { Acquaintance and interaction with ASHAs, AWWs, } \\
\text { and ANMs }\end{array}$ & Baseline $^{\text {a }}$ & \\
\hline Acquainted with ASHA, AWW, and ANM & & Endline $^{*}$ \\
Knows the ASHA of the village & 92.7 & $96.5^{* * *}$ \\
Knows the AWW of the village & 92.1 & $96.5^{* * *}$ \\
Knows ASHA or AWW & 97.7 & $98.6^{\sim}$ \\
Knows ANM & 83.8 & $77.1^{* * *}$ \\
Interacted with ASHA, AWW, or ANM one or more times in the six & & $80.7^{* * *}$ \\
months prior to the interview & 74.0 & $85.5^{* * *}$ \\
ASHA & 72.4 & $93.2^{* * *}$ \\
AWW & 86.5 & $38.9^{* * *}$ \\
AWW or ASHA & 49.0 & $\mathbf{1 0 8 1}$ \\
ANM & $\mathbf{1 0 8 1}$ & \\
Number & & \\
\hline
\end{tabular}

Notes: ${ }^{a}$ Includes only 1,081 women who also responded to the endline survey; $\sim$ and ${ }^{* *}$ indicate that the difference between baseline and endline values is significant at $p<=0.10$ and $p<=0.001$, respectively. 
the baseline interview, compared with 93 percent reporting such contact at endline (81\% and $86 \%$ with an ASHA and an AWW, respectively). In contrast, fewer women reported contact with the ANM at endline than at baseline (39\% versus 49\%), perhaps because those pregnant or post-partum women at the time of the baseline survey had transitioned out of this situation by the time of the endline survey. Almost all women reported that the ASHA, AWW, or ANM had met them to discuss such issues as maternal, newborn, and child health, nutrition, and family planning (not shown in table).

\section{Interaction with ASHAs and AWWs about marital violence}

We posed a range of questions to women, aside from the direct questions on whether they had been screened for violence, to assess whether ASHAs and AWWs had indeed discussed violence-related matters with the women. The direct question was framed as follows: In the last six months did the ASHA/AWW ask you questions about whether you had experienced violence? Other questions probed whether the ASHA or AWW had discussed women's rights, services for women who experience violence, and safety issues with them, or had provided them a brochure that contained information about violence and how to access services. In addition, a question was posed on whether the ASHA or AWW had interacted with them in the six months prior to the interview; those who reported such interaction were asked to list the topics that were discussed during such interactions. Finally, we asked whether an ASHA or AWW had talked to the woman's husband or family members. From responses to all of these questions, we constructed a summary measure that indicates the percentage of women who reported any violence-related incidents to an ASHA or AWW.

Findings, presented in Table 4.2, show that interaction with ASHAs and AWWs about violence-related matters did indeed increase impressively between baseline and endline, yet remained far from universal by endline. Indeed, just three percent of women reported at baseline that an ASHA or AWW had discussed any aspect of violence with her in the previous six months; this percentage increased to almost half (48\%) by endline.

In all, just two in five women acknowledged that the ASHA or AWW had screened them for violence (39\% by AWW or ASHA; $25 \%$ by AWWs and $27 \%$ by ASHAs). A similar proportion (40\%) reported that an ASHA or AWW had discussed husband-wife relations and/or violence-related matters with them in the course of regular family planning or maternal and child healthcare-related visits. Almost as many (37\%) reported that they had been given a brochure. In addition, 33 percent reported that an ASHA or AWW had conveyed information to them about women's rights, services for women facing violence, and safety matters. Hardly any women reported that the ASHA or AWW had engaged their husband or family members in a discussion about the perpetration of violence on women.

Findings in Table 4.3 suggest that ASHAs and AWWs were about as likely to have engaged younger and older women, those pregnant at baseline and those who were not, and those who had reported the experience of any form of violence at baseline and those who had not reported such experience. However, it appears that violence-related screening and interaction varied considerably by caste, educational attainment levels, and wage work. Indeed, it appears that ASHAs and AWWs were most likely to have concentrated on those from scheduled castes, among whom 47 percent reported that they had been screened and 60 percent had reported any interaction with the ASHA or AWW on violence-related matters; in contrast, considerably fewer women from other backward castes (30\% reporting screening and 36\% reporting any interaction on violence-related matters) and general castes (22\% reporting screening and 30\% reporting any interaction on violence-related matters) had reported any interaction. With regard to educational attainment as well, the focus was on women with no formal education: half of these women had been screened (50\%), and three in five had reported any interaction on violence-related topics with the ASHA or AWW (61\%); corresponding percentages for those with 12 or more years of education fell to 23 and 29 percent. Finally, women working for wages in the 12 months preceding the interview were more likely to report screening (51\%) and any interaction on violence-related matters $(62 \%)$ with the ASHA or AWW than were those who had not worked for wages in the 12 months preceding the baseline interview (31\% and 39\%, respectively).

In in-depth interviews with 10 women who had reported in the baseline interview moderate or severe forms of marital violence, women elaborated on their interactions with their ASHA or AWW. While all 10 women reported some contact with the ASHA or AWW about the time of the midline and/or endline interviews, narratives of several women suggested that violence-related topics were not discussed or were cursorily discussed. Narratives from both midline and endline interviews suggest that ASHAs and AWWs may not have had extensive contact with women and were likely to have lacked the skills or were uncomfortable in conveying messages about violence to those they reached, as suggested by the responses that follow. 
Table 4.2: Interaction on violence-related matters with ASHAs and AWWs

Percentage of women reporting violence-related discussion and screening, and receipt of a violence-related brochure in the six months preceding the interview, endline survey, 2016

\begin{tabular}{|c|c|c|}
\hline Violence-related services provided by ASHA or AWW & Baseline & Endline \\
\hline \multicolumn{3}{|l|}{ Screening for violence } \\
\hline ASHA & 0.0 & $27.2^{* * *}$ \\
\hline AWW & 0.0 & $25.3^{* * *}$ \\
\hline ASHA or AWW & 0.0 & $38.7^{* * *}$ \\
\hline \multicolumn{3}{|l|}{ Brochure/materials on violence provided } \\
\hline ASHA or AWW provided brochure to respondent & 0.0 & $36.6^{* *}$ \\
\hline \multicolumn{3}{|l|}{$\begin{array}{l}\text { Discussion of husband-wife relations and violence in the course } \\
\text { of routine visits }\end{array}$} \\
\hline ASHA & 0.0 & $28.6^{* *}$ \\
\hline AWW & 0.1 & $26.3^{* * *}$ \\
\hline ASHA or AWW & 0.1 & $40.1^{* * *}$ \\
\hline \multicolumn{3}{|l|}{$\begin{array}{l}\text { ASHA or AWW discussed violence-related topics to women (rights, } \\
\text { services, safety) and their husbands/family members }\end{array}$} \\
\hline Discussed rights of women and girls & 1.6 & $32.8^{* * *}$ \\
\hline ASHA & 0.8 & $13.6^{* *}$ \\
\hline AWW & 0.7 & $12.8^{* * *}$ \\
\hline ASHA or AWW & 1.2 & $20.1^{* * *}$ \\
\hline \multicolumn{3}{|l|}{ Discussed support services for women facing violence } \\
\hline ASHA & 0.6 & $19.2^{* * *}$ \\
\hline AWW & 0.3 & $18.2^{* * *}$ \\
\hline ASHA or AWW & 0.7 & $29.1^{* * *}$ \\
\hline \multicolumn{3}{|l|}{ Discussed safety issues } \\
\hline ASHA & 0.4 & $3.6^{* * *}$ \\
\hline AWW & 0.3 & $4.3^{* * *}$ \\
\hline ASHA or AWW & 0.4 & $5.6^{* * *}$ \\
\hline ASHA or AWW discussed violence with husband or family member & 0.0 & 0.8 \\
\hline Any contact with ASHA or AWW on violence & 2.8 & $47.8^{* * *}$ \\
\hline Total number of women & 1081 & 1081 \\
\hline
\end{tabular}

Note: ${ }^{* \star *}$ indicates that the difference between baseline and endline values is significant at $p<=0.001$.

I (interviewer): Have you ever been asked whether physical violence has been ever used against you by ASHA sister or anganwadi sister or ANM sister?

$\mathrm{R}$ (respondent): No, I was never asked by anybody. [ID2, midline]

I: So they must have explained things, I mean what is there and what is not in that card? What all was explained to you?

R: About education, they wanted us to educate our children. And not to fight. [ID2, endline]

I: Has the ASHA sister asked you whether your husband has ever used physical violence?

R: Yes, she had asked. It has been one and half months.

I: Had she asked ever before that?

R: No. [ID10, midline]

I: Has the ANM or ASHA, AWW talked to you?

R: She does not give any information but calls me for the polio day and when the rations are distributed.

I: Did anyone ever talk to you family, or ask why they beat you?

R: No 
Table 4.3: Characteristics of women reporting violence-related interaction with ASHAs or AWWs at endline Percentage of women according to baseline socio-demographic characteristics and violence experienced in the 12 months preceding the baseline survey, by screening status and reported interaction with ASHAs and AWWs about violence, endline, 2016

\begin{tabular}{|c|c|c|}
\hline Socio-demographic characteristics & Screened & Any contact $\mathrm{a}^{\mathrm{a}}$ \\
\hline \multicolumn{3}{|l|}{ Screening for violence } \\
\hline ASHA & 0.0 & $27.2^{* * *}$ \\
\hline AWW & 0.0 & $25.3^{* * *}$ \\
\hline ASHA or AWW & 0.0 & $38.7^{* * *}$ \\
\hline \multicolumn{3}{|l|}{ Brochure/materials on violence provided } \\
\hline ASHA or AWW provided brochure to respondent & 0.0 & $36.6^{* * *}$ \\
\hline \multicolumn{3}{|l|}{$\begin{array}{l}\text { Discussion of husband-wife relations and violence in the course } \\
\text { of routine visits }\end{array}$} \\
\hline ASHA & 0.0 & $28.6^{* * *}$ \\
\hline AWW & 0.1 & $26.3^{* * *}$ \\
\hline ASHA or AWW & 0.1 & $40.1^{* * *}$ \\
\hline \multicolumn{3}{|l|}{$\begin{array}{l}\text { ASHA or AWW discussed violence-related topics to women (rights, } \\
\text { services, safety) and their husbands/family members }\end{array}$} \\
\hline Discussed rights of women and girls & 1.6 & $32.8^{* * *}$ \\
\hline ASHA & 0.8 & $13.6^{* * *}$ \\
\hline AWW & 0.7 & $12.8^{* * *}$ \\
\hline ASHA or AWW & 1.2 & $20.1^{* * *}$ \\
\hline \multicolumn{3}{|l|}{ Discussed support services for women facing violence } \\
\hline ASHA & 0.6 & $19.2^{* * *}$ \\
\hline AWW & 0.3 & $18.2^{* * *}$ \\
\hline ASHA or AWW & 0.7 & $29.1^{* * *}$ \\
\hline \multicolumn{3}{|l|}{ Discussed safety issues } \\
\hline ASHA & 0.4 & $3.6^{* * *}$ \\
\hline AWW & 0.3 & $4.3^{* * *}$ \\
\hline ASHA or AWW & 0.4 & $5.6^{* * *}$ \\
\hline ASHA or AWW discussed violence with husband or family member & 0.0 & 0.8 \\
\hline Any contact with ASHA or AWW on violence & 2.8 & $47.8^{* * *}$ \\
\hline Total number of women & 1081 & 1081 \\
\hline
\end{tabular}

Notes: aScreened, provided brochure, discussed husband-wife relations in regular contact, discussed women's rights, services for women facing violence, safety issues, or discussed violence with other family members; The denominator for each row varied, and therefore, not shown.

I: Did you talk to the ASHA or AWW sister about this?

R: No I don't go to her [ID10, endline]

Eight out of 10 women reported at endline that they had been provided the Do Kadam brochure, and six out of these eight women did not understand the contents of the brochure.

R: Yes, she gave me some information when she came to give me the card.

I: What was shown to you and what picture was on the card? Do you have the card?

R: Yes, I had the card but I think I've thrown the card now.

I: Okay did didi (sister) tried to make you understand anything by pointing at the picture which is on the card? What was told to you about the picture on the card?

R: Yes. About education, they wanted us to educate our children.

I: Anything else that was explained to you?

R: Not to fight. [ID2, endline] 
R: Yes, they gave us a card like this, the ASHA didi... They did not talk to us about anything. They threw these cards at us and left.

I: They did not tell you what the card was for? They didn't tell you anything about it? Has anyone from ANM or anganwadi come here to talk to you?

R: No, they have never come here. They come here to give medication to the children and they leave, and that is all that they do here. They came to see us and they threw the card at us and left. They did not even bother to explain anything to us, they did not tell us anything.

I: So, she did not tell you anything at any time? They did not give you any information? Did they try to make you understand anything on the card? Did they tell you what the card was made for? They did not tell you about the card at all?

R: They did not tell us anything. [ID7, endline]

Just two women suggested that they had been given the brochure and could describe its purpose and contents, as reported below.

I: Were you provided with a card also?

R: Yes. ASHA didi gave it to me.

I: Do you still have that card?

R: I have it. It is kept inside a peti (box). I was told if my husband hits me and I am badly injured or if I am in a lot of pain then there is a number on this card so I should call on that number. If he has physically abused me a lot and there are many problems then I will call on that number. [ID3, endline]

R: Now I am not afraid of him since the day the sister had come and given knowledge (from the brochure). So I keep making him afraid.

I: What did you say?

R: See, should I call on that number which is printed on the card? The sister had come and given me that card. So they will take me with them and then what will you eat? I tell him this.... [ID5, endline]

In short, findings from both the survey and the in-depth interviews with women suggest that the project reached many but not all of the women eligible for violence-related interaction. Indeed, on the whole, fewer than half of all women reported any violence-related interaction with an ASHA or AWW, and just two out of five acknowledged that they had been screened. Survey findings suggest that ASHAs and AWWs were selectively targeting the most vulnerable-the scheduled castes and the poorly educated, for example-with screening and messaging on marital violence. However, in-depth interview insights suggest that, for the most part, information provided by the ASHA and/ or AWW was not conveyed in a way that women understood.

\section{Community messaging about marital violence}

In addition, the project conducted street plays (nukkad nataks) in each village to raise awareness about violence-related matters, such as alcohol abuse, gender discrimination, marital violence, and services available for women facing violence. Findings suggest that just 11 percent of all women attended these street plays, and just eight percent of all women had attended the play and discussed it with their husband or family members (Table 4.4).

All but one woman interviewed in-depth were aware of the street play that had taken place in their village. However, just three women reported that they had attended the street play. Most women who had heard about or attended the street play reported that it had focused on alcohol misuse, with a few noting that it also discussed the links between alcohol misuse and marital violence. The narratives reproduced below indicate that the street play was poorly attended and had less impact than expected.

Table 4.4: Attendance at street plays/nukkad nataks Percentage of women reporting attendance at nukkad nataks and conveying its messages to others in the family in the six months preceding the interview, endline survey, 2016

\begin{tabular}{lr}
\hline Attendance at street plays & Endline \\
\hline Attended nukkad natak & 11.2 \\
Attended nukkad natak and discussed contents with husband or family members & 8.4 \\
Total number of women & $\mathbf{1 0 8 1}$ \\
\hline
\end{tabular}


I: Have you attended any street play in the past 6-7 months?

R: Yes I had heard that there was a play but we didn't go. I heard it was about men who drink and that they shouldn't. I don't know anything more. I don't remember. [ID1, endline]

I: Did you see the street play?

R: Yes. There was a song that was sung in the street play. The message was that one should not drink alcohol and abuse their women. [ID4, endline]

\section{Disclosure of violence at the time of screening}

As shown in Table 4.2, at baseline, just three percent of women in our sample had any interaction on violencerelated matters with an ASHA or AWW and not a single woman had been screened about her experience of violence. All women who reported at endline that they had been screened for violence were probed about whether they had disclosed their experience to the ASHA or AWW. Others who reported that the ASHA or AWW had discussed violencerelated matters with them or had provided them a brochure were not probed about disclosure. Hence, in Table 4.5, we present the extent of disclosure among those who had been screened, and explore the extent to which disclosure varied by selected characteristics.

On the whole, findings suggest that women were reluctant to disclose their experiences of violence to the ASHA or AWW. Just 15 percent of all women who had been screened disclosed the experience of marital violence to the ASHA or AWW in the 12 months preceding the interview (Table 4.5); in contrast, as seen earlier, 89 percent of all women interviewed in the baseline survey had reported the experience of any violence and 67 percent had reported the experience of physical and sexual violence (Table 2.5). Findings also suggest that many women who were screened were not accorded confidentiality during the screening process, and many had concealed their experience of marital violence from the ASHA or AWW; in all, fewer than two in three women were screened in privacy without other family members present (64\%; not shown in the table).

Differences by socio-demographic characteristics were by and large moderate. Even so, pregnant women were somewhat less likely to disclose their experience than other women (11\% versus $16 \%)$. As far as caste-specific differences are concerned, although more women belonging to scheduled castes than other backward castes had been screened, somewhat more of women from other backward castes had disclosed their experience of violence (18\% of OBC women versus $14 \%$ of SC women). Similarly, women who had engaged in wage work in the 12 months preceding the baseline survey were somewhat more likely than their counterparts who had not engaged in wage work to disclose their experiences (18\% versus $13 \%$ ).

Differences by age and education were wider. Findings suggest a positive association between age and disclosure, with percentages on disclosure being considerably higher among 30-39 year olds than among those in ages 18-19 ( $19 \%$ versus $12 \%)$. Likewise, findings suggest that better educated women, notably those who had a high school education or more, were considerably less likely to disclose their experience to the ASHA or AWW than were those who were less educated (4\% versus $16 \%-19 \%$ ).

Those who reported experiences of physical or sexual violence in the course of the baseline survey were more likely than those who had not to have disclosed their experience to the ASHA or AWW (20\% versus 6\%).

Evidence suggests that, in general, women are reluctant to disclose violence unless it is frequent or severe. Our findings (Table 4.5) lend support to this hypothesis. Thus, women who reported that they had experienced violence more than once a month in the 12 months preceding the baseline interview were far more likely to have disclosed their experience of violence to the ASHA or AWW than were women whose experience of violence was less frequent (22\% versus $6 \%)$.

Likewise, women who had experienced one or more injuries experienced in the 12 months preceding the baseline interview as a result of the violence perpetrated by their husband were far more likely to disclose their experience of violence than were those who had not experienced an injury. On the whole, while 13 percent of women who had not experienced any injury disclosed their experience of violence to the ASHA or AWW, this percentage increased to 25 percent among those who had experienced an injury.

Women's reluctance to disclose their experience of marital violence may well have been associated with the confidentiality accorded to them during screening. In general, among those screened, marital violence was disclosed by more women who had been screened in private than others (18\% versus $10 \%)$. 
Table 4.5: Disclosure of violence experience at screening to ASHA or AWW by selected characteristics Percentage of screened women who disclosed their marital violence experience to the ASHA or AWW, by selected characteristics, endline survey, 2016

\begin{tabular}{|c|c|}
\hline Characteristics & Percentage \\
\hline \multicolumn{2}{|l|}{ Disclosure } \\
\hline All women screened & 15.3 \\
\hline Age group & $\sim$ \\
\hline $18-19$ & 11.5 \\
\hline $20-24$ & 16.7 \\
\hline $25-29$ & 13.0 \\
\hline $30-39$ & 19.0 \\
\hline \multicolumn{2}{|l|}{ Caste } \\
\hline Scheduled caste & 14.1 \\
\hline Other backward caste & 18.0 \\
\hline General castes & $(0.0)$ \\
\hline Educational attainment & * \\
\hline None & 15.9 \\
\hline $1-9$ & 19.0 \\
\hline 10 or more & 4.0 \\
\hline \multicolumn{2}{|l|}{ Economic activity in the last 12 months } \\
\hline Did not work for wages & 12.6 \\
\hline Worked for wages & 17.9 \\
\hline \multicolumn{2}{|l|}{ Pregnancy status } \\
\hline Pregnant & 11.3 \\
\hline Not pregnant & 16.1 \\
\hline Disclosure of violence in the 12 months preceding the baseline survey & * \\
\hline Reported any violence & 16.4 \\
\hline Did not report any violence & 4.9 \\
\hline Disclosure of physical or sexual violence in the 12 months preceding the baseline survey & $* * *$ \\
\hline Reported any violence & 19.5 \\
\hline Did not report any violence & 5.6 \\
\hline Frequency of violence (perpetrated by husband at baseline) ${ }^{a}$ & *** \\
\hline Rarely or sometimes & 6.1 \\
\hline Often (more than once a month) & 22.3 \\
\hline Injury experienced from violence perpetrated by husband of family members at baseline ${ }^{b}$ & $* * *$ \\
\hline No & 12.7 \\
\hline Yes & 25.3 \\
\hline Privacy during screening & * \\
\hline No privacy & 9.9 \\
\hline Privacy & 18.4 \\
\hline Total number of women screened for violence & 418 \\
\hline
\end{tabular}

Notes: ${ }^{a} F r e q u e n c y$ was asked only for emotional and physical violence perpetrated by husband; note that all women experiencing physical or sexual violence perpetrated by a family member had also experienced physical or sexual violence perpetrated by the husband; 10 women who had experienced emotional violence perpetrated by a family member had not experienced violence perpetrated by their husband; any sexual violence reported in the preceding 12 months is considered to be frequent; $b$ Includes: cuts/ punctures/bites, scratches/abrasions/bruises; sprains/dislocations; burns; deep cuts/gashes; broken eardrum/eye injury; vaginal bleeding/discharge; $\sim^{*}$ and ${ }^{* \star *}$ indicate that distribution for women who disclosed their violence experience was significantly different from the distribution for those who had not at $p<=0.10, p<=0.05$, and $p<=0.001$, respectively. 


\section{Disclosure of violence experience to ASHA and AWW versus to survey interviewers}

Findings presented in Table 4.6 enable us to better understand the extent to which women were differentially inclined to disclose their experiences of violence to an ASHA or AWW, on the one hand, and to survey interviewers on the other. Findings suggest that of the 418 women screened for violence (as reported at endline), 15 percent (62 women) reported at baseline the experience of emotional, physical, or sexual violence to the survey interviewer as well as to the ASHA or AWW. In contrast, only two women (0.5\%) disclosed their experience to the ASHA or AWW but not to the survey interviewer, and 76 percent (317 women) reported their experience only to the survey interviewer.

Table 4.6: Reporting of violence experience to survey interviewer and to the ASHA or AWW Percentage of all women screened by their reports (at baseline) of experience of violence perpetrated by their husband or other family members in the 12 months preceding the baseline interview to the survey interviewer and to the ASHA or AWW, endline, 2016

\begin{tabular}{|c|c|c|}
\hline Experience of emotional, physical, and/or sexual violence & $\begin{array}{l}\text { All women } \\
\text { screened }\end{array}$ & $\begin{array}{l}\text { Number } \\
(\mathrm{N}=418)\end{array}$ \\
\hline Disclosed in baseline survey and to ASHA or AWW & 14.8 & 62 \\
\hline Disclosed to ASHA or AWW but not in baseline survey & 0.5 & 2 \\
\hline Disclosed in baseline survey but denied to ASHA or AWW & 75.8 & 317 \\
\hline No experience of violence reported in survey and to ASHA or AWW & 8.9 & 37 \\
\hline
\end{tabular}

A number of hypotheses may be advanced to explain the difference in reporting to FLWs and survey interviewers. For one, it is likely that women were more comfortable revealing violence to an empathetic outsider than they were to workers from within their village for fear that FLWs may adopt judgemental attitudes or violate their need for confidentiality. Second, it is possible that ASHAs and AWWs were themselves uncomfortable about discussing violence with women and may not have spent as much times as survey interviewers did in building rapport, assuring confidentiality, and posing questions in a non-threatening manner. Finally, differences in reporting may be attributed to the nature of questions posed. While screening questions, of necessity, were short, survey questions were lengthy and probed about various aspects of violence individually: for example, while the screening question simply asked whether the woman had been 'hit, slapped, kicked or otherwise physically hurt,' survey questions asked individually about each of these experiences. It is possible therefore that presenting this whole battery of questions was more effective in enabling recall of experiences and that women who had experienced violence were more likely to report so in responses to the single screening question if the violence was frequent or had resulted in injury.

\section{Insights about disclosure from in-depth interviews}

Insights from in-depth interviews at midline confirm that some seven out of 10 women disclosed their experience of violence to the ASHA or AWW. By endline, narratives generally suggest that the ASHA or AWW was aware of the fact that the woman had experienced violence, although only a few narratives explicitly addressed disclosure, as indicated in the narratives given below.

I: Okay didi, has any of the three, ASHA, anganwadi or ANM, come to you and asked you if you have been hit?

R: G. didi (AWW). Yes. She is the one who came. I told G. madam that he abuses me, that he hits me and said that my brother must give him money.... I told her. That there is hitting and fights that keep happening.

I: How long ago did she come to ask?

$\mathrm{R}$ : I think it was before the voting. [ID5, midline]

I: Has the anganwadi didi or ASHA didi ever asked you about your experiences with physical violence?

R: Yes, both of them asked me about it. They asked me whether my husband hits me or not and does he force me to sleep with him. Then I told them.... They come here three times in a month. It has been about 20 days.

I: Did the anganwadi didi ask you about all these things earlier, prior to the last three months?

R: No, earlier she would only give me an injection and come for polio drops. [ID3, midline]

In a few cases, as in the following narrative, women were reluctant to disclose their experience of marital violence to the ASHA or AWW in the midline interview, but became more comfortable doing so by endline. 
I: Okay, this P. didi (AWW), has she ever tried to ask you whether your husband abuses you or not?

R: Yes. P. didi asked me in the past one and a half months about the violence I was facing.

I: So then what did you tell her?

R: Nothing. Nor did I go to P. didi and tell her that my husband hits me

I: Did you discuss this with ASHA didi? Or ANM didi?

R: No. [ID1, midline]

I: Did you speak to the ASHA or anganwadi didi or ANM workers about yourself?

R: No didi, I didn't say anything on my own; this, would come by herself; sometimes to give the children medicine, so I would tell her when she would ask me. And then she spoke to my husband and explained to him, she made me also understand. So there has been a difference. Now, when I go for injections to the anganwadi, she asks me, 'Do you have fights with your husband?' So I would say, 'Yes didi, he comes drunk so then it happens'. [ID1, endline]

\section{Perceptions about the quality of interaction with ASHAs and AWWs}

In order to assess women's perceptions about the quality of interaction with ASHAs and AWWs with regard to marital violence, we asked women who had disclosed at screening their experience to the ASHA or AWW about the response of the ASHA or AWW. Just three-fourths of women who had disclosed their experience to ASHA/AWW reported that the FLW had counselled them or had provided them information on what to do. Findings, moreover, suggest that the quality of counselling was not uniform. One-third of women who disclosed their experience of violence reported that the ASHA or AWW had simply empathised with their story or provided general information, and 12 percent mentioned that the FLW had suggested that they tolerate the violence or make efforts to reconcile with her husband. Onequarter (26\%) was advised to file a case with the police or the helpline or was provided information on how to access these services. Finally, 16 percent reported that the ASHA or AWW had encouraged them to seek support from family and neighbours, and nine percent helped women draw up a safety plan.

In in-depth interviews, women elaborated on the content of the counselling or actions taken or recommended by the ASHA or AWW (three at midline, seven at endline). Typically, ASHAs and AWWs counselled women in general terms, for example, they were advised not to fight with their husband or to keep good relations with their husband. Some women reported that the ASHA or AWW or project staff had spoken to their husband or mother-in-law (two at midline, six at endline). In one case, the ASHA or AWW had explained to the woman her rights and had advised her to seek out the ASHA or AWW if she fears or is experiencing violence. The content of interaction between FLWs and women can be ascertained from the responses of the women given below.

Table 4.7: Perceptions about quality of interaction with ASHA or AWW on marital violence Percentage of women who disclosed their experience of marital violence and who reported that the ASHA or AWW had counselled them and paid them repeated visits, and the content of counselling provided, endline survey, 2016

\begin{tabular}{lr}
\hline Quality of interaction & All women \\
\hline Counselled or provided information about what to do & 34.4 \\
ASHA & 48.4 \\
AWW & 76.6 \\
ASHA or AWW & 33.0 \\
Content of counselling to women & 12.2 \\
Empathised, generally counselled & 15.6 \\
Advised woman to tolerate it or reconcile with her husband & 9.4 \\
Encouraged women to seek support from family or neighbours & 26.6 \\
Advised woman to make a safety plan & $\mathbf{6 4}$ \\
Advised woman to go to, or informed them about going to the police, helpline ${ }^{\text {a }}$ & \\
Respondents who disclosed violence to ASHA/AWw & \\
\hline
\end{tabular}

Note: ${ }^{2}$ No women reported that they were counselled to seek help from a doctor/health facility, a short stay home, or an NGO. 
I: So has she (anganwadi didi) ever helped you?

R: Yes, she helps me. At times she has tried to make him understand and she also gives food to my children. About two months ago, she explained to my husband and asked him why he hits me. Then about eight days ago, my mother-in-law had hit me so she explained to both my husband and my mother-in-law. She asked them not to hit me ever again. She has instructed me that now when he hits me I should not go running to my mother's house, rather I should go to her. Now when he hits me I go to her and take my children along; she gives us food and takes care of us very well. [ID4, midline]

I: So at that time did ASHA didi come to you and make him understand?

R: Yes, she came twice, she told me what I should do, and tried to make my husband understand that he should not misbehave. [ID4, endline]

R: G. didi came. She asked whether there are still fights and hitting? I told her that hitting and fights keep happening. I said that the didis who came told me to phone them and then they would catch him. But nothing has happened. [ID5, midline]

R: ASHA sister came, she asked about beating. She asked why do you fight so I told her that he comes drunk and abuses and beats me. I also used to abuse sometimes.

I: So she offered help or advice?

R:Yes. She made him understand that you are being very unfair to your wife. Now no more injustice will be done. So he asked, 'What will you do sister?' and she said that he would be arrested. So he said, 'I do not beat her. I only beat her when she makes a mistake'. [ID5, endline]

R: No, anganwadi didi made me understand that if he abuses me again then I should not run back to my parent's house. [ID3, midline]

I: Did anganwadi didi ask you whether or not your husband has abused you or consumed alcohol?

R: Yes, she asked and made me understand also. She told me that I can get help from the helpline or go to the panchayat and meet the headman if he beats me. [ID3, endline]

I: What did she tell you?

R: ...that we should not consume alcohol, we should educate our children. Two sisters came and told us this. The anganwadi sister also came.

I: So did she talk to your family that one should not use violence. There should not be any physical violence did they talk to your husband about this?

R: They did not talk to my husband; there was some man who came with them and he talked to my husband. They said that everyone should live together. The AWW sister told me that I can go to women helpline or you can take help from the police? [ID8, endline]

Reiterating survey findings, textual data suggest that, in some instances, screening and/or probing about marital violence experiences were conducted in a group. This denied women the privacy to respond to such sensitive questions, as evident from the narratives below.

I: Okay. Did the ASHA sister ever ask you about physical violence or beating on you?

$\mathrm{R}$ : No she has never come to ask.

I: Have you ever been asked about physical violence or beating by the anganwadi sister?

R: No sister, I was never asked about this by the sister of the anganwadi.

I: Did the ASHA sister or anganwadi sister ever help you?

R: No, I did not say anything to anyone so how will they help? I have not got any help from anyone.

I: Now I am asking you once again about whether you have ever been asked about physical violence or beating by the ASHA sister or anganwadi sister in the last two months?

R:Yes, the anganwadi sister once asked me just like that (casually) 'Had you told the person who had come for the survey about physical violence or beating?' She was asking this to everyone. She was not writing down anything. She just asked like this and went away.

I: Did she ask you all this at your home?

R: No, she was walking in the street and we were sitting there, so the anganwadi sister asked everyone whether we had reported about physical violence and beating to the person who had come for the survey.

I: So when was this?

$\mathrm{R}$ : It has been three months.

I: Had she ever asked before three months ago?

R: No, she had never asked. [ID7, midline] 
I: So, when would the anganwadi worker come to visit you and how often would she come?

R: She calls us over, we go to her house and that is when she tells us about all of this. She does not come to our homes to tell us; we go there and she tells us a few things.... Nor does the ANM or ASHA didi ever come here. [ID6, endline]

\section{Help-seeking}

One of the messages the project aimed to convey was the importance of breaking the silence about the violence experienced. In order to assess the extent to which this was accomplished, we asked women who reported the experience of physical and/or sexual violence in the six months preceding the interview about their help-seeking behaviours. We assessed the extent to which they sought help from informal sources, namely, family, friends, and neighbours, as well as help-seeking from formal sources, namely, a doctor or healthcare facility, the police, the helpline, a short stay home, a community group, or an NGO.

Table 4.8 presents the percentage of women who had experienced physical and/ or sexual violence in the six months prior to the baseline and endline interviews and who reported that they had shared their experience of violence with friends and family and had sought the services of a healthcare provider, a lawyer, or the police. In particular, the table explores help-seeking according to whether these women had interactions with ASHAs/AWWs on violencerelated matters and whether they had disclosed their experience of violence to the ASHA or AWW. Findings confirm that help-seeking was far from universal, and many women suffered their experience in silence, neither sharing it with family and friends nor seeking available services.

Findings show that a larger proportion of women had shared their experiences with friends and family or had sought services from formal sources at endline (among those reporting physical and sexual violence with no interaction with FLWs on this matter as well as those reporting such experiences but having had interaction with FLWs) than at baseline (34\%-41\% versus $20 \%)$. They also indicate that access to formal sources of support was more limited than access to informal sources. Both at baseline and at endline, fewer women had sought services from formal sources ( $7 \%$ at baseline and $10 \%-15 \%$ at endline) than they had sought support from informal sources by way of sharing their experiences ( $18 \%$ at baseline and $32 \%-37 \%$ at endline for informal sources). Indeed, not a single woman from any group had sought the services of a helpline, a short stay home, a community group, or an NGO. Those who had sought services from formal sources of support had typically visited a doctor, perhaps to seek healthcare for an injury that they might have experienced as a result of violence rather than to prevent further violence.

Findings also show that those who had interacted with an ASHA or AWW about violence-related topics were more likely than others to have shared their experiences informally as well as to have sought services from formal sources ( $34 \%$ of those who had reported no interaction compared with $41 \%$ of those who had reported such interaction). Of those who had disclosed their experiences to ASHAs/AWWs, as many as 59 percent had sought help from a formal or informal source.

In-depth interviews reiterate that few women actively sought help or shared their experience with a family member, neighbour or friend, largely because they feared for their own reputation or believed that it may exacerbate the violence. Even so, given the small homes and the close quarters in which homes are situated, they reported that a family member or neighbour who would hear or see the violence would try to stop it or explain to their husband (six out of 10 at midline, three out of five who discussed the issue at endline). Most women who discussed the issue reported that while their family, neighbours, and/or friends had 'explained' to their husband (and may have stopped a particular incident of violence), their efforts were not helpful in the longer term, as can be seen from their responses given below.

I: So have you ever asked your family (parents, etc.) for help because he hits?

R: No what will I tell them? Even when I go to his parents after he has beaten me, I tell them that he doesn't hit me and that I have just come like that. I have to go back to the same house so how can I complain. I don't say anything because I don't want to be insulted everywhere. I just kept it within me. Then he came to call me so I came back.

I: Okay didi, have you ever asked for help from your friends?

R: What help will I ask for? We both suffer from the same sorrow. She tells me what I tell her so what help will she give me .... I didn't tell anyone, but everyone in the house and nearby asks why are you fighting and why is he hitting you. Others and important people of the village all see it. They all live in the village. I haven't told anyone from here that he abuses me. But all say it is the fault of the wife.... They told us not 
Table 4.8: Help-seeking practices of women who experienced physical and/or sexual violence, by interaction on violence-related topics with ASHAs/AWWs and disclosure status

Percentage of women reporting experiences of physical and/or sexual violence in the six months prior to the baseline and endline interviews and had sought help from family, friends, or from service providers, 2015 and 2016, baseline and endline survey

\begin{tabular}{|c|c|c|c|c|}
\hline \multirow{2}{*}{$\begin{array}{l}\text { Informal sources of sharing and } \\
\text { formal sources of help }\end{array}$} & \multicolumn{2}{|l|}{ Baseline } & \multicolumn{2}{|l|}{ Endline } \\
\hline & $\begin{array}{c}\text { Women who } \\
\text { reported physical } \\
\text { or sexual } \\
\text { violence in the } 6 \\
\text { months prior to } \\
\text { the interview }\end{array}$ & $\begin{array}{l}\text { Women who } \\
\text { reported physical } \\
\text { or sexual } \\
\text { violence in the } \\
6 \text { months prior } \\
\text { to interview, } \\
\text { but had no } \\
\text { violence-related } \\
\text { interactions with } \\
\text { ASHA/AWW }\end{array}$ & $\begin{array}{l}\text { Women who } \\
\text { reported } \\
\text { physical or } \\
\text { sexual violence } \\
\text { experience in the } \\
6 \text { months prior } \\
\text { to the interview } \\
\text { and had } \\
\text { violence-related } \\
\text { interactions with } \\
\text { ASHA/AWW }\end{array}$ & $\begin{array}{l}\text { Women who } \\
\text { disclosed their } \\
\text { experience to } \\
\text { ASHA/AWW }\end{array}$ \\
\hline Informal sources of sharing & 18.0 & $31.6^{* * *}$ & $36.9^{* * *}$ & $50.0^{* * *}$ \\
\hline \multicolumn{5}{|l|}{ Friends and neighbours } \\
\hline \multirow{2}{*}{$\begin{array}{l}\text { Natal family (parents, siblings, aunt/ } \\
\text { uncle) }\end{array}$} & 8.7 & $15.6^{* *}$ & $18.5^{* * *}$ & $31.0^{* * *}$ \\
\hline & 9.5 & $16.4^{* *}$ & $18.5^{\star * *}$ & $23.4^{* * *}$ \\
\hline Husband's family member & 4.5 & 5.8 & $11.3^{\star * \star}$ & $14.1^{* \star *}$ \\
\hline Formal sources of help* & 6.6 & $10.2^{\sim}$ & $14.9^{* * *}$ & $23.4^{* * *}$ \\
\hline Police or lawyer & 0.7 & $2.2^{*}$ & 0.5 & 1.6 \\
\hline Doctor & 6.1 & $9.8^{\sim}$ & $12.8^{* *}$ & $17.2^{* * *}$ \\
\hline ASHA or AWW & 1.1 & 0.0 & $4.6^{* *}$ & $14.1^{* * *}$ \\
\hline Other & 0.0 & 0.0 & 0.0 & 0.0 \\
\hline Formal or informal sources & 19.9 & $34.2^{* * *}$ & 41. $0^{* * *}$ & $59.4^{* * *}$ \\
\hline Number of respondents & 738 & 225 & 195 & 64 \\
\hline
\end{tabular}

Note: $\sim{ }^{*},{ }^{* *}$, and ${ }^{* * *}$ indicate that the difference between baseline and endline values is significant at $p<=0.10, p<=0.05, p<=0.01$, and $p<=0.001$, respectively.

to fight and to live together in harmony. I just tolerated everything and listened to what everyone said that don't fight, let it be, let him say, he is drunk and saying it.

I: Okay didi, so did you ever tell it to the police?

R: No, I never told them.

I: To the lawyer?

R: No.

I: Did you ever ask for help from any organisation?

R: No. Nobody has come that I will tell them. You all have come the first time.

I: So do you tell anyone else, outside your family?

$\mathrm{R}$ : Yes if they come then I tell them. [ID5, midline]

R: I had told his mother that he harasses and abuses me all night so she said, 'I do not know what kind of man I gave birth to', and told me I should go from here (to my parents' home for my safety). He got scared of her, then he told his mother, 'I will not beat her'.

I: Okay so had you told this to anganwadi sister or ever contact the panchayat or the police or the women's helpline?

R: Yes, I contacted the women's helpline. They came and left quickly after making him understand. [ID5, endline] 


\section{Experience of further violence}

We also explored whether disclosure to the ASHA or AWW of violence the women had experienced was indeed associated with a decline in violence perpetrated by their husband or family members. We note that numbers are small and findings are illustrative rather than conclusive, and hence findings are not presented in tables. They suggest that among women who reported the experience of violence at baseline and had disclosed their experience to the ASHA or AWW in the course of the project, 95 percent (out of 62 women) continued to experience emotional, physical, or sexual violence perpetrated by their husband and/or other family members, and 63 percent (out of 57 women) had continued to experience physical and/or sexual violence.

In in-depth interviews, we asked women whether they had experienced physical, sexual, or emotional violence perpetrated by their husband and the context in which it took place. Findings suggest that at midline, nine out of ten women reported the experience of physical violence, nine out of ten reported the experience of sexual violence, and all ten reported the experience of emotional violence. By endline, somewhat fewer reported experiences of violence: five out of ten reported physical violence, four out of nine reported sexual violence, and eight out of ten reported emotional violence. Also, fear of violence was reported by many women at both the in-depth interviews (nine at midline, six at endline). Those who discussed the reasons for the continued experience of violence attributed it to their husband's misuse of alcohol, husband's suspicions of the wife's infidelity, wife's delay in preparing the husband's meal, and, in one case, dowry demands that the woman's family could not fulfil. The narratives that follow are descriptions of marital violence experienced by women and the reasons for the violence.

Yesterday he hit me, and I attempted to jump in the well. I don't know why, but when he hits me I go crazy, when he grabs my hair I go crazy. I just thought about my children and then this stopped me from jumping.... After drinking alcohol, he goes for gambling, and this is the reason I ask him not to drink. He hits me after I ask him not to drink. He does this every two or three or four months. [ID1, midline]

Yes, my husband drinks and then hits me and sometimes with a stick. I don't know didi, why he hits. If I ask for money, so for that he hits. When I ran off to my parents' home, he had hit me with a cane stick. He hits, he drinks, and gambles. Sometimes, when he hits me, then he forces me to have sex. Who can say no to men?... My husband comes home drunk and criticises me, why haven't you done this or that, will your parents do it? And then he abuses me badly. What to do, I have to listen. But since the anganwadi didi explained, there has been some improvement. Otherwise, before he used to say that you are only delivering daughters, will a son come from your father's house? Yes I feel scared. Every woman has to be a little scared of her husband. What if I say something and he translates it into something else and it is misunderstood, that's why one should keep what we think in our mind. There is no use in telling men, they don't listen to what women say. They do whatever they feel like doing. [ID1, endline]

He starts hitting me if I ask him to earn money. A few days ago he hit me. He hit me with a 'khunti' (tool used for ploughing). He hit me on my face with it. There was chicken and he was drinking and having the chicken, so then I asked him if I could eat some chicken. I told him that every time he gets chicken he alone eats it and doesn't let others eat it. It pinched him and he started verbally abusing me. He started saying that why had I interrupted him while eating, he called me a whore and then started hitting me. He verbally abused me, and started hitting me with a bamboo stick. He hit me so much that my left arm was swollen.... Do these men listen to us? Even when women don't want relations, he forces us to do it because we are their wives. For example, if I say that I don't want to have sex then he says that I am his wife and I have married him so I have to listen to him. He says that it will happen whenever he wants it and then he forces himself on me. It is very difficult for women to make her man understand. ...If I don't listen to my husband then he will kill me. I don't leave the house without his permission and I don't do anything without his order. I am scared he will hit me. [ID3, midline]

I: Since the monsoons ended, has he ever hit you or abused you?

R: No.

I: Are you still scared of your husband?

R: He is a man so obviously I am very scared of him. [ID3, endline]

R: If I say anything, the result is that he will start hitting me. He accuses me, saying I went out of the house and took so long returning because I was having an extramarital relationship. He said that he doesn't want to eat food as I have cooked it. He kicked me, then he used a pipe to hit me and then he also used a bamboo stick to hit me. He said that one day he will insert this pipe inside my body. Another time, when I was pregnant with this child of mine, one day he came home and I had not prepared his 
food. So he got very angry and kicked me right in my stomach. He said that I was having relations with someone else and this is the reason I got pregnant. He said that this child is not his.

I: Does he force you to sleep with you whether you are interested or not?

R: We do it whenever he wants it

$\mathrm{I}$ : Does he abuse you verbally?

R: My husband says that I am not a good woman and he calls me a prostitute. He calls me by these dirty names and abuses me verbally.

I: And if you have to talk about yourself then do you tell him openly?

R: No, I am very scared didi so I don't tell him. [ID4, midline]

I: Since the monsoon has your husband physically abused you?

R: Yes.... He physically abuses me often, usually when he is in a drunken state. Because he thinks that I am having an affair with three men.

I: Did he hit you when you were pregnant with the youngest child?

R: Yes he did at that time. Yes he hit a little bit. To have sex, that's why. Then after this child I got operated after which he hit me also. He wanted to have sex, so I said that you only think of me as a body so then he told me to get out, and hit me.

I: Are you scared of your husband?

R: Obviously. When he comes home in a drunken state and starts beating me, I get scared and run away from him. He verbally abuses me when he is drunk, and even throws the food at me. I am scared because he hits me. [ID4, endline]

R: About every two months or so. It is usually because I say rubbish things to him. He comes home and when I serve him dinner, I always forget to serve him water. I have this bad habit of not serving him water while I am giving him his food, so then he says a few things to me. He gets angry once in a while. About food, if I get late to give him food, he gets very angry. Day before yesterday. I got late while cooking food so he abused me.

I: Lot of women have told me that their husband forces them to have sexual relations when they are not willing. Have you ever faced something like this?

$\mathrm{R}$ : Yes, he is very naughty. He forces me every week, he did this two days ago, he forced me even though I didn't feel like it. I asked him to stop and he said to me that he will die. So what could I do? I have to do what he says.

I: Are you scared of your husband?

R: Yes, I am. Because I am scared, I hide things from him. I know how tense I am from inside, I cannot even tell you the amount of tension I have. [ID8, midline]

I: So over the last 7-8 months has your husband beaten you or abused you?

R: Fights happen because of consuming alcohol and because of money problems. He does not talk to me properly, he does not go to work so I have to go out to earn money. If I say something, he tells me to keep quiet. He abuses me when he gets angry. I don't say anything to him. [ID8, endline]

Although several women reported at endline that emotional, physical, and/or sexual violence perpetrated on them had reduced or stopped, just a few attributed this change to the intervention of the ASHA or AWW, as reported below.

I: Like we people are discussing personal matters, are you afraid to tell him about these things?

R: I am afraid to tell my husband about personal matters. But now I am not so afraid of him-since the day the sister had come and given information. Now I keep making him afraid. I say, 'See, should I call on that number which is printed on the card, the sister had come and given me that card. So they will bring me with themselves so what you eat? So they will show me some way'. I tell him this. [ID5, endline]

R: Before my husband used to fight a lot but now he doesn't, ever since the anganwadi didi came and made him understand. Since then my husband fights much less. If the anganwadi madam explains, then people understand. Since she explained to me and my husband, I don't feel scared in telling him anything. I say everything, wrong or right. Since didi explained to him, he hasn't hit me.... He doesn't hit that much, he goes to sleep after he drinks. There has been a lot of change. It has been a month. Let's see now what happens. [ID1, endline] 
Others suggested that the ASHA or AWW had not been helpful, or that she had showed empathy and had counselled them, but that her action had not succeeded in reducing the violence that she experienced.

$\mathrm{R}$ : I told them that I had committed mistake so he slapped me.

I: Did the anganwadi didi try to help you?

R: He had hit me, I mean, he gave me one or two slaps and in this how can she help me? It was my

mistake and it was not an issue at all where I would need any help. [ID9, midline]

I: Did she ever help you?

R: No. How will she help? [ID10, midline]

I: Did they provide any help to you?

R: They do help us a lot... but there has been no change in my husband since the time didi came to make him understand. He will fight with me again during holi. [ID4, endline]

\section{Summary}

Almost all women interviewed at both baseline and endline were acquainted with and had reported some contact with the ASHA and/or anganwadi worker serving their village, typically in relation to maternal, newborn and child health, nutrition, and family planning. Despite the fact that the intervention called for all ASHAs and AWWs to contact and screen an assigned number of women for their experience of violence, just under half of all women (48\%) reported that the ASHA or AWW had screened them, provided them the Do Kadam brochure on services for women experiencing violence, informed them about women's rights, available services, and safety issues relating to violence, and/or counselled their husband or family members. Fewer-39 percent of all women-reported that the ASHA or AWW had screened them for their experience of violence, with screening more likely to have been conducted among women belonging to scheduled castes, poorly educated women, and working women than others. In in-depth interviews at both midline and endline, several women suggested that violence-related topics were not discussed or fleetingly discussed, and a few of those who were given the brochure could not explain its contents, which raised questions about the skill and comfort levels of ASHAs and AWWs in addressing issues relating to violence. The reach of the project was limited, but we note that as compared with the situation at baseline, far more women reported interaction on violence-related topics with an ASHA or AWW at endline than at baseline (48\% versus 3\%).

Also suggestive of the limited rapport between the ASHA or AWW and women on matters related to violence, was that relatively few women who were screened by ASHAs and AWWs disclosed their experience of violence to them. Indeed, of all women screened at endline, as many as 76 percent had reported their experience of violence to the survey interviewer at the time of the baseline survey but not to the ASHA or AWW; in contrast just two women (less than 1\%) had disclosed their experience to the ASHA or AWW but not to the survey interviewer. On the whole, 16 percent of screened women who had acknowledged in the baseline survey that they had experienced emotional, physical, or sexual violence perpetrated by their husband or a family member in the year preceding the interview and 20 percent of those who had reported physical or sexual violence acknowledged their experience of violence to the ASHA or AWW at screening. Disclosure of violence was more likely among older than younger women and among poorly educated than well-educated women; milder differentials were observed by caste, pregnancy status, and economic activity status. Likewise, disclosure was more evident among women who had experienced frequent violence or severe violence than among women who had experienced less intense violence and more evident among women who had been screened in private than those who had been screened in the presence of other family members or in a group. Insights from in-depth interviews suggest that disclosure may be associated with the number of visits made by ASHAs and AWWs to discuss violence-related matters and their skill in drawing out women who might otherwise have resisted revealing their experiences.

The quality of interaction between the ASHA or AWW and the woman was mixed. One-third of all women who had disclosed their experience of violence reported that the ASHA or AWW had simply empathised with them or provided general information, one out of eight had recommended that they tolerate the violence or make efforts to adjust to their husband's demands. Just one-quarter reported that the worker had recommended that she access a service (police, helpline), one out of six was encouraged to seek support from family and friends, and one out of ten was helped to draw up a safety plan. In in-depth interviews, women reiterated the general nature of counselling, although some women did report that they had been counselled to seek out the ASHA or AWW when violence was experienced and had actually sought refuge with the FLW when they had subsequently experienced violence, and others reported that the worker had counselled their husband or family member. 
Informal and formal sources of support were probed in both the survey and in the in-depth interviews. Findings show that even at endline, many women continued to suffer the violence perpetrated against them in silence. A larger proportion of women at endline than baseline had shared their experiences with friends and family or had sought services from formal sources (34\%-41\% versus 20\%). Findings also indicate that access to formal sources of support was more limited than was access to informal sources. Both at baseline and endline, fewer women had sought services from formal sources (7\% at baseline and $10-15 \%$ at endline) than they had sought support from informal sources by way of sharing their experiences (18\% at baseline and $32 \%-37 \%$ at endline). Those who had sought services from formal sources of support had typically visited a doctor, perhaps to seek healthcare for an injury that they might have experienced as a result of violence experience rather than to prevent further violence. Findings also show that those who had had an interaction with ASHAs/AWWs about violence-related topics and those who had disclosed their experiences to ASHAs/AWWs were more likely than others to have shared their experiences informally or sought services from formal sources than had women who had no interactions on violence-related matters with ASHAs/AWWs (34\% of those who had reported no interaction compared with $41 \%$ of those who had reported such interaction and $59 \%$ of those who had disclosed their experiences to ASHAs/AWWs). In-depth interviews reiterated the finding that help-seeking and access to support were limited.

Finally, while numbers are limited and findings are just illustrative, we note that among women who had reported the experience of violence at baseline and had disclosed their experience to the ASHA or AWW in the course of the project, there was no more than weak evidence that violence had abated over the course of the intervention. Indeed, of those reporting the experience of emotional, physical, or sexual violence at baseline, 95 percent continued to report such violence at endline. Evidence of a reduction in violence was more apparent when we considered only those who reported physical and/or sexual violence (irrespective of whether they had also experienced emotional violence): here, 63 percent of women reporting the experience at baseline continued to do so at endline.

In in-depth interviews, women expounded on their experiences. While narratives at midline suggest that almost all the ten women interviewed continued to experience marital violence, somewhat fewer reported at endline that they had experienced emotional, physical, and/or sexual violence. Of those who reported continued experience of violence, most attributed their experience to their husband's misuse of alcohol, husband's suspicions of the wife's infidelity, wife's delays in preparing the husband's meal, and, in one case, dowry demands that the woman's family could not fulfil. Of those who reported a reduction in marital violence, just a few attributed this decline to the intervention of the ASHA or AWW; at least one woman attributed the decline in violence that she faced to her ability to threaten her husband with the options provided to her by the ASHA or AWW and a second to the counselling that the ASHA or AWW had provided her husband. 


\section{Chapter 5 \\ Perspectives of ASHAs, AWWs and ANMs}

This chapter, drawing on in-depth interviews conducted with ASHAs, AWWs, and ANMs at baseline and endline, describes the orientation that they had received about issues related to violence against women prior to and during the course of the Do Kadam project. It presents their experiences in probing marital violence among women, making referrals, and participating in awareness-raising activities, their perceptions about changes in their community following the introduction of the project, and views on up-scaling the project.

\section{Characteristics of ASHAs, AWWs, and ANMs}

Most ASHAs were aged above 35 years (11 out of 16) and had completed secondary education (nine out of 13 for whom data on years of schooling were available). All of them were Hindu and most belonged to other backward castes (13 out of 16). Most of them had been working as an ASHA for 10 or more years (eight out of 16). As among ASHAs, most AWWs were aged above 35 years (14 out of 18) and all of them had completed secondary education or more. All of them were Hindu and most belonged to other backward castes (13 out of 18). Half of them had been working as an AWW for over 15 years. Of the five ANMs, four were aged above 35 years, and all of them had completed secondary education or more. All of them were Hindu and four of them belonged to other backward castes. Three had been working as an ANM for 5-9 years.

\section{Orientation about issues related to violence against women}

In the course of in-depth interviews conducted at baseline, ASHAs/AWWs/ANMs were asked whether they had been oriented about issues related to violence against women in any of the training programmes that they had attended. At endline, they were probed about their participation in capacity-building activities, namely, the three-day workshop and monthly meetings, organised as part of the Do Kadam project.

\section{Orientation prior to the Do Kadam intervention}

Orientation on violence-related matters, as reported in the baseline in-depth interview, was far from universal. Indeed, just four ASHAs (out of 14 whose narratives contained information on this) and one out of five ANMs acknowledged that they had ever been oriented about such issues. Unlike ASHAs and ANMs, many more AWWs (eight out of 15 whose narratives contained information on this topic) reported that they had been oriented about the topic of violence against women.

Narratives from all three groups of FLWs suggested that their orientation had focused on the unacceptability of violence against women. The ANM reported that her training had focused on violence in pregnancy, an issue not mentioned by others. AWWs were more likely than others to report that their orientation had focused on recourse that women in distress could take and the FLWs' role in supporting women and reducing violence. They noted that they had been taught that women should not tolerate violence and that they should raise their voice against it. In the course of their orientation, they were also told that AWWs should form groups of women in their village and fight the perpetration of violence against women, that they should make women understand that they are not weak and, have the same rights as men, and that they should inform the helpline if they witness violence perpetrated against women. The narratives given below from FLWs describe the orientation/training they had received on the prevention of marital violence among women assigned to them.

I was told once during a training workshop that I had attended a long time ago. [ASHA, ID3, baseline]

I was oriented about violence matters a long time ago, it has been 8-10 years. There, a teacher had come; she told us, with the help of pictures, about a man who was about to hit his wife with a stick, but was stopped by 10 women who together saved the wife, and as a result, the husband's stick remained in his hands unused. He wasn't able to hit her because he felt shy to beat his wife in front of 10 women.... This teacher told us that there is a lot of violence committed on women, and this should not be done, this should be stopped. [ASHA, ID13, baseline]

The teacher out there told us everything. We were told that during pregnancy if a woman's husband beats her or does something wrong to her, then it will affect the baby in her stomach, they told us that. Yes, if during pregnancy, a woman is going through mental stress or if there is any kind of tension, it adversely affects the baby, because the baby is connected to the mother. [ANM, ID1, baseline] 
AWW: Yes I was told during training about violence against women. We were told that violence should not be committed on women. Yes, a year ago, there was a training programme and there we were told about this. We were told that violence is committed on women and that it should not happen. We were told to explain to men if we get to see anything like this. We were told to explain to women that we women are not weak and that we are equal to men in the society and can do anything we want to. They told us many other things but I do not remember all that now. [AWW, ID4, baseline]

Yes once a ma'am told us that if we see a woman being beaten, we should call them on the phone so that they will go and check on her and try to make her husband and family members understand. Earlier the CDPO (Child Development Project Officer) ma'am told us the same thing; she told us that if we saw something to tell her about it and she would talk to the family members, and if they didn't listen she would do something else. [AWW, ID12, baseline]

\section{Capacity-building activities organised as part of the Do Kadam project}

Almost all FLWs had attended the Do Kadam training programme (one ANM was unable to do so because of serious illness) and recalled its emphasis on raising awareness about violence among women, introducing the screening form to recognise women at risk, and identifying their role in imparting the intervention and filling the screening form.

\section{Awareness-raising about violence against women}

Most FLWs reported that they been oriented about violence against women; several suggested that exposure to the programme had increased their awareness of various forms of violence, gender issues, and support services available for women in distress (10 out of 16 ASHAs and five out of 18 AWWs whose narratives are given below).

It was all about violence against women and we were completely unaware about these matters earlier. After the training we were able to understand the issue and observe these things in our own homes and outside also. Yes, we were told all this in the training session at Phulwari. Yes, there were several questions; one was on domestic violence, if I am earning money then the other person doesn't have the right to spend that money, and this is domestic violence.... If he throws something on her with the intention of hitting her then that is also domestic violence but I am not able to remember other things.... It has been beneficial because we got information about various issues. You provided us with information about how to improve a woman's future and that helped us a lot.... [ASHA, ID2, endline]

I didn't know that if a husband hits his wife then she can go the the women's helpline and seek help from the village leaders. So I got to know all this. We also learnt that people shouldn't differentiate between girls and boys. Both should be equal. [ASHA, ID5, endline]

Earlier, we did not know anything, we did not have any knowledge at all, we may have faced injustice as well but we did not have any knowledge or awareness about what to do about it. Everyone would keep their mouth shut and continue to bear it. [ASHA, ID15, endline]

Yes, I did attend the training programme. It was organised at the PHC and it lasted for three days....We were told about four types of violence. We were also told that if a woman has faced physical violence and has bruises on her body then she should be provided with help immediately.... Yes, I learnt the legal issues relating to violence. I learnt about the Acts that are imposed to protect women from violence that happens in our society. [AWW, ID11, endline]

It was a three day training.... Yes, through this, we came to know that women can go to a lot of people for help, for example, the village headmen, the ward member, or any person who she trusts. No, madam there was nothing at all to not like about the programme. Everything that was told there was very beneficial and I really liked the programme. I believe that this programme should continue.... We didn't even know what the women helpline was, and through this training we got to know that if a woman is facing torture, she should call the women helpline for protection. She can call and then her husband can be charged of assaulting her. [AWW, ID5, endline]

I liked each and every thing in the training session. I got to learn a lot of things because earlier I didn't have so much knowledge, but after I went for two training sessions, I learnt a lot.... I learnt that men and women should be treated equally. Girls and boys should be treated equally, and both should be given equal amounts of love as well as nutrition. Violence against women should not take place and a woman should not be forced to sleep with her husband. [AWW, ID8, endline] 
The training was for all three, ASHAs, AWWs, and ANMs. They told us everything related to violence against women. [ANM, ID2, endline]

\section{Introduction to the screening form and how to use it}

The narratives of several ASHAs, AWWs, and ANMs (given below) throw light on their introduction to the screening form and orientation about its use (eight out of 16 ASHAs, 11 out of 18 AWWs, two out of four ANMs). They reported that they were asked to screen women using a prepared set of questions that reflected physical, emotional, and sexual violence. ANMs were aware of the screening form, and recognised that it was the ASHAs and AWWs, and not ANMs, who were expected to fill it.

The questions that we had to ask them were on mental, physical, sexual, and domestic violence. [ASHA, ID2, endline]

We also learnt how to fill up the form. Yes we were trained in asking these four questions to women and we can definitely ask these questions to women.... [ASHA, ID9, endline]

Questions were like, is there anyone who harasses you, anyone who tortures you, anyone who physically abuses you, anyone who forces you, and does anyone taunt you because your parents don't have resources.... [ASHA, ID11, endline]

Yes, questions were on psychological violence, domestic violence, sexual violence, and physical violence.... [AWW, ID9, endline]

The ASHA and AWW fill that screening form and ask those questions. And the people who had come to train would explain everything. [ANM, ID2, endline]

No, it doesn't take much time to ask these questions to women, and yes, it should be included in ASHA/ ANM/AWW regular activities. [ANM, ID3, endline]

\section{Orientation about how to approach women and what services to provide}

The FLWs extensively discussed what they had been taught on how to approach women and the range of services they should provide, namely, counselling, referral, and so on, to those who experienced violence (extensively discussed by six out of 16 ASHAs, eight out of 18 AWWs, and three out of four ANMs). Narratives described the extent to which the training had oriented FLWs to recognise signs and symptoms indicating that a woman had experienced violence, such as those ranging from physical injuries to a general sense of fear about discussing experiences. They emphasised the importance of making women comfortable about frankly disclosing their violence experiences and the importance of privacy and assurances of confidentiality. They gave suggestions about discussing violence matters, posing screening questions in the course of routine visits, and the kinds of follow-up actions to be taken, such as trying to make the perpetrator understand the gravity of the issue, or, if the perpetrator did not heed the advice of the FLW, take up the case with the PRI. Most FLWs reported that they had been trained to refrain from asking the screening questions if they perceived that women were uncomfortable or if privacy was not assured. The following narratives recount the training given to FLWs to screen women for violence.

We were also told about what is the best time to meet women and when to go for the interview. We were told that for example if we go to talk to the woman, and if that woman's husband is present, the woman will not give us any information because she is afraid of her husband. Therefore, she should be approached when her husband is out for work, as during this time, she will open her heart to us. She will tell us all her experiences when we meet her alone. [ASHA, ID9, endline]

We were told about the ways through which we can recognise victims of violence. We were also told that the victim will not tell us her story completely in the first meeting.... We were told that some victims may have black and blue bruises on their face, or their face may be swollen, and some will panic as well as cry.... I learnt how to talk to them so that they reveal their experiences. Earlier we would just talk to them once and then leave the place, but now we know how to talk to them.... With the screening form, it is very easy to ask these questions but there are many problems that one has to face... there are some people who don't want to understand at all so then it causes a lot of problems.... It takes time when we see that the guardian is there and then we have to assess the atmosphere of the house. We talk about general things and then come to the point. It doesn't take much time though. [ASHA, ID11, endline]

Yes, they told us that we are not supposed to go their homes and directly ask them about any violence that they may be facing from their mother-in-law or husband. At first you have to only talk about the things 
related to the work that you are doing and slowly come to the main issue. You should not jump directly to such issues.... I feel like I have learnt everything now. There was a lawyer who came here as well, and there was a woman also who works at the police station. We were told everything about what needs to be done in various cases. [ASHA, ID15, endline]

I don't remember that much didi about the training, it was for three days.... We were told to visit women. We were told that if the family is understanding then we can go whenever we want, but if the family is not so then we should visit the woman only when her family members are not around.... Regarding those questions, we were asked to first read the woman's face and if she seemed sad then ask her the reason. We were asked to build a rapport with the woman and make her comfortable about sharing her sorrow. We were told that once she tells us her story, it is our responsibility to meet her husband and make him understand her problem. If he refuses to understand, then he should be taken to the village headman or ward member. If the husband still doesn't understand, then he should be taken to women helpline for suggestion and negotiation. [AWW, ID1, endline]

We were told about everything and then we got the card, which we gave to all the women. The training was about asking questions on violence, how to ask them, for example, that first we should get to know a little bit about the family, and then ask the woman about whether she is hurt or got cut anywhere. She will first deny it, but slowly as we gain her trust and we continue to ask, then she will tell us. Then we advise her and tell her that we will help her to get any kind of support that she needs.... She only reveals her experience when asked repeatedly; then she will say whether her husband forces her or her in-laws trouble her. Then we tell her that if she wants any help to tell us. [AWW, ID15, endline]

In our training we were told about physical and mental torture. If we see any woman with a wound on her body then it definitely means that her husband has abused her, and if a person is being tortured by harsh words, then it is mental torture... They made us understand and explained a lot of things in a very nice way. We were also told that if we are not able to improve the situation for a woman, then we should provide these women with the telephone numbers of the police station and the helpline. [AWW, ID16, endline]

Yes, we received a lot of information... and we got an opportunity to make other people aware also.... They gave us very good information. For example they told us how to take help from the police station or how to go to the Women's Commission. First we were very scared about what would happen if our names are disclosed, but then we were given an assurance that our names will not be disclosed. We were given a card to distribute, and they also told us that we can go in a group for support. [AWW, ID14, endline]

The training had been organised for three days.... We were taught about how we should make women understand well about domestic violence. We were also told that if her husband is with her, we should not discuss these matters. We should talk to her privately. We should talk to them politely. [ANM, ID3, endline]

Training took place for a total of three days. If a woman has been beaten up, she looks depressed, her face is black and blue. Earlier she would hesitate to talk to me but then later on she would tell me everything.... Yes, I have learnt... [ANM, ID4, endline]

\section{Experiences with screening women and referrals}

In the course of in-depth interviews, we probed FLWs about their experiences. For one, in order to assess whether there had been an increase in their provision of violence-related counselling and services, we enquired from ASHAs and AWWs, at baseline and endline, whether they had discussed violence-related matters with women or had offered to help women whom they recognised as having experienced violence, and whether women had ever sought their help to stop the violence they were experiencing. We also discussed, based on their endline reports, their experiences of screening women, their perceptions about women's reactions to their questions, and the kind of counselling they provided women in need. Finally, we inquired whether they had referred women to the ANM or other support services.

\section{Discussion of violence-related matters}

A comparison of narratives from the baseline and endline in-depth interviews confirms that several more FLWs had interacted with women about their experiences of violence at endline than at baseline. 


\section{Baseline}

Narratives from the baseline in-depth interviews show that prior to the launch of the Do Kadam programme, only five out of 12 ASHAs and eight out of 12 AWWs (no ANM discussed this issue) whose narratives contained any discussion about their interactions with women on violence-related matters had enquired from women about their experience of violence or offered help to women who experienced violence. ASHAs and AWWs often suggested that they would help only if a woman sought support, that they would not intervene as violence is a personal matter, and that those they had tried to help often reported that their intervention had not succeeded in reducing the violence. Baseline responses included the following:

Yes, one man started beating his wife after drinking alcohol because his wife refused to make physical relations with him, so her husband beat her and she was injured. Then somehow I got to know so I mediated between them and scolded him and told him that if he did more injustice I would get him locked up in the police station. I also told him that a woman's helpline had opened and I would go and file a case against him there. I got that woman to a health centre and then I brought her home. Her hands-feet were shaking (in fear), now she is better. [ASHA, ID13, baseline]

There is one woman whose husband did not do any work and did not bring money back home, so there is always a fight about this. The situation becomes bad, and they start fighting. The woman took help from me, and I took her to the headman. She told the headman: 'He comes home after drinking alcohol and fights with me, how will I rear my children?' So the headman tried to make her husband understand but he is still like this. [ASHA, ID3, baseline]

If I get to see something like this, then I go and make them understand, otherwise I don't go. [ASHA, ID6, baseline]

No, I have never gone to anyone. No one has come to me for help yet. Sometimes men come home drunk and beat their wives but there hasn't been anything serious. No one has ever come to me with this problem of violence or fights. I have never talked to anyone about it. [ASHA, ID2, baseline]

Yes I meet with one woman whose husband beat her. I told her that if she gave me permission, I could do something against her husband. I told her, 'You say your husband hits you badly. If you want, I can register your complaint, take help from the police or helpline', but she refused so then I remained quiet. Yes, I get information about someone experiencing violence, so I go to them. There are 2-3 women like this who were beaten up by their husbands so I went to meet them. [AWW, ID1, baseline]

No, I did not take her anywhere. I just explained to her husband 3-4 times but he still beats her daily so how much can I explain. [AWW, ID4, baseline]

I don't do anything in these situations, I stay away from these cases. I just observe these instances, because it is their personal matter and I have no business to intervene in their personal matters. If she comes to my place to share it with me then I make her understand, else I don't. [AWW, ID9, baseline]

Yes there is a family who lives next to us. The man beats his wife daily; he drinks alcohol all the time and gets so intoxicated that he doesn't even know where he is going.... He beats his wife daily when he is drunk, he beats her in the morning and at night also. Many times I have threatened to put him in jail or to call my CDPO ma'am who will put him in jail but he doesn't get scared at all. What to do? I feel very sorry for her but they have a small kid, so we can't even put him in jail. Many times she has asked me to get her some work from which she can earn something. I told her, 'What work can I give you?' I tried but I couldn't find anything for her. If her husband is not drunk I talk to him about his ways and he promises me he will stop, but he doesn't. [AWW, ID12, baseline]

\section{Endline}

By endline, 15 out of 16 ASHAs and all 18 AWWs reported their interactions with women, including their experiences of administering the screening tool and providing referral services. Each ASHA and AWW was asked about the number of women assigned to them for screening and follow-up, which they reported as varying from 26 to 58, among ASHAs, and from eight to 51, among AWWs. The following narratives suggest that the number of women who disclosed their violence experience to FLWs ranged from one out of 10 to more than half among both ASHAs and AWWs.

I think 29 women were assigned to me, out of which three had experienced violence... [ASHA, ID4, endline]

There were names of 46 women in the list... 23 of those women had experienced some kind of violence or the other.... [ASHA, ID5, endline] 
There were around 25 women... out of that we found around 16 women who had faced some violence, who told us about it themselves.... [ASHA, ID15, endline]

I was given 51 names and out of them 28 had experienced violence. [AWW, ID2, endline]

I was given 40 names and their names were written in the screening form... out of which 4-5 were victims of violence.... [AWW, ID8, endline]

Total 20 names were given to me... 13 women were victims of violence. [AWW, ID9, endline]

While the screening questions did not differentiate between severe and non-severe forms of violence, it appears, from the narratives of two AWWs that they had probed about the severity of violence experienced and considered that only severe violence was worthy of reporting, as narrated below.

20-25 women... every woman faces some amount of violence, but I haven't seen a major case of violence .... [AWW, ID12, endline]

I was given 22 names of women, of whom none had experienced severe violence. They reported the experience of a little but not a lot of violence.... Yes, among the 22, there were some who had experienced a little violence. [AWW, ID15, endline]

\section{Women's reactions to screening and follow-up}

Several ASHAs and AWWs confirmed that women were not always forthcoming in revealing their experiences of violence when initially probed about it, although in most instances, they were able to allay the fears of women and succeeded in obtaining their responses. Common reactions noted by ASHAs and AWWs included a hesitation to disclose experiences (four and 10, respectively). In some instances, women rejected offers of help while others made efforts to avoid the ASHA or AWW. The narratives that follow indicate the hesitancy of women to report experience of violence to the FLWs.

Initially they don't reveal violence or hesitate.... They don't reveal their experience to us or they say that they will find solutions to their problems on their own. Some of them don't even reply. Some women sit very quietly and when I ask them what is the matter, after a lot of coaxing they open up.... When we ask them the questions they ask why I am meeting them without informing their husband and what do I want to know from them. At times they are away at work but still we go to their homes. [ASHA, ID2, endline]

Many women ran away when I would ask them. They wouldn't give me time and said that I ask them the same question every day. [ASHA, ID5, endline]

The main reason why women don't tell us about their violence experience is because they fear that if they tell us, then their family will behave in an even worse manner with them and will stop their food. They are afraid they will not be able to look after their children. Some women are scared and don't tell.... [ASHA, ID7, endline]

There were one or two women who were not ready to give me time. I told them that I just need five minutes from them and once I had explained to them, they responded openly and I wrote down their responses.... I suggested to them that if they have any problems now or in the future, they should feel free to tell me, and I will advise them about what to do.... [AWW, ID1, endline]

Yes, there are cases where ladies face violence while pregnant. But they hesitate to admit this and seek help. They keep saying that there is no violence in their home and that they don't need help from anyone. Gradually, we make them understand and they start coming to us....People were not ready to inform us and did not feel safe while sharing their problems with us earlier.... [AWW, ID9, endline]

A few ASHAs (two) and AWWs (three) described the angry response that their questions elicited. While some were snubbed, others were taunted by suggestions that they should first set things right in their own home before advising other women about these matters. The narratives that follow are accounts of unfavourable reactions to screening for violence by ASHAs and AWWs.

When we would meet them, they would get angry sometimes, they wouldn't say much if the mother-in-law was there for fear that she would shout at them after I left. [ASHA, ID4, endline]

When we go to call them on vaccination day, they say, 'First manage your own home and then come and make us all understand'. [ASHA, ID7, endline] 
There was this one woman who got very angry when I asked her those questions. She just stood up and left the place. [AWW, ID4, endline]

So the women would say, 'What do you come here to do every day?' Some would get angry or would run away. Women asked why we ask these questions, so I would tell them that like them, I am also a woman and somebody's sister, daughter, mother. Even their family members would question me and ask why I had come to their home. So we have to listen to this but it is my work, I have to do it. [AWW, ID15, endline]

A key challenge that ASHAs and AWWs faced was in gaining access to the woman. Indeed, three ASHAs and AWWs alike reported that the mother-in-law or husband had made attempts to block the woman from meeting the ASHA or AWW and had accused them of interfering in family matters or of trying to spoil their wife or daughter-in-law. Evidence of such behaviour is seen in the following narratives.

At first, people would ask us why we had come to their home and what information we wanted. Some of them would also accuse me of ruining their daughter-in-law, but eventually they understood that we have been assigned duties to spread awareness about various social issues. [ASHA, ID3, endline]

Yes, we had to face many problems.... First and foremost the mother-in-law of the woman would be at the entrance, and she would not let us meet the woman. We followed what we were taught in the training. [ASHA, ID11, endline]

Her mother-in-law said, 'You have come to spoil my daughter-in-law'. So we say that we have not come to spoil her, rather, to make her understand. [ASHA, ID13, endline]

At times, the woman's mother-in-law would hear our conversation and then she would fight with us.... [AWW, ID14, endline]

There are many problems, for example, women may hesitate to talk to us and if she tried to talk, she couldn't talk freely because her husband was there. The husband may get angry so then we had to look for a time that was convenient for them (women) to talk to us. [AWW, ID3, endline]

\section{Rapport building and counselling provided}

Compared with baseline responses, at endline, more ASHAs and AWWs reported that they had taken proactive action in identifying women who had experienced violence and offering them help. Indeed, they reported that they put into practice the emphasis of the project on privacy and confidentiality and on asking questions in a non-threatening way. Many described the effort they took to ensure privacy, assure confidentiality, and gain the trust of women. Narratives also describe the ways in which ASHAs and AWWs counselled women, and, in many instances, their husbands as well. A few suggested that the card provided to women acted as a deterrent to further violence, and a few suggested that it was they who had requested their own husband to intervene with the husband of women experiencing violence. That FLWs followed the guidelines in screening women for violence is evident from their reports that follow.

They all answered the questions but only when they were alone would they answer the questions properly.... No, no one has yelled at me or refused to answer my question because I would ask them questions in a discreet manner. I didn't bombard them with questions at our first meeting.... Yes, there was one case where a woman's husband would drink alcohol and then hit her. He used to also force her to sleep with him, she told me about all these things. I tried to talk to her mother-in-law and now things have improved. I am thinking that in a day or two I will call her to our centre because there is a lot of disturbance at her place and her husband starts behaving like a hooligan. Once he was lying on the road after consuming alcohol and he did this because he didn't want to sleep with her. How stupid is this? Now what to say.... Yes didi, I faced lot of problems explaining to him; he abused my husband and my husband tried his best to make him understand. My husband has counselled a lot of people and they have improved. [ASHA, ID10, endline]

There was one case of physical violence. The husband had hit his wife so badly that her forehead had been injured badly... even then, the woman blamed herself for all this. She said that it was her fault because she had been out of the house for a long time, and her husband thought that she had run away so he hit her with a bamboo stick. As her forehead was bleeding a lot, her husband took her to the clinic for treatment. We got to know about this later and then we went to their place. He told us that he was drunk and that is why he had behaved this way with her. I told him that there is no point in doing all these things-hitting and causing her physical trauma and having to take her for treatment .... Yes I met him and he said he won't behave this way in future.... [ASHA, ID12, endline] 
I gave them advice.... the card we gave her made a lot of difference. They understood that what we were telling them is right and thought that whatever we had told them was for their own good. [ASHA, ID16, endline]

When their in-laws were not at home, they would talk to us, sometimes, even if the mother-in-law was at home we took the woman outside the house [courtyard] to talk to her peacefully. [AWW, ID9, endline]

First I would go to them, ask them about general things. I would ask them about their children, then about their family members and then she would tell me about herself. We were told not to ask her directly about her problems.... No, no one yelled at me but there was one woman who got embarrassed when I asked her the questions and she said that she didn't face any such problems. I tried to reassure her. I told her that if she has faced violence and does not want to talk about it, then how was I to know her problems. But she got angry.... I always assure them that I will not reveal what they tell me to anyone and that they can freely talk to me about anything. I tell them that whatever they tell me, I will keep it to myself and not disclose it to anyone. I also told them that I am here to help them so if they have a problem, I can help them and I assured them that they don't have to be scared about anything. They were given information about the legal steps that they can take against their husbands, and also told that the government will also provide help in these matters.... There was one case where the woman initially didn't tell me anything but after meeting her for the sixth time, she told me that her husband doesn't give her any money. She requested me not to reveal this to anyone but I wanted to meet her husband. Unfortunately I didn't get to talk to him. [AWW, ID10, endline]

\section{Referral to the ANM or other support services}

Many ASHAs (11 out of 16) and AWWs (six out of 12) who discussed referrals reported that they were able to resolve the woman's problem on their own, that women had heeded their advice, and that there had been no need to refer any women to an ANM or to anyone else, including the helpline. ASHAs reported that, at most, they had taken the help of the AWW or their own husband to resolve the issue instead of seeking the help of an ANM. Some suggested that the violence experienced by women they approached was 'not serious enough' to warrant referral to an ANM or support services. Several ASHAs and AWWs reported that they had resolved issues of marital violence among women without needing to refer them to ANMs or support services as is evident from their narratives below.

No, there was no need to refer women to the ANM because they understood what I told them.... was able to make women understand so then there was no need to take them to a helpline or anywhere else. [ASHA, ID9, endline]

No, I have not referred any woman to the ANM didi, but I did take them to the AWW didi, I thought that if I take them to the AWW didi it will have more impact. [ASHA, ID12, endline]

No I didn't refer any case to the ANM. We first send the case to the AWW or ask the AWW to accompany us to the victim's home and then we both make efforts to explain to them.... [ASHA, ID10, endline]

No I didn't refer anyone to the ANM didi as these women listen to me and I have been able to help them out. [AWW, ID1, endline]

No there was no need to refer any case to the ANM or the ASHA.... I met them 3-4 times and then they understood..... [AWW, ID3, endline]

No. Cases were not so serious that I needed to refer any women.... [AWW, ID9, endline]

Only two ASHAs and five AWWs had referred women to an ANM or to support services for women in distress, and a few reported that they had requested the ANM to counsel men who perpetrated violence on their wife. Some of their narratives are reproduced below.

Yes, there was one woman from Patna. I suggested to her that she should stay at a short stay home for sometime as her husband was not financially supporting her and he was not willing to improve. I referred her to a home and told her that she can stay at this short stay home and the helpline people will help her to get justice and claim all her rights. I told her that if she stays at short stay home, she can live in peace. [ASHA, ID3, endline]

I had referred four to five women. I referred victims of violence to the ANM sister. The ANM sister had come here and I had brought three women to meet her....Also, one woman was in a lot of distress so I took her to the women's helpline. Yes, that case is now closed. In another case, the woman's husband had forced her during pregnancy so I had to make him understand-I told him that the baby is in the womb and that sex would harm the baby. Anything could happen. [ASHA, ID8, endline] 
I took a woman to the ANM for her vaccination, At that time she talked about her experience and as the ANM has access, through the Ananya programme, to information on her mobile phone, we made this woman listen to the recording. Later on, madam told her about many things-not exactly about violence but indirectly about such things. Madam talked to her and made her understand that both the children should be treated equally irrespective of their gender. Madam made her understand that she should not treat her son and daughter differently and that this kind of thinking is not right.... told the woman about the women's helpline and gave her the telephone number. If I see a woman who is physically abused then I suggest the helpline to her also. [AWW, ID8, endline]

I told one woman about the legal provisions and in another case I told her about the short stay home where she can stay for three months with her child.... [AWW, ID11, endline]

Once, I referred a woman to the helpline, but she could not get connected to the helpline number.... [AWW, ID17, endline]

\section{Positive feedback from women}

Five ASHAs and two AWWs reported that women appreciated what they were doing. Some elaborated that this was because they posed screening questions in a non-threatening and non-judgemental way, and others because they had helped to reduce the violence they faced. Narratives of favourable responses to the intervention of ASHAs and AWWs are given below.

The women whom I have met, they would listen carefully and say, 'Sister, it is good that you scold him as you would your brother or nephew to make him understand'. People also say that the women's helpline no. is printed on card, and if violence takes place, something would happen now.... [ASHA, ID8, endline]

No madam, we didn't face any problem meeting them, because we work as ASHAs and so we get a lot of love and affection from them. When I ask them something, they just smile give me their answer. They don't get angry with me, I didn't face any problems.... [ASHA, ID9, endline]

No, nothing like this at all. No one got angry or screamed at me when I asked them these questions, they would answer all my questions in a nice way.... [ASHA, ID12, endline]

One day we were talking to a woman and then we saw her husband coming so I stopped him midway. I asked him the reason for forcing her while she is pregnant and not taking financial responsibility. Next day this woman came to me and thanked me a lot as her husband had changed. [AWW, ID14, endline]

If women told me that their husband was troubling them, we would meet their husband and explain to him....Before they used to hit their wife even when she was pregnant, so I explained to them that they should not beat their wife, as she is going to have a child and the violence could harm the child. Violence has reduced now. [AWW, ID7, endline]

\section{Role of ANMs}

ANMs reported that women who are referred to them by the ASHA or AWW do not generally seek their help directly; rather it is the ANM who approaches them. They reported that they mainly counselled women, their husbands, and other family members not to engage in violence and that they informed women about support services available for women in distress. Not a single ANM reported having referred a women to such services. The role of ANMs in the prevention of marital violence among women is indicated in the following excerpts.

No woman has come directly to us, we go to them. First the anganwadi worker goes to the woman's home to make them understand. She asks them several questions. Then the ASHA didi asks them. And if her family or husband does not understand at all, then I talk to them. I tell them to stay well, not to beat their wife. I tell them that beating their wife will be bad for the family. We explain to the woman also when we meet her. I tell her, 'Look, you also have to be aware now, women have the same amount of rights as men have. If your in-laws or husband torture you in any way then you should not be scared, you should ask them why they are behaving badly with you'. And I advise them to go to the women's helpline where they will get help from the police and the law. No, I haven't referred anyone yet....to talk to and make the women of the village understand is very difficult. Their in-laws say things to us like, 'What have you come her to ask?' or tell us that we will ruin their home. So we have to listen to all this abuse but still there has been some change. [ANM, ID2, endline] 
I just go to them and make them understand. I also make their husband understand that they should not beat their wife and should instead live peacefully with their family. I tell them that they should educate their children. No, I have never referred any women who has experienced violence to the police station, women's helpline, or to any other NGO services....No. Initially women didn't want to answer my questions, but then I also talk to them about general things and then they answer my queries. I have to try hard to make them respond, because, at first, they don't open their mouth at all. They would question me about why I need this information and would worry that their husband would be jailed because of this information, and that there would be no one to feed them. We had to try hard to make them understand...but eventually it became better and easier for us. [ANM, ID5, endline]

\section{Participation in community sensitisation activities}

In addition to building the capacity of FLWs, the project also sought to sensitise the community at large to issues related to violence against women by organising street plays. In the course of in-depth interviews, ASHAs/AWWs/ ANMs were asked whether they had attended any of the street plays organised as part of the Do Kadam project. Most ASHAs (nine out of 16) and AWWs (13 out of 18) and all four ANMs were familiar with the street plays organised in their village, and many had attended a play or had been unable to attend but had heard about their content. Their narratives suggest that the street plays sought to convey messages about egalitarian socialisation processes, violence in public spaces, marital violence, linkages between alcohol abuse and the perpetration of violence, and support services for women in distress. The following narratives are reports by FLWs of their attendance at street plays and the extent of their awareness of its contents.

I hadn't taken part. They were talking about education, that both girls and boys should be given equal education. The husband said, 'What will the girl do after studying? She will go to her husband's home whereas the boy will earn and look after us'. So the woman said: 'Even the girl will earn and look after us and will stand on her own feet. If you don't educate her, what will she do in the future?' She explained in this way. Then they showed a husband who was drunk and hit his wife and threw her out of the house, so the woman called up the women's helpline, and they came and explained to them, then everything was all right. [ASHA, ID1, endline]

Yes I attended the street play, it was about a drunken man, and just because his wife didn't cook dinner on time he started hitting her. It was also about eve-teasing. Yes, lots of things were told and it was very good. [ASHA, ID9, endline]

In that play there was an AWW, a woman, and her husband. Her husband would torture her and then the AWW didi came to counsel them but he didn't change, so she took help from the helpline and police station. [AWW, ID3, endline]

It was staged in my village. Both women and men had gone to see it. There has been quite a lot of change after the street play.... whatever was shown in the play was really true of the society; like they showed that if people stay well together and work together then society can progress. The play showed that one shouldn't differentiate between daughters and sons, they are both equal and both should be given an education. [AWW, ID15, endline]

Yes, a street play was staged and I was here that day. A lot of people had seen it. They had shown how an alcoholic was fighting with his wife, so women were hitting him with a broom.... In the entire block, people were talking about it, so it felt good. There has been some change in some people. Everyone said that what was shown was good and that it will lead to change in society. [ANM, ID2, endline]

No, I didn't attend, but I heard about it. On the day of the street play, I was busy with some other work so I could not see their play. [ANM, ID5, endline]

\section{Perceptions about changes}

We probed changes that ASHAs/AWWs/ANMs had observed among men and women in their villages following the implementation of the Do Kadam project. As seen below, most workers perceived significant positive changes-14 out of 16 ASHAs, 15 out of 16 AWWs and all four ANMs-following the implementation of the Do Kadam project. Many suggested that activities to generate awareness among men and women about violence against women and the support services for such women as well as messages conveyed through street plays and the distribution of the resource card had made inroads into reducing violence (nine ASHAs and six AWWs) and alcohol abuse (one ASHA and four AWWs). They attributed these changes to an increase in women's awareness and self-confidence 
and their recognition of options other than suicide as a means of escaping violence, on the one hand, and an increase in men's sense of responsibility towards their family and their heightened fears about the possible adverse consequences they may face for perpetrating violence, on the other.

An increase in women's self-confidence and agency was described by many FLWs, and a few also pointed out that as a result of the programme, women recognised that there are options apart from suicide to escape violence.

Many threatened their husband with dire consequences if they continued to perpetrate violence on them, and some considered wage-earning opportunities so that they did not need to depend on their husband.

Several pointed to women's perceptions on alternatives to suicidal thoughts. The excerpts from interviews given below draw attention to the change in attitudes among men and women and experience of violence among women subsequent to the Do Kadam intervention.

Yes, I have seen a lot of change. I think it (violence) has reduced a little bit.... The women of the village have become more aware and say that since the street play was staged and they had got the women's helpline card, they don't think of dying (as the only option available to them to escape violence) and directly confront their husband and remind him of what was shown in the play. They threaten to call the helpline number and tell them that their husband is not giving them money or is hitting them. So they say this and some women even call for us and tell their husband that these didis will come. We are women and so are they. So there has been considerable change in the society. [ASHA, ID1, endline]

A lot of change has come. Now all these things [violence] have decreased. No one commits suicide. No one thinks of taking poison. [ASHA, ID13, endline]

Yes, now women are very strong and confident.... No, now women don't tolerate the violence or commit suicide as a way of escaping it. Now there is awareness among them (about other options). [AWW, ID1, endline]

Earlier women would hang themselves or would burn themselves but now women are wiser. If women get angry they go to their parents' home or somewhere else, but they won't commit suicide if they experience violence.... Earlier there were such cases (of suicide) but not now. Earlier I used to hear people talking about this kind of incident but not now. Earlier two women had set themselves on fire and one had hung herself from the ceiling. [AWW, ID6, endline]

Some reported that women had become more self-confident about confronting a violent husband, as evident from the following narratives.

Yes, they are more aware of issues and gradually we can see development taking place. Now in $M$ village, women say that if their husband hits them, then they will hit him back... Yes this a good way to help such women didi, because in the future, there will be more improvement and development in our society. I feel very good that I am able to help women who face violence, and when we visit them they are very happy to meet us. They talk to us openly about everything. [ASHA, ID10, endline]

We tell them that in this village there are many influential people whom they can ask for help and we can help them also. These women can also take help from the police and we have also provided them with a card which has the helpline number. Now women use this number to scare their husbands or in-laws if there is violence. Women use this number as a weapon.... [ASHA, ID12, endline]

Yes, yes, definitely there is a change. Now women confidently answer the questions that are put to them by the society. Earlier women were very shy and were scared to say anything, but that is not the case any more. Some women ask me that what they should do because their husband doesn't support them financially. Women tell me that if the man of the house is the sole earning member, then it becomes difficult to make ends meet and this causes a lot of tension in the family, so then such women ask me about work place. They ask me where can they get work so that they can earn some money and reduce the tension at home. [ASHA, ID3, endline]

Yes, women are now more aware and now lots of men have reduced their consumption of alcohol. In our village if a woman reported violence or came to me with her children because her husband had been drunk and had abused them, I asked them to sign on a paper. I would then call the police to arrest these men when they bothered their wife. As a result, men started having a problem with me, but I told them that this is my work and I have to do it. Everyone was after my life. [AWW, ID13, endline]

Women now talk about the Women's Helpline and tell their husband, 'If you hit me I will take you there'. [AWW, ID7, endline] 
Yes, some of them have changed, for example, they warn their husbands about behaving badly with them or they complain about this to me. [AWW, ID10, endline]

Transformation or change doesn't take place suddenly but gradually... Yes, definitely there has been a change in women's reactions to the violence that is inflicted on them. Now they are well informed .... Yes, now they are aware about various issues. [AWW, ID14, endline]

Yes didi, women have become more aware now and have learnt how to protect themselves. They know that they can go directly to the women's helpline. Now women say that they will no longer think about committing suicide to escape from violence but will go to the police or take help from the Mukhiya or Sarpanch (head of the village). They say this to their husband and in-laws.... Yes didi, the intervention provided a nice way for women to share their sorrows and joy and to get help to succeed and enable the society and the generation to come to progress.... The intervention gave me the strength to help such women and showed me how to give them support. [AWW, ID15, endline]

Yes, a lot has changed.... Yes didi, women are now aware and they talk openly about various things. Since the time we have given information and made suggestions to these women, these women have become aware and vigilant about important issues. When we ask them about their experiences, they take a little time to open up but tell us everything .... Yes, due to the activities there has been a lot of improvement in our society. [ANM, ID5, endline]

The FLWs also perceived that the intervention had a positive effect on men, notably that they had better understood their responsibilities within the home and that they now feared that they may be apprehended for perpetrating violence as can be seen from the following reports.

Earlier men would abuse women a lot, but that has reduced. Men who would spend money on alcohol now think before spending that money, because didi explained to them that this money should be saved for the future of their children.... Right now improvement is 50 percent. [ASHA, ID2, endline]

A lot of change has come about and men have stopped being violent.... they don't suppress women that much anymore.... they take the help of the woman in whatever work they do. [ASHA, ID4, endline]

Yes, there has been a change in our society.... A positive change because now men have understood how to behave with their wife and accept that they should treat women with respect.... Earlier, men would not give money to their wife but now they are giving money to their wife to spend. [AWW, ID3, endline]

Men tell me that their wife always shows them the card and threatens them, telling them that if they do anything to them then they will call on this number. The woman tells her husband that if she calls on the number then they will come and take him away. [ASHA, ID12, endline]

No one was there to listen to these women and their husband would torture them whenever they wanted to.... But after the activities, there has been a huge change. A street play was organised and after that the transformation was observable. Now men don't consume alcohol as frequently as earlier and neither do they abuse their women as much when they consume alcohol. Before we took the training, women were facing a lot of violence and torture but now it has substantially reduced. Since I attended the training, I have been telling everyone that whosoever consumes alcohol will be arrested by the police, and I threaten men with the card containing information about the helpline. I tell men that if there is any incident of violence, then his wife can call on this number and he will be arrested.... Yes, definitely, as a lot of people saw the play and got information, they are well aware about things... I mean, men know now that they should not drink alcohol, should not abuse their family members, and should educate their children well. All this has led to a change.... [AWW, ID6, endline]

Ward members attended the play, and they said that more street plays should take place.... Yes, the impact was felt by men who had watched the street play. Now men are scared and tell their wives not to say anything about them. [AWW, ID10, endline]

Yes, there has been an improvement because now men know that women are associated with the helpline and are aware of many things. [ANM, ID4, endline]

\section{Recognition that many women are still reluctant to disclose violence or seek help}

Notwithstanding the changes that FLWs articulated, many reported that they had not observed change among many women, that women do not seek help to prevent further violence, that they continue to fear the consequences for their husband if they lodge a formal complaint. Such instances are elaborated in the narratives reproduced below. 
Nobody comes to me for help, I go to them myself. It would be good if all of them understood and sought help themselves. They say that if they send their husband to jail, then who will feed them and where will they go? Women are scared to go to anyone and don't want to ask for help, so how much can we tell them and force them? [ASHA, ID1, endline]

The woman doesn't tell us anything. She says that they have no option but to stay with their husband. And they fear telling other women because when women talk, they gossip about what is happening in whose house. [ASHA, ID7, endline]

\section{Perceptions about integrating Do Kadam activities into the responsibilities of FLWs and up-scaling of the programme}

Nine out of 16 ASHAs and all AWWs and ANMs suggested that the programme was beneficial, that it had built their own confidence about confronting cases of violence, and that its activities, including the implementation of the screening tool, should be integrated into the regular tasks of the ASHA and AWW, and into the supervisory responsibilities of the ANM. They also suggested that the programme be upscaled at state level. Narratives given below confirm the positive feedback about the project from FLWs.

Before we didn't know anything, but now we have gained all this information and it feels good when we counsel or advise someone. I did this earlier also, but now it feels better. This programme should now be taken forward. Yes didi. Here only nine villages were chosen and see how many women affected by violence have been identified. Women in the entire state of Bihar who are facing problems should be informed about these things so their life will also improve. Like the women here have become more aware, the women from everywhere will also become aware. There will be improvement everywhere. [ASHA, ID1, endline]

ASHAs, AWWs, and ANMs are perfectly capable of asking the screening questions to women and advising and referring women affected by violence and associating them with other kinds of facilities.... Violence is prevalent in all villages and not just one. I can explain to women experiencing violence in this village, but if a girl goes to another village and experiences violence then I can't go there to explain. The ASHA and ANM there should be able to explain. I can only try to solve the problems of this village. [ASHA, ID4, endline]

Yes, ASHAs, AWWs, and ANMs are capable/ skilled enough to ask those screening questions and then counsel, advise, or refer women, or give support to women who are the victims of violence.... Our work is mainly to go for home visits in the area that has been allotted to us, and during these visits, we ask women these questions, so it's not time consuming....Yes, asking these questions should be part of our usual work, because it doesn't require us to spend any extra energy on this, as we go for our rounds anyway. [ASHA, ID12, endline]

Yes, definitely because this is good work that we are doing....No there won't be any problem if this gets added to our daily work...because it is good that I will be able to help another woman.... There are anganwadi centres everywhere and because women come to them, it becomes easier to counsel them.... Earlier we would not go to their homes, but now it is our duty and we go to their home and counsel them. I try to understand each and every case. Earlier, women would not discuss their problems with us but now they do. [AWW, ID1, endline]

Didi, we can do this. As we do our other work, in the same way we can do this work also. I think that ASHAs and AWWs can do it but ANMs won't be able to because they come from very far away places. We can do this work any time and during vaccination days, the ANM didi can make these women understand certain things.... yes, everyone should be given this training. Violence is not limited to just our village. It is happening everywhere, within the domestic sphere, so workers in all villages should get training. [AWW, ID6, endline]

Yes, definitely. I feel that this training should be given to everyone because violence takes place in every village and it is not confined to only Panchayat $\mathrm{K}$ or Panchayat N. Violence takes place in every district and panchayat, so workers everywhere should receive this training. Only then can women be freed from this violence.... Yes, AWWs, ANMs, and ASHAs should be given training to ask those screening questions, refer cases, provide counselling, and support victims of violence.... Yes, definitely ANMs, ASHAs, and AWWs are capable of asking the screening questions.... Definitely. I feel that there is no problem now at all. Earlier, no one was aware, and so women didn't open up and we also didn't ask questions to them, but now the scenario has changed. We now give information to women whenever we meet them or see them in distress. These women come to me and tell me all their stories. [AWW, ID13, endline]

Yes, it should happen. That way maybe all the workers should be informed, so they will get a chance to help those women who experience violence or have done so at one point. That is why the Bihar Government 
should get all the ASHAs, AWWs, and ANMs trained.... Now this programme is reaching a population of 5,000 or 7,000. It should happen in the entire state of Bihar. [ANM, ID2, endline]

Yes, this is a good way. Ask your leadership to extend the programme all over the state. It has been done only in four villages in my area. It is better if ASHA and AWW training is extended to more places. [ANM, ID3, endline]

Yes asking the screening questions and providing women counselling and advice or referring them can be included in the daily routine of AWWs and ASHAs but not ANMs, as ANMs have a heavy workload. [ANM, ID4, endline]

I believe that everyone should be given this training so that people become more aware. It is also important for women's safety and their protection from physical abuse, I think this training should take place in every village. [ANM, ID5, endline]

\section{Summary}

With regard to orientation and training about violence against women, several FLWs (ASHAs, AWWs, and ANMs), particularly AWWs, reported that they had received some orientation on the topic prior to the baseline survey. Narratives confirm however that capacity-building associated with the Do Kadam project not only reached all FLWs, but also covered it far more comprehensively than the orientation imparted earlier and encompassed awareness about violence against women and women's rights, an introduction to the screening tool and its use, ways of approaching women about violence, and the services FLWs should offer women.

The interaction between ASHAs/AWWs and women had also undergone considerable change as a result of the intervention. By endline, for example, ASHAs and AWWs were far more proactive about approaching, screening, and counselling women about violence than they were at baseline. Given that few women would, of their own accord, seek help from a FLW, this more passive approach at baseline resulted in fewer interactions between FLWs and women in distress at baseline than at endline. By endline, moreover, ASHAs and AWWs were confident about screening women for violence and helping women to overcome their reluctance and fears about revealing their experiences to them. They were also sensitive to the need for privacy while discussing violence, the importance of assuring women about confidentiality, and posing questions in a non-threatening manner. Some ASHAs and AWWs had enlisted the support of their own husband in counselling the husband of women reporting experiences of violence. Several reported that the project-developed card that they distributed to women had a positive effect on both informing and empowering women about their rights and options and raising fears among men about the consequences of violating these rights.

Not all ASHAs and AWWs referred women in distress to the ANM or to other support services. On the contrary, 11 out of 16 ASHAs and six out of 12 AWWs who discussed referrals reported that their own intervention was sufficient to address the woman's problem or that the violence was not 'severe' enough to warrant referral to an ANM or other service. Only two ASHAs and five AWWs had referred women to the ANM or to a police station, helpline, or short stay home. ANMs confirmed that they intervened only in cases that were referred to them by the ASHA or AWW, and while they informed women about support services, they had never referred a woman to any such service.

The programme also conducted street plays at village level to sensitise communities at large on violence against women. Almost all FLWs were aware of and familiar with the themes of these nataks, and narratives indicate the these plays sought to convey messages around gender egalitarian socialisations processes, violence in public spaces, marital violence, linkages between alcohol abuse and the perpetration of violence, and support services for women in distress.

Most ASHAs/AWWs/ANMs-14 out of 16 ASHAs, 15 out of 16 AWWs who discussed changes, and all four ANMsreported that they had observed significant changes among men and women in their villages following the implementation of the Do Kadam project. Many suggested that women had gained awareness and self-confidence and recognised options other than suicide as a means of escaping violence and that husbands had begun to recognise their responsibilities in the family and feared the possible adverse consequences they may face for perpetrating violence.

Nine out of 16 ASHAs and all AWWs and ANMs suggested that the programme was beneficial, that it had built their own confidence about confronting cases of violence, and that its activities, including the implementation of the screening tool, should be integrated into the regular tasks of the ASHA and AWW, and the supervisory responsibilities of the ANM. They also suggested that the programme should be upscaled at state level. 


\section{Chapter 6 \\ Summary and recommendations}

This chapter summarises the major findings of the project with regard to the acceptability and feasibility of the Do Kadam Barabari Ki Ore model. It also highlights lessons learned for programme implementation, sustainability, and upscaling. To our knowledge, interventions that have employed FLWs, as opposed to facility based workers to screen and counsel women about violence have not been conducted, and this is a first effort to implement and evaluate the feasibility of such a model.

\section{Summary}

\section{Significantly increased interactions between FLWs and women on violence-related issues}

Findings show that interactions between FLWs and women on violence-related issues increased significantly following the implementation of the Do Kadam project. By endline, half of all women (48\%) reported that the ASHA or AWW had screened them, provided them the Do Kadam brochure on services for women experiencing violence, informed them about women's rights, available services, and safety issues relating to violence, and/or counselled their husband or family members. Fewer -just 39 percent of all women-reported that the ASHA or AWW had screened them for their experience of violence, with screening more likely to have been conducted among women belonging to scheduled castes, poorly educated women, and working women than others. At the same time, we noted that in in-depth interviews at both midline and endline, several women suggested that violence-related topics were not discussed or only fleetingly discussed, and a few of those who were given the brochure could not explain its contents, which raised questions about the skill and comfort levels of ASHAs and AWWs in addressing issues relating to violence.

\section{Reluctance of women to disclose their experiences to ASHAs and AWWs}

Relatively few women who were screened by ASHAs and AWWs disclosed their experience of violence to them, and this is suggestive of the limited rapport between the ASHA or AWW and women on matters related to violence. Indeed, of all women screened at endline, as many as 76 percent had reported their experience of violence to the survey interviewer at the time of the baseline survey but not to the ASHA or AWW; in contrast just two women (less than 1\%) had disclosed their experience to the ASHA or AWW but not to the survey interviewer.

On the whole, just 16 percent of screened women who had acknowledged in the baseline survey that they had experienced emotional, physical, or sexual violence perpetrated by their husband or a family member in the year preceding the interview and 20 percent of those who had reported physical or sexual violence at baseline acknowledged such violence to the ASHA or AWW at screening. Disclosure of violence was more likely among older than younger women, poorly educated than well-educated women, those who experienced frequent violence or severe violence than those who had experienced less intense violence, and those who had been screened in private than those who had been screened in the presence of other family members or in a group. Insights from in-depth interviews suggest that disclosure may be associated with the number of visits made by ASHAs and AWWs to discuss violence-related matters and their skill in drawing out women who might have resisted revealing their experiences. Finally, we acknowledge that because screening questions, of necessity, were short and survey questions were lengthy and probed about various aspects of violence individually, the latter was more effective in enabling recall of experiences.

\section{Mixed quality of interaction between the ASHA or AWW and the women}

One-third of all women who had disclosed their experience of violence reported that the ASHA or AWW had simply empathised with them or had provided general information, and one out of eight had recommended that they tolerate the violence or make efforts to adjust to their husband's demands. Just one-quarter reported that the worker had recommended that she access a service (police, helpline), one out of six was encouraged to seek support from family and friends, and one out of ten was helped to draw up a safety plan. In in-depth interviews, women reiterated the general nature of counselling, although some women did report that they had been counselled to seek out the ASHA or AWW when violence was experienced and had actually sought refuge with the worker when they had subsequently experienced violence, while others reported that the worker had counselled their husband or family member. 


\section{Informal and formal sources of support}

Findings from both the survey and the in-depth interviews emphasise that even at endline, many women continued to suffer the violence perpetrated against them in silence. However, among women who had reported physical and/ or sexual violence, we found that a larger proportion of women at endline had shared their experiences with friends and family or sought services from formal sources than they had at baseline. Moreover, those who had interacted with ASHAs/AWWs about violence-related topics and those who had disclosed their experiences to ASHAs/AWWs were more likely than others to have shared their experiences informally or sought services from formal sources of support.

\section{Disclosure and subsequent experience of violence}

While numbers are limited and findings are just illustrative, we note that among women who had reported the experience of violence at baseline and had disclosed their experience to the ASHA or AWW in the course of the project, there was no more than weak evidence that violence had abated over the course of the intervention. Indeed, of those reporting the experience of emotional, physical, or sexual violence at baseline, 95 percent continued to report such violence at endline. Evidence of a reduction in violence was more apparent when we considered only those who reported physical and/or sexual violence (irrespective of whether they had also experienced emotional violence): here, 63 percent of women reporting the experience at baseline continued to report this at endline. In in-depth interviews, considerably more women reported that they had not experienced emotional, physical, and/or sexual violence at endline than at baseline. Of those who reported continued experience of violence, most attributed their experience to their husband's misuse of alcohol, husband's suspicions of the wife's infidelity, wife's delay in preparing the husband's meal, and, in one case, dowry demands that the woman's family could not fulfil. Of those who reported a reduction in marital violence, just a few attributed this decline to the intervention of the ASHA or AWW; at least one woman attributed the decline in violence that she faced to her ability to threaten her husband with the options provided to her by the ASHA or AWW and a second to the counselling that the ASHA or AWW had provided her husband.

\section{Links of alcohol abuse and violence against women}

While our intervention was undertaken and completed several months before the Bihar Prohibition and Excise Act, 2016, was enacted, our study provides insights into the links of alcohol abuse and violence. Capacity-building efforts did indeed sensitise FLWs on incorporating messaging about alcohol abuse and helping women to develop contingency safety plans about action to take if the husband was drunk and aggressive. Our in-depth interviews highlighted, moreover, that women did indeed attribute the violence they experienced to their husband's alcohol abuse, and some recalled discussions about the linkages of alcohol and violence in the course of one-on-one communication with FLWs as well as in street plays.

\section{Frontline worker perspectives}

Narratives confirm that the capacity-building associated with the Do Kadam project not only reached all FLWs, but also covered it far more comprehensively than the orientation imparted earlier and encompassed awareness about violence against women and women's rights, an introduction to the screening tool and its use, ways of approaching women about violence, and the services they should offer women. By endline, moreover, ASHAs and AWWs were far more proactive about approaching, screening, and counselling women on violence than they were at baseline and more confident about screening women for violence, helping women to overcome their reluctance and fears about revealing their experiences to them, while recognising the need for privacy, giving assurances of confidentiality, and posing questions in a non-threatening manner. Some ASHAs and AWWs had enlisted the support of their own husband in counselling the husband of women reporting experiences of violence. Several reported that the projectdeveloped card that they distributed to women had a positive effect on both informing and empowering women about their rights and options and raising fears among men about the consequences of violating these rights. For the most part, ASHAs and AWWs reported that they had resolved women's problems on their own, and very few reported referring women in distress to the ANM or to other support services. Most FLWs were aware of and familiar with the content of the last component of the programme, that is, street plays to sensitise communities at large to violence against women. Many of them suggested that these events had an effect on changing attitudes to violence in their village.

On the whole, FLWs were fairly unanimous in their view that the project had resulted in positive change at community level, that project activities could easily be incorporated into the regular responsibilities of FLWs, and that the 
programme should be scaled up throughout the state. Indeed, FLWs recognised that with adequate training, ASHAs and AWWs were well placed to provide screening of women for violence, counselling, and referral to women in need, and were receptive to the idea that these responsibilities must be formally incorporated into their responsibilities.

\section{Way forward}

On the whole, our findings from the experience of implementing the Do Kadam programme have been encouraging. They suggest that interactions between FLWs and women on violence-related issues increased significantly and that project activities can be incorporated into the regular responsibilities of FLWs. Yet, we note that many women did not disclose their experiences of marital violence to the FLWs and that the quality of counselling and support was not uniform. Several recommendations emerge, including the need to recognise that domestic violence is both a public health concern and a violation of women's rights, one the one hand, and the need to understand, on the other hand, the importance of incorporating screening, counselling, and referrals of women experiencing violence into the responsibilities of FLWs.

\section{Build an appreciation of the public health consequences and rights violations of domestic violence}

Programmes are needed that sensitise communities as well as key community influentials on the adverse public health consequences of domestic and intimate partner violence, as well as on the rights violations that such violence implies. Strong advocacy measures must be undertaken not only at community level, but also through the Department of Health and Family Welfare department and the Department of Social Welfare, and other related bodies that address women's concerns to enable a deep engagement into understanding the health and rights implications of violence.

\section{Strengthen capacity-building efforts}

Efforts are needed to strengthen the capacity-building of ASHAs and AWWs, particularly to enable them to communicate empathetically with women in need and develop the confidence to draw out women who suffer violence. ASHA, AWW, and ANM training programmes need to incorporate a strong focus on skill-building and include demonstrations on how to approach women, build trust, and provide effective counselling and support to those in need.

We speculate that efforts to incorporate responsibilities to address violence into the duties of FLWs requires a more intensive capacity-building component than we were able to provide, and we suggest that a more intensive focus on violence against women is incorporated into the FLW training package, with efforts to enable FLWs to integrate issues relating to the identification and support of women facing violence into their regular responsibilities.

\section{Prioritise violence reduction as a key component of FLW responsibilities}

Efforts are needed to place counselling and services for violence-related matters at par with other sexual and reproductive health services offered by ASHAs and AWWs and supervised by ANMs; compensation for accompanying women who experience violence to referral points may be considered.

\section{Build stronger links between ASHAs/AWWs and ANMs}

Challenges were also experienced in facilitating a strong and supportive relationship between ASHAs and AWWs, on the one hand, and ANMs on the other. Indeed, few ASHAs and AWWs sought the help of ANMs, and few ANMs appeared interested in supporting or encouraging ASHAs and AWWs. ANMs need to be better engaged in violencereduction activities and be held responsible for monitoring the work of ASHAs and AWWs. They need to demonstrate to those who are uncomfortable about approaching women how to conduct screening and counselling and mentor them on how to address difficult cases.

\section{Address links to support services and referrals for women in distress}

We acknowledge that while the programme was intended to raise awareness among FLWs and women themselves about services available for women in distress, attention must be paid to improving the quality of services provided by others, notably, the police and courts, orienting service providers about bringing services closer to women, and making efforts to empower FLWs to accompany women in need to reach these services. 


\section{Sensitise communities and stakeholders to the link between alcohol abuse and violence against women}

Our project made efforts to sensitise FLWs to the link between alcohol abuse and violence, and our capacity-building efforts did include sessions that drew attention to alcohol abuse. Our modules may be useful in efforts to use the public health system and support FLWs in particular to modify men's attitudes and behaviours relating to alcohol consumption, given laws prohibiting the consumption of alcohol in the state.

\section{Incorporating the Do Kadam experience into the regular responsibilities of ASHAs and AWWs}

Finally, we note that FLWs are ideally placed to screen, counsel, refer, and support women in their communities who experience violence. Many FLWs acknowledged that the inclusion of counselling and screening for violence was acceptable and could well be incorporated into their regular activities. Findings lend support for the integration of elements of the Do Kadam programme-screening mechanisms, basic counselling, referral linkages-into the FLW capacity-building programmes as well as into their job descriptions and performance monitoring activities. Findings also call for a convergence in FLW service delivery responsibilities between the Department of Health and Family Welfare and ICDS, Department of Social Welfare.

Our model has shown that FLWs can be engaged to screen women on their experience of marital violence, provide them information about the options available to women who experience violence, and counsel those in need. At the same time, our experience has drawn attention to the need for extensive investments in capacity-building and supportive supervision, so that reducing the incidence of violence becomes as much of a priority in the health system as enhancing pregnancy-related outcomes, improving nutrition levels, and promoting family planning. 
Appendix Table 1: Construction of the wealth index

The wealth index is measured by adding the scores assigned to each of the following infrastructure and amenities the household has. The wealth index score ranges from 0 to 57.

Type of house: 2 for pucca; 1 for semi-pucca; 0 for kachcha.

Agricultural land owned: 1 if the household owns some land; 0 for no land

Main source of light: 3 for electricity 2 for kerosene

Access to toilet facility: 4 for own flush toilet; 2 for shared flush toilet or own pit toilet; 1 for shared pit toilet or other types of toilet; 0 for no toilet facility

Cooking fuel used: 2 for liquid petroleum gas, electricity or bio-gas; 1 for kerosene, wood, crop residue, dung cakes, coal or charcoal; 0 for other types of cooking fuel, for example, straw, shrubs or grass

Access to drinking water facility: 4 for own piped water, hand-pump or covered well; 3 for own open well; 2 for public or shared piped water, hand-pump or covered well; 1 for public

or shared open well; 0 for other sources of drinking water, for example, surface water, tanker/truck or rainwater

Access to electricity: 3 for electricity; 0 for no electricity

Ownership of household assets: 4 for car or truck; 3 each for motorcycle or scooter, refrigerator, computer/ laptop, telephone (landline or mobile), colour or black and white television; tractor or thresher; 2 each for bicycle, electric fan, radio or transistor, sewing machine, water pump, animal-drawn cart; 1 for watch or clock; 0 for each of the above items that the household does not possess. 


\section{References}

Ackerson, I. K., and S. V. Subramanian. 2009. 'Domestic violence and chronic malnutrition among women and children in India'. American Journal of Epidemiology, 170 (2): 268.

Agrawal, S. and A. Banerjee, 2012. 'Perception of violence against women among future health professionals in an Industrial Township'. Industrial Psychiatry Journal, 19(2): 90-93.

Ahmed, S., M.A. Koenig, and R. Stephenson. 2006. 'Effects of domestic violence on peri-natal and early-childhood mortality: Evidence from North India'. American Journal of Public Health, 96 (8): 1423-428.

Baker-White, A. 2010. Analyzing the implementation of India's Protection of Women from Domestic Violence Act (2005) in the coastal districts of Orissa. Presentation at 138th American Public Health Association Annual Meeting, Denver, CO.

Basile, K. C, M. F. Hertz, and S. E. Back. 2007. Intimate Partner Violence and Sexual Violence Victimization Assessment Instruments for Use in Healthcare Settings: Version 1. Atlanta (GA): Centers for Disease Control and Prevention, National Centre for Injury Prevention and Control.

Bates L.M., S.R. Schuler, F. Islam, and K. Islam. 2004. 'Socioeconomic factors and processes associated with domestic violence in rural Bangladesh'. International Family Planning Perspectives, 30(4): 190-199.

Boyle, M.H., K. Georgiades, J. Cullen, and Y. Racine. 2009. 'Community influences on intimate partner violence in India'. Social Science Medicine, 69(5): 691-697.

Chowdhury, N. and V. Patel, 2008. 'The effect of spousal violence on women's health: findings from Stree Arogya Shodh in Goa, India.' J. Postgrad Med. 54(4): 306-312.

Dalal K., F. Rahman, and B. Jansson. 2009. ‘Wife abuse in Bangladesh'. J. Biosoc., 4(5): 561-573.

Directorate of Census Operations, Bihar. 2014. District census handbook, Patna: Village and town wise primary census abstract (PCA). Series -11, Part XII-B. Patna: Directorate of Census Operations, Bihar. Accessed at http://www.censusindia.gov. in/2011census/dchb/1028_PART_B_DCHB_PATNA.pdf on 3 March 2016.

Garcia-Moreno C., H. Jansen, C. Watts, M. Ellsberg, and L. Heise. 2005. WHO Multi-country Study on Women's Health and Domestic Violence against Women. Geneva: WHO

International Institute for Population Sciences (IIPS) and Macro International. 2007. National Family Health Survey (NFHS-3), India, 2005-06. Mumbai: IIPS.

International Institute for Population Sciences (IIPS) and Population Council. 2010. Youth in India, Situation and Needs $2006-07$. Mumbai: IIPS.

International Institute for Population Sciences (IIPS). 2016. National Family Health Survey-4, 2015-2016, State Factsheet, Bihar. Mumbai: IIPS.

Jejeebhoy, S. J. 1998. 'Associations between wife-beating and fetal and infant death: impressions from a survey in rural India'. Studies in Family Planning, 29(3): 300-308.

Jejeebhoy, S.J., 1998. ‘Wife-beating in rural India: a husband's right?' Economic and Political Weekly, 33:855-862.

Santhya, K.G. and S.J. Jejeebhoy. 2005. 'Young women's experiences of forced sex within marriage: Evidence from India,' in Sex Without Consent: Young People in Developing Countries, Shireen Jejeebhoy, Iqbal Shah, and Shyam Thapa (eds.). London: Zed Books, pp. 59-73.

Jejeebhoy, S. J., K. G. Santhya, and R. Acharya. 2010. Health and Social Consequences of marital violence: A synthesis of evidence from India. New Delhi: Population Council.

2014. 'Violence against women in South Asia: the need for the active engagement of the health sector'. Global Public Health, 9(6): 678-690.

-2013. 'Physical and sexual violence and symptoms of gynaecological morbidity among married young women in India'. Global Public Health, 8(10): 1151-167.

Jejeebhoy S. J., Santhya K. G., and S. Sabarwal. 2013. Gender-based Violence: A Qualitative Exploration of Norms, Experiences, and Positive Deviances. New Delhi: Population Council of India.

Johnson, N., and M. Sengupta. 2008. 'Do battered wives have more fetal and infant deaths? Evidence from India'. PSC Research Report, No. 8. 
Krug, E.G., L. L. Dahlberg, J. A.Mercy, A. Zwi, and R. Lozano. 2002. World Report on Violence and Health. Geneva:WHO.

Majumdar, B. 2004. 'Medical and nursing students' knowledge and attitudes toward violence against women in India'. Education Health, 17: 354-364.

McFarlane, J. B. Parker, K. Soeken and L. Bullock. 1992. 'Assessing for abuse during pregnancy. Severity and frequency of injuries and associated entry into prenatal care', JAMA:267(23): 3176-178.

Ministry of Health and Family Welfare. n.d. Mobilising for action on violence against women: A handbook for ASHA. New Delhi, Ministry of Health and Family Welfare.

Muthal-Rathore, A., R. Tripathi, and R. Arora. 2002. 'Domestic violence against pregnant women interviewed at a hospital in New Delhi'. Int J. Gynaeccol Obstet., 76: 83-85.

Office of the Registrar General and Census Commissioner, India. 2013. Annual Health Survey 2012-13, Fact Sheet: Bihar. New Delhi: Office of the Registrar General and Census Commissioner.

-n.d. Annual Health Survey 2012-13, Fact Sheet: Bihar. New Delhi: Office of the Registrar General and Census Commissioner. Accessed on 29 February 2016 at http://www.censusindia.gov.in/vital statistics/AHSBulletins/AHS Factsheets 2012-13/ FACTSHEET-Bihar.pdf.

- 2015a. C -1 Population by Religious Community - 2011. Accessed on 1 March, 2016 at http://www.censusindia.gov. in/2011census/C-01/DDW10C-01\%20MDDS.XLS.

— 2015b. C -2 Marital Status by Age and sex. Accessed on 1 March, 2016 at http://www.censusindia.gov.in/2011census/Cseries/c-2/DDW-1000C-02-fer3-MDDS.xls.

-2015c. F -1 Number of women and ever married women by present age, parity and total children ever born by sex. Accessed on 3 March, 2016 at http://www.censusindia.gov.in/2011census/F-series/f1/2011-F01-1000-Rev4-MDDS.XLSX.

Patel, V., B. Kirkwood, S. Pednekar, H.Weiss, and D. Mabey. 2006. 'Risk factors for common mental disorders in women'. The British Journal of Psychiatry, 189 (6):547-555.

Planning Commission. 2013. Press note on poverty estimates, 2011-12. Accessed on 14 October, 2015 at http://planningcommission.nic.in/news/pre_pov2307.pdf.

Silverman, J.G., M.R. Decker, N. Saggurti, D. Balaiah, and A. Raja. 2008. 'Intimate partner violence and HIV infection among married Indian women'. JAMA, 300 (60): 703-710.

Singh, A., B. Mahapatra, and S. Dutta. 2008. 'Spousal violence and infant mortality in India'. Asia Pacific Journal, 23 (2).

Stephenson, R., M. A. Koenig, and S. Ahmed. 2006. ‘Domestic violence and contraceptive adoption in Uttar Pradesh'. Studies in Family Planning, 37(2): 75-86.

Stephenson, R., M. A. Koenig, R. Acharya, and T. K. Roy. 2008. 'Domestic violence, contraceptive use, and unwanted pregnancy in rural India'. Studies in Family Planning, 39(3): 177-186.

Sudha, S., S. Morrison, and L. Zhu. 2007. 'Violence against women, symptom reporting, and treatment for reproductive tract infections in Kerala state, Southern India'. Health Care for Women International, 28(3): 268-284.

Weiss, H.A., V. Patel, B. West, R. Peeling, B. Kirkwood, and D. Mabey. 2008. 'Spousal sexual violence and poverty are risk factors for sexually transmitted infections in women: a longitudinal study of women in Goa, India'. Sexually Transmitted Infections, 84(2): 133-139.

World Health Organization. 2013. Responding to intimate partner violence and sexual violence against women: WHO clinical and policy guidelines. Geneva: WHO. 


\section{Authors}

Shireen J Jejeebhoy, formerly Senior Associate, Population Council, New Delhi

K G Santhya, Senior Associate, Population Council, New Delhi

Santosh Kumar Singh, Assistant Programme Officer II, Population Council, New Delhi

A J Francis Zavier, Senior Programme Officer, Population Council, New Delhi

Neelanjana Pandey, Programme Officer II, Population Council, New Delhi

Rajib Acharya, Associate II, Population Council, New Delhi

Komal Saxena, Senior Programme Administrator, Population Council, New Delhi

Aparajita Gogoi, Executive Director, Centre for Catalyzing Change, New Delhi

Madhu Joshi, Senior Advisor, Centre for Catalyzing Change, New Delhi

Sandeep Ojha, State Programme Coordinator, Centre for Catalyzing Change, Patna 


\section{List of Investigators}

\section{House Listers}

Devendra Kumar

Keshaw Kumar

Kundan Kumar

Deepak Kumar Pandey

Jai Prakash

Avadhesh Singh

\section{Field Supervisors/Editors}

Kamini Devi

Sulekha Gautam

Ruchi Kumari

Ram Shankar

\section{Field Investigators}

Deepshikha
Tasnim
Vanshika Bharti
Kiran Devi
Ranju Devi
Shahida Khatoon
Krishna Kumari
Pushpa Kumari
Reshmi Kumari
Shivani Kumari
Kanchan Lata
Renu Kumari Prabha
Menka Priya
Anjana Sahu
Nanda Sahu
Rachna Singh
Kajal Varma
Priyanka Vhaisnav


Printed at :

Systems Vision

Email:systemsvision96@gmail.com

Mobile:98102 12565 
